January 2005 • NREL/TP-620-37388

\title{
Emerging Markets for Renewable Energy Certificates: Opportunities and Challenges
}

Ed Holt

Ed Holt and Associates Inc.

Lori Bird

National Renewable Energy Laboratory

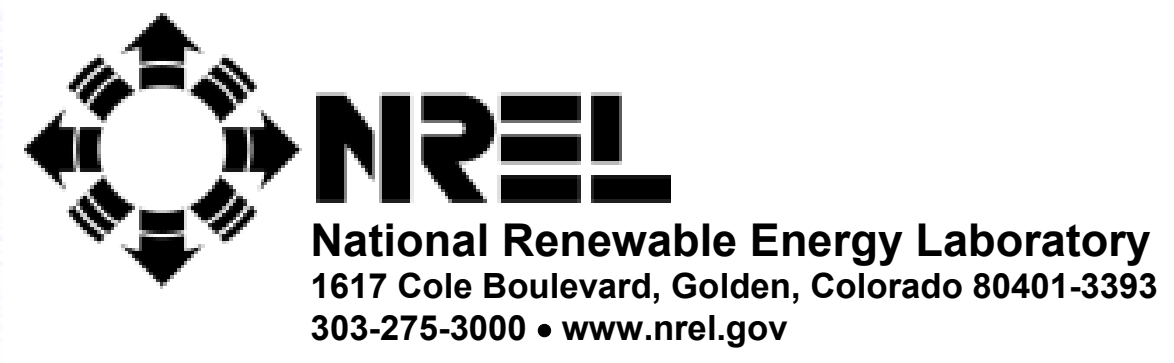

Operated for the U.S. Department of Energy

Office of Energy Efficiency and Renewable Energy

by Midwest Research Institute $\bullet$ Battelle

Contract No. DE-AC36-99-G010337 


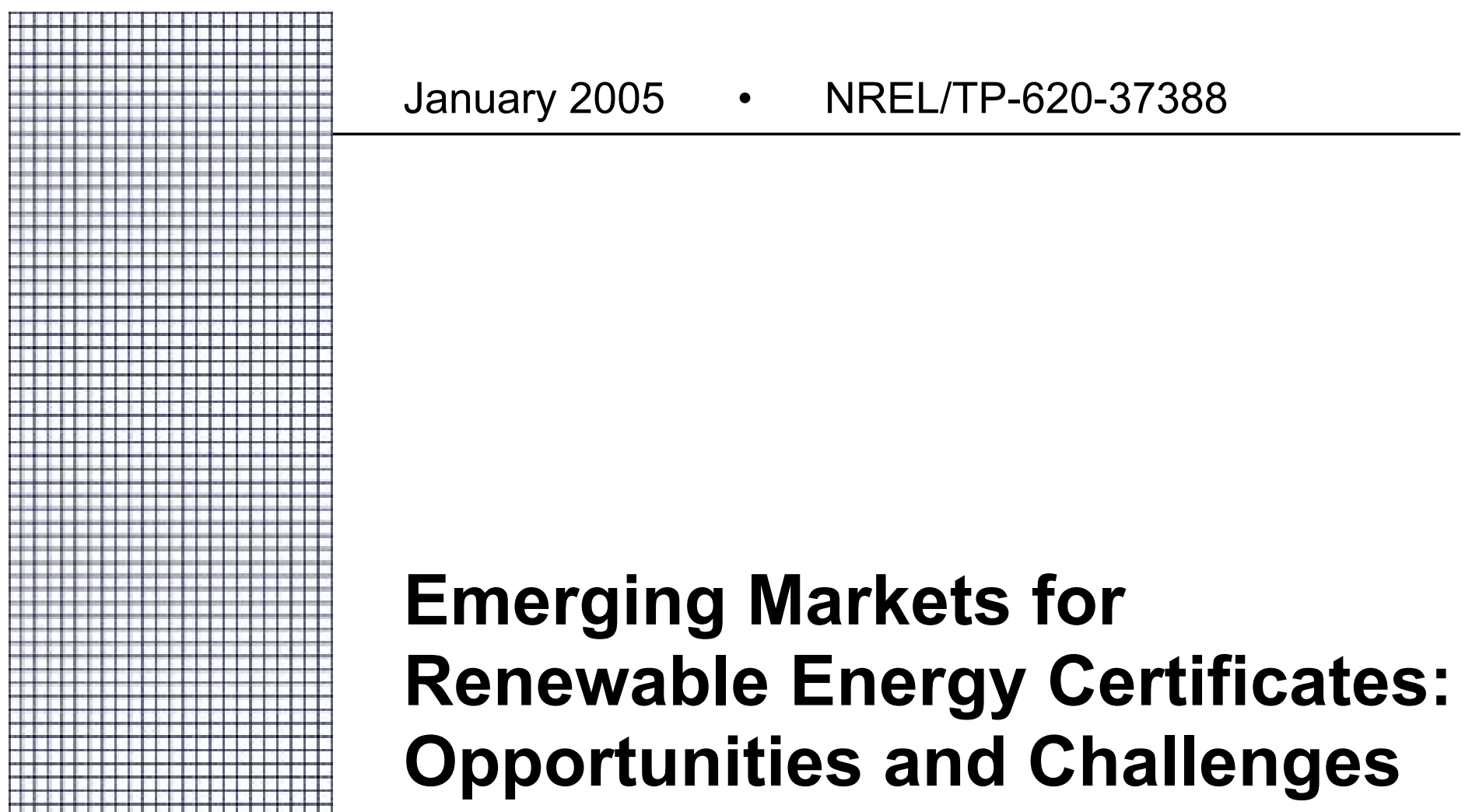

Ed Holt

Ed Holt and Associates Inc.

Lori Bird

National Renewable Energy Laboratory

Prepared under Task No. ASG4.1005

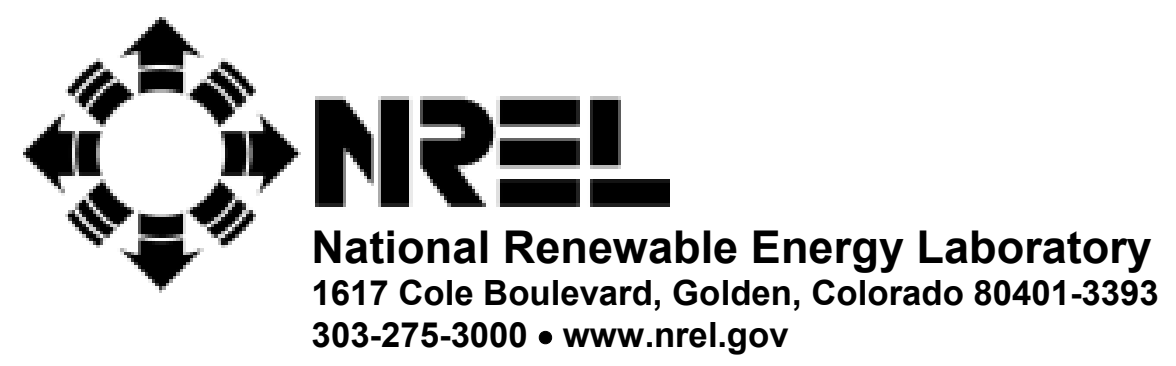

Operated for the U.S. Department of Energy

Office of Energy Efficiency and Renewable Energy

by Midwest Research Institute • Battelle

Contract No. DE-AC36-99-G010337 


\section{NOTICE}

This report was prepared as an account of work sponsored by an agency of the United States government. Neither the United States government nor any agency thereof, nor any of their employees, makes any warranty, express or implied, or assumes any legal liability or responsibility for the accuracy, completeness, or usefulness of any information, apparatus, product, or process disclosed, or represents that its use would not infringe privately owned rights. Reference herein to any specific commercial product, process, or service by trade name, trademark, manufacturer, or otherwise does not necessarily constitute or imply its endorsement, recommendation, or favoring by the United States government or any agency thereof. The views and opinions of authors expressed herein do not necessarily state or reflect those of the United States government or any agency thereof.

Available electronically at http://www.osti.gov/bridge

Available for a processing fee to U.S. Department of Energy and its contractors, in paper, from:

U.S. Department of Energy

Office of Scientific and Technical Information

P.O. Box 62

Oak Ridge, TN 37831-0062

phone: 865.576 .8401

fax: 865.576 .5728

email: mailto:reports@adonis.osti.gov

Available for sale to the public, in paper, from:

U.S. Department of Commerce

National Technical Information Service

5285 Port Royal Road

Springfield, VA 22161

phone: 800.553 .6847

fax: 703.605.6900

email: orders@ntis.fedworld.gov

online ordering: http://www.ntis.gov/ordering.htm 


\section{TABLE OF CONTENTS}

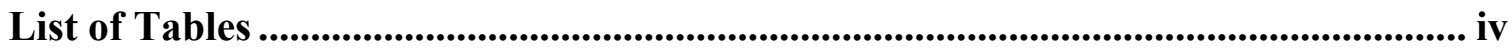

List of Figures..................................................................................................................... iv

Acknowledgments .........................................................................................................................v

Executive Summary …….................................................................................................1

1. Introduction .............................................................................................................

2. Background ........................................................................................................................

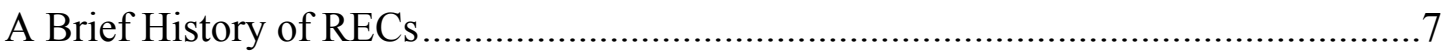

Benefits and Barriers to REC Market Development....................................................9

3. Market Applications of RECs........................................................................................10

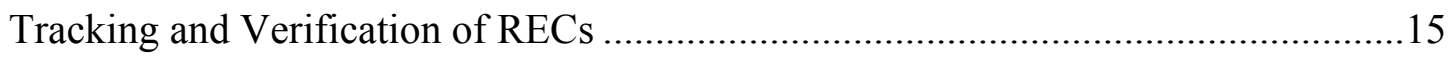

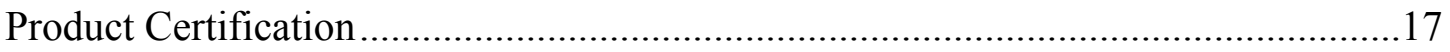

4. Market Volume, Prices, and Value ...............................................................................19

Compliance Markets ..............................................................................................

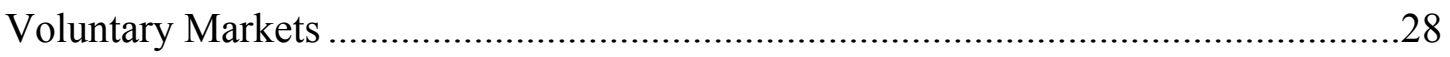

5. Issues and Challenges in Expanding RECs Markets....................................................36

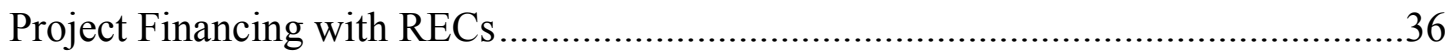

Marketing and Communications Challenges ............................................................38

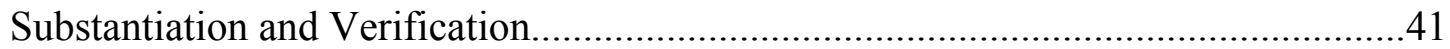

National Markets and REC Liquidity ....................................................................4

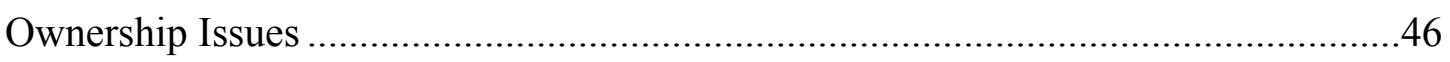

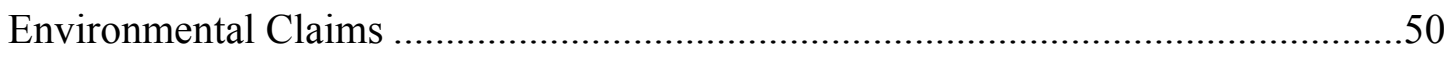

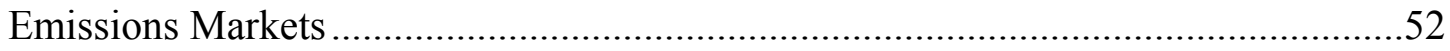

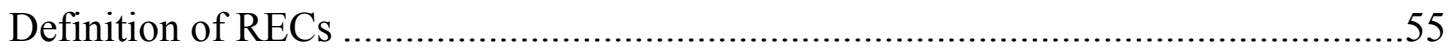

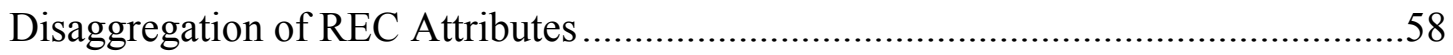

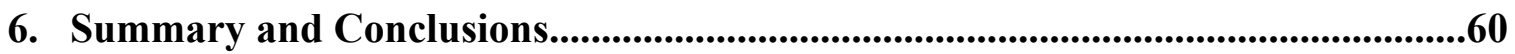

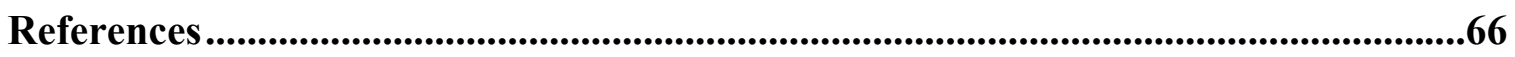




\section{LIST OF TABLES}

Table 1. Sample Range of REC Trading Prices in Compliance Markets ....................20

Table 2. Texas REC Generation and RPS Compliance ..........................................21

Table 3. RECs Eligible for RPS Compliance in New England ...................................22

Table 4. Estimated Value of Compliance REC Markets Through 2010......................27

Table 5. Green-e Certified REC Customers and Sales ............................................29

Table 6. Utility Use of RECs to Supply Green Pricing Programs .............................29

Table 7. Estimated Wholesale RECs Supplying Voluntary Markets (2003)................30

Table 8. Voluntary Market REC Retirements in Texas and NEPOOL ..........................30

Table 9. Renewable Energy Certificate Product Offerings (July 2004) ......................32

Table 10. Sample Range of Voluntary Market REC Prices for New Sources (by Type and Region/Powerpool in \$/MWh) ...............................................33

Table 11. Sample Range of Voluntary Market REC Prices for Existing Sources (by Type and Region/Powerpool in $\$ / \mathrm{MWh}$ ) ..............................................35

Table 12. Estimated Voluntary REC Market Size and Value in 2003 and 2010 ............36

Table 13. Status of Renewable Energy Eligibility in Emission Markets .........................54

Table 14. Comparison of Emission Market Values and Energy Market Values .............54

\section{LIST OF FIGURES}

Figure 1. States with Renewable Portfolio Standards ..............................................20

Figure 2. New Wind REC Prices in Voluntary Markets by Region

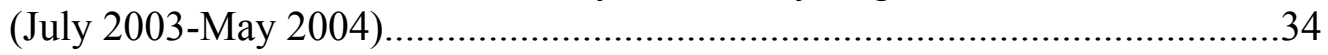

Figure 3. Regions with REC Tracking Systems in Operation or Development..............42

Figure 4. States Included in EPA CAIR Proposal.................................................53 


\section{ACKNOWLEDGMENTS}

This work was funded by the U.S. Department of Energy (DOE) Office of Energy Efficiency and Renewable Energy (EERE). The authors wish to thank Linda Silverman, David McAndrew, and the renewable energy technology programs of DOE for their support of this work. We also wish to thank the following reviewers for providing thoughtful comments on the draft report: Blair Swezey, Chandra Shah, and Laura Vimmerstedt, NREL; Craig Hanson, World Resources Institute; Kevin Rackstraw, Clipper Windpower; Rob Harmon and Tom Starrs, Bonneville Environmental Foundation; Ryan Wiser, Lawrence Berkeley National Laboratory; Jeff Anthony, We Energies; Dan Lieberman, Center for Resource Solutions; Alden Hathaway, Environmental Resources Trust; Ashley Mason, CSG Services, Inc.; and Brent Beerley, Community Energy, Inc. In addition, we would like to thank Jeff Deyette of the Union of Concerned Scientists for the data he provided to assist us in estimating the size of future compliance markets. And finally, we offer many thanks to Michelle Kubik of NREL for her editorial assistance. 


\section{EXECUTIVE SUMMARY}

Renewable energy certificates (RECs) represent the attributes of electricity generated from renewable energy sources. These attributes are unbundled from the physical electricity, and the two products - the attributes embodied in the certificates and the commodity electricity - may be sold or traded separately. RECs are quickly becoming the currency of renewable energy markets because of their flexibility and the fact that they are not subject to the geographic and physical limitations of commodity electricity. RECs are currently used by utilities and marketers to supply renewable energy products to enduse customers as well as to demonstrate compliance with regulatory requirements, such as renewable energy mandates.

The purpose of this report is to describe and analyze the emerging market for renewable energy certificates. It describes how RECs are marketed, examines RECs markets including scope and prices, and identifies and describes the key challenges facing the growth and success of RECs markets.

\section{REC Applications}

- $\quad$ RPS compliance. In 14 of the 18 states with RPS policies, RECs either are required or may be used to demonstrate compliance. Several other states have yet to address the issue.

- $\quad$ Bundled with electricity in retail products. Green power marketers and some utilities use RECs to supply renewable electricity products sold to retail consumers.

- $\quad$ Sold unbundled within region. Some marketers sell RECs at retail, separate from electricity within the region where the RECs are generated, so that customers need not switch from their electricity providers.

- Sold unbundled nationally. A number of marketers sell RECs at retail, sourced from renewable energy generators located anywhere in the nation separate from electricity. This approach may offer cost savings and is particularly appealing for large nonresidential consumers.

- $\quad$ Marketed in cooperation with standard-offer providers. A growing number of standard-offer or default providers are teaming with retail REC marketerssometimes nonexclusively - to offer green power products sourced from RECs.

- Sold in advance of generation. Some marketers sell a future stream of RECs from new or planned renewable energy projects to retail customers. This approach provides an upfront revenue stream for renewable energy project developers and allows consumer green power premiums to be used to bring new renewable projects on-line.

- $\quad$ Aggregated from small systems. Some organizations are aggregating RECs from small, distributed renewable energy systems for sale in compliance or voluntary markets. 


\section{REC Volume and Value}

In 2003, an estimated 3 million MWh of RECs were sold to end-use customers in voluntary markets. RECs are most commonly purchased wholesale and bundled with commodity electricity to supply retail products; but they are also sold separate from electricity, particularly to large consumers.

Compliance markets offer larger opportunities for REC trading than voluntary markets. Currently, states that allow the use of RECs for RPS compliance provide an annual potential market of about 13 million MWh. Although REC trading is not yet underway in some of these states, we estimate that nearly 8 million MWh of RECs were used for RPS compliance in New England and Texas in 2004. Thus, compliance markets are currently about three to four times the size of voluntary markets, as shown in Table ES-1.

Table ES-1. Estimated REC Market Size and Value in 2004 and 2010

\begin{tabular}{|r|c|c|c|c|}
\hline & $\begin{array}{c}\text { Current REC } \\
\text { Market Size } \\
\text { (million MWh) }\end{array}$ & $\begin{array}{c}\text { Current REC } \\
\text { Market Value } \\
(\$ \text { millions })\end{array}$ & $\begin{array}{c}\text { 2010 REC } \\
\text { Market Size } \\
\text { (million MWh) }\end{array}$ & $\begin{array}{c}\text { 2010 REC } \\
\text { Market Value } \\
\text { (\$millions) }\end{array}$ \\
\hline Compliance Markets & $8-13$ & $\$ 140$ & 45 & $\$ 600$ \\
\hline Voluntary Markets & 3 & $\$ 15-\$ 45$ & 20 & $\$ 100-\$ 300$ \\
\hline Total & $11-16$ & $\$ 155-\$ 185$ & 65 & $\$ 700-\$ 900$ \\
\hline
\end{tabular}

REC prices vary among the different markets and can also vary by region, resource type, vintage, and volume. Based on limited data provided by brokers, REC prices have generally been higher in compliance markets than in voluntary markets, particularly in supply-constrained New England. Prices for RECs used for compliance range from as low as $\$ 0.70 / \mathrm{MWh}$ for existing renewables in Maine and Connecticut to $\$ 4 / \mathrm{MWh}$ to $\$ 8 / \mathrm{MWh}$ in New Jersey, $\$ 10 / \mathrm{MWh}$ to $\$ 15 / \mathrm{MWh}$ in Texas, and as high as $\$ 35 / \mathrm{MWh}$ to \$49/MWh for new renewable energy sources in New England (Figure ES-1). From these prices and market size estimates, we calculate that REC markets are worth roughly $\$ 140$ million currently (Table ES-1).

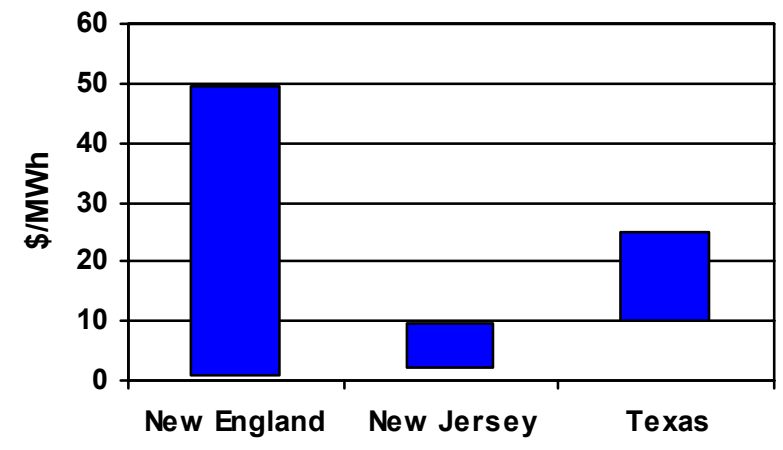

Figure ES-1. Compliance REC Prices by Region 
Generally, RECs used in voluntary markets have traded in the range of $\$ 2 / \mathrm{MWh}$ to $\$ 6 / \mathrm{MWh}$. However, voluntary markets have supported higher prices for preferred resources, such as solar and wind, or local resources (Figure ES-2). For example, solar RECs have traded for as much as $\$ 200 / \mathrm{MWh}$ in voluntary markets. RECs from preexisting sources have generally traded at lower prices, in the range of $\$ 1 / \mathrm{MWh}$ to \$3/MWh typically. Based on wholesale REC trading prices and retail prices, voluntary markets are estimated to be worth from $\$ 15$ million to $\$ 45$ million annually.

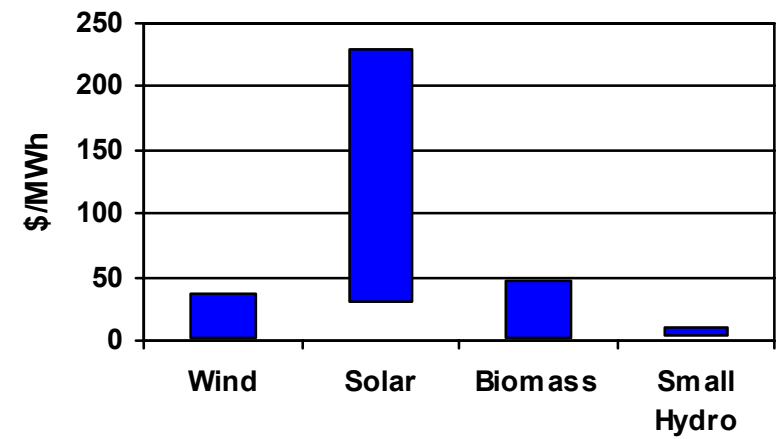

Figure ES-2. Wholesale Voluntary REC Prices, by Resource Type

A national laboratory forecast of demand for green power was used to estimate the future volume of REC voluntary markets in 2010 (Wiser et al. 2001), and RPS requirements were used to estimate the future volume of compliance markets for the same year. As shown in Table ES-1, compliance REC markets could reach about 45 million MWh, while voluntary markets could reach 20 million MWh in 2010. Coupling these volumes with our own best judgment about how REC prices might trend in different regions, we estimate that compliance REC markets could reach more than $\$ 600$ million annually by 2010 , and that voluntary REC markets could grow to perhaps $\$ 100$ million to $\$ 300$ million annually by 2010 . This represents significant revenue to support the development of renewable energy generation.

\section{REC Challenges}

To enable continued growth of REC markets, however, a number of issues need to be resolved.

- Project finance and RECs. Renewable energy developers generally need an upfront guaranteed revenue stream to obtain financing for new projects. This can come from the long-term sale of either the bundled energy and RECs, or the energy and RECs sold separately. Currently, voluntary markets provide insufficient security for project finance, and even compliance markets are not certain enough to completely ameliorate concerns about risk on the part of lenders or equity investors. Some possible solutions include long-term purchase commitments by large institutions or corporate buyers; state renewable energy funds offering price floors (option contracts) for future RECs; states requiring long-term contracts as part of RPS regulations; state 
regulators requiring utilities to buy RECs or bundled energy from new projects to supply green pricing programs; and consumer purchases of future RECs from unbuilt renewable energy projects.

- Communicating RECs. RECs are intangible and difficult to explain, yet the National Association of Attorneys General suggests that marketers disclose to consumers when they are providing certificates, not power. Increasing consumer awareness of the distinction between RECs and renewable electricity will require consistent public education, perhaps over many years. Government, regulatory commissions, consumer advocates, REC marketers and market intermediaries such as brokers and independent product certifiers bear a significant responsibility for this education.

- REC substantiation and verification. Creating electronic databases that track the movement of RECs at the wholesale level can improve the integrity of REC markets. While REC tracking systems have either been developed or are under development in a number of regions, some areas of the country will not be served by these systems. For regions without a tracking system, a simple default system could be created as a temporary measure until a more permanent system is developed. Through this stopgap system, regional RECs would gain more legitimacy and credibility than if no tracking system is present. There is also a need for greater coordination among regional tracking systems. And a national registry would ensure that a generator is not registered in — and issued RECs from—-more than one tracking system.

- National REC markets. Legitimate regional preferences and policies may hinder the development of a national REC market, but it is important for regional rules and tracking systems to enable buyers and sellers to trade across regions. Tracking systems that allow regional REC imports and exports would help facilitate national trade. Other factors that could encourage broader markets include a federal RPS that supports national REC trading, a federal greenhouse gas policy that recognizes the contribution of renewables, stronger federal direction to states on including renewables in emission cap-and-trade programs, and more large companies buying nationally sourced RECs.

- REC ownership uncertainty. In certain circumstances, REC markets have been hindered by questions about ownership. REC ownership is not specified in many PURPA contracts between utilities and qualifying facilities, in most state netmetering laws, nor in situations where generators receive financial incentives from public or quasi-public funds. To reduce market uncertainty, regulators and legislators need to clarify their intent when designing regulations and incentive programs.

- Emissions markets. Opportunities for renewables to participate in emission markets are still emerging. In many cases, renewables are not eligible to participate - or rules have not been finalized to allow participation. The rules for the national $\mathrm{SO}_{2}$ market discourage renewable participation, while only seven states currently allow renewables to participate in NOx cap-and-trade programs. Renewables may be able to play in $\mathrm{CO}_{2}$ markets, but these are currently unregulated and are consequently 
generally weak and illiquid. It is possible that a few additional states will make renewables eligible under the expanded NOx program proposed by the U.S.

Environmental Protection Agency (EPA), and perhaps the northeast states will make renewables eligible under the Regional Greenhouse Gas Initiative, if it is adopted. It is important for federal and particularly state governments to recognize the emissionreduction benefits of renewable energy and include renewables in their allowance allocations.

- Environmental claims. One challenge for marketers is communicating the environmental benefits associated with RECs. This is especially problematic for RECs sourced from areas where emissions markets (such as $\mathrm{SO}_{2}$ and $\mathrm{NOx}$ ) are regulated by cap-and-trade programs that do not provide allowances for renewables. Although most renewables have low or no emissions, they are unlikely, in these circumstances, to reduce overall emissions. The simplest way to resolve this issue is for cap-and-trade programs to grant allowances to renewable energy generators. Alternatively, emissions caps should be set at lower levels to take into account not only existing RPS policies (which is done now) but also projected renewables requirements and voluntary demand for renewable energy. And because greater use of renewables would lead to lower emissions caps, renewables owners should then be allowed to claim environmental benefits.

- REC definition. The debate about the definition of a REC, driven largely by the interaction between RECs and emissions markets, could fragment and confuse REC markets further, unless some agreement is reached. A REC definition that includes environmental attributes (insofar as federal and state laws and regulations have not taken specific attributes as a matter of law) is more credible and more practical given policy precedent, difficulties in tracking the separation of attributes, the potential for consumer confusion if an alternate definition were used, and the fact that the market has been operating for a number of years under a definition that assumes environmental attributes are included.

- Disaggregation of attributes. There is general agreement that a REC owner can choose to sell a whole REC (assuming a REC is defined to include all attributes) in voluntary or compliance markets or sell the attributes in emissions markets without double counting. But the desire to maximize revenue from multiple markets leads to an interest in disaggregating whole RECs and selling component parts in separate markets. REC disaggregation could be appropriate in certain circumstances, for example, where policy-makers explicitly state that RECs without environmental attributes may be used for compliance with an RPS, or where voluntary REC sales are negotiated in customized contracts with knowledgeable counterparties such as large institutional or corporate customers. However, there is potential to confuse lesssophisticated customers who may assume that environmental attributes are included and may not understand disclosure. Whether REC disaggregation will lead to greater revenue for renewables projects is uncertain, because it is not yet known whether multiple markets will provide more revenue than selling the whole REC. 
Given both the current and potential future size of REC markets, it is very important to resolve these issues. A lack of resolution creates uncertainty in the marketplace and slows market development. To make progress on the challenges still facing REC markets, state policy-makers and regulators (both energy and environmental) must be educated about these issues and the implications of their choices relating to REC ownership, RPS rules, net metering, and environmental cap-and-trade program rules. Clear policies are important because silence leads to ambiguity, which stymies markets. Finally, lack of uniformity may be a barrier to expansion of REC markets, or at least to larger and more liquid markets. Some form of federal direction to states regarding a uniform method of allocating emission allowances - or a uniform standard for regional REC imports and exports - could foster greater harmonization of REC markets. 


\section{INTRODUCTION}

Renewable energy certificates (RECs) represent the attributes of electricity generated from renewable energy sources. These attributes are unbundled from the physical electricity, and the two products - the attributes embodied in the certificates and the commodity electricity - may be traded separately. RECs are quickly becoming the currency of renewable energy markets, primarily because of their flexibility and the fact that they are not subject to the geographic and physical limitations of commodity electricity. RECs are currently used by utilities and marketers to supply renewable energy products to end-use customers as well as to demonstrate compliance with regulatory requirements, such as renewable energy mandates.

The purpose of this report is to describe and analyze the emerging market for renewable energy certificates. It provides an examination of RECs markets including scope and prices, describes how RECs are marketed, and identifies and describes the key challenges facing the growth and success of RECs markets.

Section 1 provides a brief history of the development of RECs. Section 2 provides additional background on RECs, including the concept and definition, as well as the current status of certificate tracking systems and REC product certification. Section 3 presents a number of applications and business models for selling RECs, along with illustrative examples. Section 4 discusses, in greater detail, both compliance markets and voluntary markets for RECs. It estimates the size of the current markets, summarizes recent prices, and provides a rough estimate of the potential size and value of future markets. Section 5 describes issues and challenges that could impact the continued growth of RECs markets, such as marketing challenges, verification and substantiation of claims, ownership issues, and the interaction of REC and emissions markets. The final section summarizes our conclusions, based on this review of the state of the market.

\section{BACKGROUND}

\section{A Brief History of RECs}

The first mention of distinguishing the attributes from electricity came in 1995 or 1996 as part of the discussion about how to design a California renewable portfolio standard (RPS). Stakeholders made a number of proposals, including credit trading, to the California Public Utilities Commission (Renewables Working Group 1996). Although the RPS was not adopted at that time, the idea resurfaced in early1997 during discussions about implementing environmental disclosure (electricity labels) in New England. Stakeholders were wrestling with the challenge of verifying the fuel mix and emissions data claimed by electric service providers. The first proposal was to follow the money by an audit of power purchase agreements that would document the chain of custody-the so-called contract-path or "settlements" method of verification. Because this would be impractical for electricity purchases from the spot market, one of the stakeholders 
suggested that the fuel and environmental attributes be traded separately from the commodity (Enron 1997). ${ }^{1}$

A year after this discussion took place, electricity markets in California, Massachusetts, and Rhode Island were opened to retail choice - but California was the most active. The day before the California market officially opened on April 1, 1998, Automated Power Exchange (APX) opened a separate market for green power. This was a wholesale market for scheduled electricity deliveries, designed to serve electric service providers seeking to differentiate themselves and their products. The APX Green Power Market traded electricity generated by renewable resource technologies as defined by the California legislation and renewable energy programs (Pepper 1998). Recognizing the greater flexibility and market liquidity of separating the environmental attributes from the commodity, APX began operating a market for "green tickets" in May 1999 (APX 1999). These wholesale green tickets were purchased and rebundled with commodity electricity for retail green power sales.

In June 1999, the Texas Legislature adopted Senate Bill 7, a restructuring law that included a renewable portfolio standard. The law also resulted in the first renewable energy credit-trading program in the United States. The Texas PUC adopted rules for a credit-trading program in December 1999.

The development of tradable certificates was not uniquely a U.S. phenomenon. In 1997, EnergieNed, the Dutch association of electric utilities, developed a certificate-trading program for The Netherlands as a way to share the burden of meeting voluntary renewable energy targets. This program, which included an electronic tracking system to monitor progress, began operation at the beginning of 1998 and continued for three years (Niermeijer 2005). Out of this experience grew the idea for a Renewable Energy Certificate System, which was proposed, in December 1998. Although the planning group included government observers, it was not a government-sanctioned effort. Planning for the Renewable Energy Certificate System took place in 1999 and 2000, and the first certificates were issued in 2001 (RECS 2004). Finally, the EU Renewable Energy Directive adopted in 2001 has given further impetus to certificate trade in some member states, and potentially across all member states. (EU Directive 2001)

Back in the United States, it wasn't long after certificate trade in wholesale markets was initiated that a few marketers began selling the attributes unbundled from electricity to retail customers. In May 1998, AllEnergy Marketing Company in Massachusetts launched its Regen product, which was sold separately from electricity. This product qualified as the first retail REC product, although it was called neither green power nor certificates, but a "renewable upgrade service."

In May 2000, Bonneville Environmental Foundation made its first sale of Green Tags to the U.S. Environmental Protection Agency (EPA). In 2001, Sterling Planet launched a

\footnotetext{
${ }^{1}$ The Enron representatives directly involved were Dan Allegretti and Malcolm Jacobson. This proposal was a natural outgrowth of Enron's focus on creating new markets and trading opportunities for Enron traders.
} 
national green certificates product, which they touted as an "unprecedented opportunity for millions of Americans to choose green energy without leaving their current electric utility." And later in 2001, NativeEnergy began to solicit customers to purchase RECs to support the development of new renewable generating projects.

As the retail marketing of certificates began to proliferate, the risk of consumer confusion and the potential for misleading advertising quickly became apparent. The Center for Resource Solutions, which manages the Green-e renewable electricity product certification program, ${ }^{2}$ saw a need to establish a certification standard for tradable renewable certificate (TRC) products. After a series of national stakeholder meetings, a Green-e certification standard for REC products was adopted in early 2002.

In this brief recounting of recent history, it is evident that various entities and interest groups use different terminology to describe the attributes of renewable energy, including green tags, renewable energy credits, tradable renewables certificates, and renewable energy certificates. Because the term "credits" connotes an application where the attributes are used to satisfy a debt or obligation - and because the term "green tags" is used by some marketers to describe certain products - we prefer to use the more generic term renewable energy certificates. Generally, all refer to the same thing, although there is a renewed debate about what the definition should be, which is discussed later in this report.

\section{Benefits and Barriers to REC Market Development}

RECs are primarily a means to facilitate markets for renewable energy. ${ }^{3}$ RECs are an attractive option for market participants because they offer a number of benefits, such as:

- Monetizing the value of the attributes separate from the value of commodity electricity.

- Relying on market forces to distribute benefits to those who value them most.

- Providing cost-effective substantiation of green marketing claims and verification of compliance with renewable portfolio standards or other policies such as fuel-mix disclosure.

- Enabling consumers to direct their dollars toward supporting renewable energy sources, even if their electricity providers do not offer a green power option.

- Facilitating transactions across regional boundaries, because they are not subject to the same geographic constraints as commodity electricity.

- Possibly reducing transmission costs. Transmission is still needed to get electricity to market, but not to get renewable electricity to the REC buyer.

- Eliminating the temporal mismatch between generation profile and demand profile, because RECs are separated from electricity.

\footnotetext{
${ }^{2}$ For more information on the Green-e certification program, see http://www.green-e.org.

${ }^{3}$ However, in some regions, certificates are not limited to renewable generation. In New England, for example, the concept has been extended to the creation of certificates representing the attributes of all generation, not just renewable generation. Similarly, the PJM region is considering a certificate tracking system for the attributes of all generation.
} 
- Allowing for sale anytime within the period in which the RECs remain valid, despite the fact that intermittent resources must still be integrated with the grid.

- Allowing purchasers to seek the lowest-cost renewable energy attributes regardless of where the RECs are generated.

In short, RECs offer the potential to create more liquid markets for renewable energy attributes, increasing competition and lowering costs. However, REC markets also face a number of barriers and challenges (which will be discussed in more detail in subsequent sections of this paper, particularly Section 5). For example, RECs markets may be hindered by:

- A lack of understanding of RECs among industry participants, including generators, electricity providers, regulators, and consumers.

- Difficulty in marketing and communicating the concept of a REC in simple advertising language.

- Difficulty in making claims about the environmental benefits of RECs.

- The need for additional consumer protection measures, because REC transactions may not be subject to the regulatory scrutiny typically required for electricity sales.

- Limited availability of market infrastructure to track and verify REC transactions (tracking systems are only available in a few regions to date).

- Inconsistency in REC definitions among industry participants.

- Lack of clarity regarding the ownership of RECs under certain circumstances, such as when the generator receives financial incentives or operates under a net-metering arrangement.

- Insufficient liquidity and price transparency because of the lack of exchanges, forward markets, and price indices.

\section{MARKET APPLICATIONS OF RECS}

Retail marketers, utilities, and other market participants use RECs in a variety of ways and to meet various objectives, such as complying with renewable energy mandates or other regulatory requirements (compliance markets) or offering consumers the option of purchasing green power products (voluntary markets). Because RECs are not bound to the same geographic or physical constraints of commodity electricity and can be purchased or sold separately, they offer great flexibility in their application. The following paragraphs describe a number of current applications of RECs, focusing first on compliance markets and then on voluntary markets, in which there are a variety of business models for using RECs to serve end-use customers.

1. RECs for Compliance with Renewable Energy Requirements Electricity service providers have used RECs to demonstrate compliance with renewable energy mandates in a number of states. In fact, 14 of the 18 states with RPS policies to date allow RECs to be used for compliance purposes, while several states have yet to address the issue (Wiser 2004). Generally, REC tracking 
systems have been used to record the retirement of RECs once they are used for compliance.

2. Wholesale RECs Bundled with Electricity and Marketed to Retail Customers Utilities and green power marketers also use RECs to supply renewable electricity products sold to retail consumers. In this case, the utilities or marketers purchase RECs at wholesale and bundle them with commodity electricity to supply renewable electricity to end-use consumers.

In competitive retail electricity markets, some green power marketers offer renewable electricity products in which both the electricity and the RECs are supplied from within the power pool. One advantage of this approach is that the REC is invisible to the end-use customer. Because the consumer is purchasing electricity as well as RECs, there is no need for the marketer to disclose the use of RECs or explain the concept of a REC, which many marketers have found to be a difficult task - particularly when dealing with residential consumers. For these reasons, bundled renewable electricity products have been largely targeted to residential consumers in competitive electricity markets.

One example of a company that uses this approach in some markets is Green Mountain Energy Company. Green Mountain bundles wholesale RECs with commodity electricity to supply its customers in states such as New Jersey, Pennsylvania, Ohio, and Texas. Under this approach, consumers must switch from the standard-offer provider to the renewable energy provider for all of their electricity needs.

In regulated electricity markets, some utilities (e.g., PacifiCorp, Puget Sound Energy, Sacramento, and Palo Alto) purchase RECs or contract with a third-party who supplies the RECs and assists in marketing the program. According to NREL, about one-third of the green power sold through utility green pricing programs in 2003 was supplied from RECs (Bird and Cardinal 2004). Most utility green pricing programs have relied on RECs sourced from local or regional renewable energy sources; thus, the use of RECs may be motivated primarily by the flexibility of the transaction or the availability of REC products in the region. However, a few utilities in states with limited renewable resources purchase RECs from distant renewable energy generators in order to minimize the cost of participating in the program. If the RECs are supplied from local or regional renewable energy facilities, the use of RECs can be invisible to the end-use customer because electricity is also being supplied. Nevertheless, some utilities disclose the use of RECs or discuss RECs in their advertising materials.

3. Retail RECs Marketed within Region as Stand-alone Product Another approach is to sell RECs from new renewable energy sources in a particular region to retail consumers in the same region, separate from electricity service. The primary difference between this approach and the one described above (RECs bundled with electricity) is that the retail customer does not need to 
switch from his/her current electricity provider. This is particularly advantageous, because getting consumers to switch providers has been shown to be a major barrier to selling green power in competitive markets. In addition, this approach offers a significant advantage for the retail marketer because it avoids the need to purchase electricity through the spot market or through bilateral contracts to meet consumer loads. Thus, it eliminates the difficulties of scheduling electricity, the cost of transmitting the renewable energy to the end-user, as well as the price risks associated with spot market electricity purchases - but it means that the REC concept must be explained to consumers.

One example of a marketer specializing in this approach is Pennsylvania-based Community Energy Inc. (CEI), which markets a product called "New Wind Energy" supplied from new wind energy projects in Pennsylvania, New York, and West Virginia to end-use customers in these and other Northeast states. The company has primarily targeted nonresidential customers for this product and, as of April 2004, CEI was serving about 100 large business, universities, and government agencies, with the majority purchasing RECs (CEI 2004). In addition, CEI works with a number of partners to offer bundled renewable electricity products.

Another example is Bonneville Environmental Foundation (BEF), a nonprofit organization based in Portland, Oregon, which markets "Green Tags" supplied from new wind, solar, and biomass projects in Oregon, Washington, and Wyoming primarily to businesses, government agencies, and other large consumers in the Pacific Northwest. BEF has also marketed its RECs wholesale to a number of utilities in the region, which then rebundle the RECs with electricity and sell them to retail consumers through green pricing programs. The BEF Web site lists about 50 organizations_-including large businesses, government agencies, nonprofit organizations, and green buildings - that purchase green tags, primarily in the Pacific Northwest. ${ }^{4}$

\section{Retail RECs Marketed Nationally as Stand-alone Product}

A slight variation on the approach discussed above is marketing RECs sourced from renewable energy generators located anywhere in the nation to retail consumers, separate from electricity service. One advantage of this approach is that it is possible to purchase RECs from the most cost-effective projects in the country, reducing the cost. On the other hand, one downside is that the marketer may not be able to make any claims about local environmental benefits, if those accrue only in another part of the country, or must disclose where the environmental benefits occur. Other challenges to this approach are that the benefits may be less tangible - if the marketer cannot point to a local project that is the source of the RECs - and it is very expensive to conduct mass-marketing to a national audience. In addition, all of the advantages and disadvantages of marketing RECs discussed above apply here as well.

\footnotetext{
${ }^{4}$ See the BEF Web site at https://www.greentagsusa.org/GreenTags/gt_cust_list.cfm
} 
Because of these issues, marketers generally report that they have been more successful in marketing nationally sourced REC products to large nonresidential customers. Generally, this is the case because businesses and institutions are more sophisticated consumers that understand the concept of a REC, may not care about local environmental benefits (particularly if they have facilities in multiple locations across the country), and consider price to be a more important factor (Hanson and Van Son 2003).

One example of a company that has had some success in selling nationally sourced REC products is Georgia-based Sterling Planet. In the fall of 2003, Sterling Planet announced that it had signed agreements to supply nationally sourced RECs to a handful of Fortune 500 companies totaling nearly 800 million kWh over several years (Sterling Planet 2003). In addition, California-based 3 Phases Energy Services and Colorado-based Renewable Choice Energy have announced a number of large deals in recent years in which they are supplying nationally sourced RECs to government facilities and large businesses.

Renewable Choice Energy also markets its nationally sourced RECs to residential and small commercial customers through grassroots marketing efforts, including direct door-to-door sales and community events.

Finally, most marketers allow customers to purchase RECs via the Internet, although most report having limited success with this strategy. Using this approach, customers from anywhere in the country can purchase RECs, no matter where they were generated.

5. RECs Sold through Standard-Offer or Default Providers in Competitive Markets Recently, a number of programs have been developed in which standard-offer providers or incumbent utilities in competitive markets have teamed with retail marketers to offer green power products sourced from RECs. Under this approach, the end-use consumer is essentially getting a bundled renewable electricity product, because the consumer is also purchasing electricity from the standard-offer provider or utility. If the RECs are sourced from within the power pool, then this approach is essentially no different than No. 2 above, except that the customer does not need to switch from his/her current electricity provider to buy green power. It is also similar to No. 3 in that the marketer simply provides the RECs and leaves the job of providing electricity to the customer's electricity provider.

The first standard-offer provider to offer a green power option to its retail consumers in conjunction with green power marketers was Niagara Mohawk, which serves customers in upstate New York. Under its Green-Up program, which was launched in the fall of 2002, customers can purchase RECs from one

\footnotetext{
${ }^{5}$ See the 3 Phases news releases at http://www.3phases.com/company/news-menu.pl?s=\&g=About\%20Us, including "3 Phases Energy Announces Three-Year Green Power Agreement with Corporate Purchasing Group," December 15, 2004.
} 
of several participating retail marketers. Niagara Mohawk adds the cost of the RECs to participating customers' electric bills. Similar programs have since been offered by other National Grid distribution utilities in Massachusetts and Rhode Island. A handful of incumbent utilities in New York and Pennsylvania offer similar programs, although they are in conjunction with a single green power marketer. More of these types of offerings are expected in the near future, as both Connecticut and New Jersey are requiring standard-offer providers to offer green power options.

Similar to other unbundled REC products (No.3, No. 4), one advantage of this approach is that customers do not need to switch electricity suppliers. But unlike other REC offerings, this approach has the added advantage that customers receive only one bill, because the surcharge appears on the standard electricity bill. Further, marketers may benefit from sharing the incumbent utility's credibility and reputation, while the utility benefits from the marketers' expertise in selling green power. Another advantage is that the use of RECs can be invisible to the end-use customer if they are supplied from local or regional generators, because electricity is also being supplied. Nevertheless, some utilities disclose the use of RECs or discuss RECs in their advertising materials.

\section{Forward Selling of RECs}

Another approach is to sell a future stream of RECs from new or planned renewable energy projects to retail customers, separate from electricity service. For example, Vermont-based NativeEnergy's customers purchase RECs that will be generated during the expected operating life of renewable energy projects. Through its Windbuilders product, NativeEnergy helped support the development of the 750-kW Rosebud Sioux wind turbine in South Dakota by selling the RECs that will be generated during the 25 -year expected life of the turbine. NativeEnergy discounts the RECs price to account for the time value of money and the avoided risk of the project not being able to sell all of the future RECs. The company has worked with the Climate Neutral Network to estimate the RECs' associated $\mathrm{CO}_{2}$ emissions reductions. Because NativeEnergy markets RECs from prospective projects, the company guarantees that it will support an alternate project or purchase RECs from other new renewable facilities, in the event that the initial project is not completed.

Generally, the advantage of forward selling RECs is that it can potentially provide an upfront revenue stream for renewable energy project developers to use in financing a project, and consumer green power premiums can assist in bringing new renewable projects on-line. However, this has only been done on a small scale to date, because of the challenge of forward selling the entire output of a large project. One possible disadvantage of this approach is that if the REC price is not discounted, then consumers would pay today's dollars for RECs generated in the future. Another risk for consumers is that the plant is not yet operatingand may not get built. This risk could be mitigated by a guarantee of building an alternate project or of purchasing new RECs off the market. 
7. RECs Aggregated from Small Systems and Used for Compliance or Voluntary Markets

One final approach is to use RECs from small, distributed renewable energy systems for compliance with RPS policies or to supply retail green power products. For example, the New Jersey RPS calls for at least $0.16 \%$ of retail sales (about $90 \mathrm{MW}$ ) to be met with solar electric generation by 2008. Most of this will be met through residential and commercial PV systems, which are eligible for incentives through the state's renewable energy fund. To demonstrate compliance with the solar set-aside, electric suppliers must use an on-line tracking system established by the state to facilitate the issuance, transfer, and retirement of the solar RECs. ${ }^{6}$

On the retail side, the Energy Cooperative Association of Pennsylvania, a nonprofit, Philadelphia-based competitive energy supplier, has incorporated RECs from small PV systems owned by its members into the resource mix of its green power product offering. The cooperative pays $20 \notin / \mathrm{kWh}$ for the PV RECs.

Similarly, the Bonneville Environmental Foundation has teamed with the Northwest Solar Cooperative to market RECs from small solar installations throughout Oregon and Washington. Under the agreement, the cooperative enters into five-year contracts with PV system owners and pays them $10 \notin / \mathrm{kWh}$ for their RECs. BEF then purchases the RECs from the cooperative for resale to its wholesale and retail customers.

BEF also teams with a cooperative called "Our Wind Co-op" to support the development of farm-scale wind turbines in the Pacific Northwest. Under the arrangement, BEF provided an upfront payment to turbine owners equivalent to approximately one-third the cost of the turbines and plans to recover its investment by selling "Green Co-op Tags."

\section{Tracking and Verification of RECs}

Renewable energy certificates can be formally recognized through contracts between buyers and sellers or through certificate-issuing bodies, such as REC tracking or accounting systems. Today, bilateral contracts for electricity from renewable generators usually acknowledge the RECs and determine which party takes ownership.

Increasingly, REC tracking systems are being developed to verify compliance with renewable energy requirements and other policies, to substantiate voluntary marketing claims, and to provide protection against trading abuses and misrepresentations. To be issued certificates, a generator must register with the tracking system and provide essential information about facility characteristics, which may be verified by the tracking

\footnotetext{
${ }^{6}$ See the solar REC tracking system at http://www.njcep.com/srec/
} 
system administrator. ${ }^{7}$ When the registered generator (or its control area or independent system operator) reports its metered generation to the issuing body, the tracking system issues electronic certificates, each with a unique serial number. Each certificate contains data (attributes) such as the renewable energy resource, facility location, facility vintage, emissions, and certificate issue date. ${ }^{8}$ In addition to issuing certificates, these tracking systems record changes of certificate ownership (both parties confirm the trade) and retire certificates when they are used for different purposes, such as compliance with a renewable energy mandate or to supply retail green power products. ${ }^{9}$ In this way, tracking systems can help alleviate concerns over double counting, by retiring a REC when it is used for RPS compliance or sold into voluntary markets.

Currently, electronic certificate tracking systems are established and operating in New England (the New England Power Pool or NEPOOL Generation Information System), Texas (operated by the Electric Reliability Council of Texas or ERCOT) and Wisconsin (operated by the Wisconsin Public Service Commission). Nonelectronic tracking systems are also in operation in Arizona, Nevada, and New York.

Electronic tracking systems are under development for the Western Interconnect (the Western Renewable Energy Generation Information System or WREGIS) and the MidAtlantic states (the Pennsylvania-Jersey-Maryland (PJM) Generation Attributes Tracking System or GATS). In addition, a revised tracking system is under consideration for New York; and a regional tracking system is under consideration for the Midwest states of Minnesota, Wisconsin, Iowa, North Dakota, and South Dakota.

These tracking systems were developed (or are being developed) for a variety of reasons. The NEPOOL Generation Information System, for example, was developed with the support of state regulatory commissions that wanted consistent treatment of fuel mix and emissions disclosure requirements within New England and to verify compliance with renewable portfolio standards (RPS). The Texas and Wisconsin systems were undertaken specifically to help electric service providers demonstrate compliance with each state's RPS. WREGIS is being undertaken to help demonstrate compliance with RPS policies in several states, and to facilitate a wholesale market for the region's generous endowment of renewable resources. In the PJM region, GATS was initially motivated by state requirements for disclosing fuel mix and emissions information to consumers-at the start of planning, only one state had an RPS. Now that several states in the region have adopted RPS policies, there is additional interest in developing the system for verifying compliance with these policies. The Midwest Renewable Energy Tracking System is intended to support both voluntary and compliance markets for RECs.

\footnotetext{
${ }^{7}$ Whether generator participation is voluntary or mandatory depends on the purposes for the system and the decisions made by policy-makers.

${ }^{8}$ The specific data included with each certificate varies by system, and depends on the purposes of the system and the policies to be supported.

${ }^{9}$ For a more complete discussion of functional capabilities and policy choices for tracking systems, see National Wind Coordinating Committee, Design Guide for Renewable Energy Certificate Tracking Systems, July 2004, at www.nationalwind.org.
} 
These examples illustrate that tracking systems are used primarily to verify compliance or voluntary claims; tracking systems are part of the infrastructure of REC markets, but they are not market-makers. Generally, RECs are transacted through bilateral contracts and it is up to the buyer or seller to find a counterpart. Some tracking systems offer a bulletin board where a buyer or seller can post information to encourage inquiries, but trades are done off-line. In addition, several environmental brokers specialize in bringing together REC buyers and sellers. ${ }^{10}$ To date, REC exchanges or trading floors are not very active, because the markets are still too small and illiquid. ${ }^{11}$

\section{Product Certification}

Product certification is different from the verification of data on which a REC is based, but the two are related. For consumers who make voluntary purchases of RECs, product certification can provide some assurance that a supplier's claims are accurate and that the product meets minimum standards for quality. In addition, certification may ensure that RECs are not also being used for compliance with a mandate or for some other purpose. Verification is usually one part of the certification process, in which products are subject to an ex-post audit, to make sure that sales are backed by at least an equal supply of RECs that meet the claimed product specifications. Certifying organizations may rely on REC tracking systems to simplify the job of verifying the type and quantity of RECs supplied, but must also conduct a sales audit (i.e., billing records) to ensure that purchases of verified RECs match sales to consumers (Lieberman 2004).

To be effective, the certifying organization should be credible and independent of the market. In the case of RECs, there are currently two organizations offering product certification.

The Center for Resource Solution's Green-e TRC Standard is the most widely used in the United States. Preliminary figures for 2003 show that 23 REC products were Green-e certified, accounting for sales of more than 1.8 million MWh of renewables. Green-e certification is available for REC products that meet both environmental standards and consumer protection standards. To earn Green-e certification, a REC product:

- Must originate entirely from new renewable facilities; ${ }^{12}$

- Must be supplied in a minimum quantity (i.e., $100 \mathrm{kWh}$ );

- Must originate only from eligible resources, which are defined as solar electric, wind, geothermal, Low Impact Hydro Institute (LIHI)-certified hydro, and biomass. The biomass product must be generated from the following fuels:

\footnotetext{
${ }^{10}$ A list of REC brokers and marketers is available on the Green Power Network Web site at http://www.eere.energy.gov/greenpower/markets/certificates.shtml?page $=2$

${ }^{11}$ It should be noted that in 1998 APX began operating a green power exchange in California, then switched to a "green tickets" exchange in 1999. This continued until 2001 when the market collapsed in California. APX also opened a green ticket trading platform in Ohio and Illinois in 2000.

12 The term "new" is defined to include any eligible renewable facility beginning operation after January 1 , 1999, or repowered after this date. Local Green-e definitions of "new" take precedence over the default definition, where applicable. New state or regional Green-e standards must use a 1/01/1999 date or later. The full Green-e standards for TRC products are available at www.green-e.org.
} 
landfill gas; digester gas; plant-based agricultural, vegetative, and food-processing wastes; bioenergy crops, clean urban waste wood, and mill residues; and

- Must include all environmental attributes associated with a unit of renewable generation, to the extent possible under current law.

For consumer protection, RECs:

- Must be generated within the calendar year in which they were sold, the first three months of the following year, or the last six months of the previous year;

- Must not be derived from a facility that has been mandated by a government agency;

- Must not be used to satisfy a local, state, or federal mandate, such as an RPS, government procurement order, or air quality requirement;

Products must also undergo an annual verification process audit to document that the provider purchased a sufficient quantity and type of renewable certificates to meet customer demand and marketing claims, and that renewable certificates are sold only once. REC providers must abide by the Green-e Code of Conduct, and submit marketing materials to CRS to meet Green-e disclosure and truth-in-advertising requirements. And finally, each certified provider agrees to disclose the quantity, type, and geographic source of renewable energy associated with REC products.

The second organization offering certification services is the Environmental Resources Trust (ERT). ERT defines a REC differently, however, stating that it is a record of the claim of energy generation placed into the grid. An ERT REC does not necessarily include environmental attributes. ERT's EcoPower ${ }^{\mathrm{SM}}$ label is available to renewable electricity products or REC products that meet the following standard:

- The product must contain a minimum of $10 \%$ new renewable energy; and

- A minimum of at least $50 \%$ of the product must come from renewable energy (from both new and existing renewable energy sources), with exceptions.

For consumer protection, ERT will verify the environmental attributes of energy or RECs in the product, including, if desired, a calculation of the specific emissions savings that resulted from the power associated with the RECs. In addition, ERT will conduct a postsale audit to verify supply and demand are in balance.

REC product certification has been important during the past few years because RECs are so intangible, and marketing could easily be abused to the detriment of public confidence. Certification has helped to give RECs credibility to the point that certified RECs products are often specified by commercial and institutional buyers (Hanson and Van Son 2003). 


\section{MARKET VOLUME, PRICES, AND VALUE}

There is not one single market for RECs; instead, there are a variety of fragmented markets, in which prices may vary considerably. As already discussed, one way to differentiate REC markets is to distinguish between compliance and voluntary markets. In addition, there are also distinct geographic markets for RECs, created by a variety of regional supply and demand considerations. Some of the specific factors that influence REC trading in geographic regions are rules regarding eligible renewables and imports of renewables under RPS policies, the quality and quantity of renewable resources in the region, the degree of difficulty in siting and developing new renewable energy projects in the region, and consumer demand for clean energy sources (which can vary regionally because of targeted marketing efforts or demographics). State or regional REC tracking systems may also create different geographic markets to the extent that they place conditions on the import of RECs from outside their region. If tracking system rules require a delivery of power into the region to accompany RECs imports, for example, it limits the trade of certificates to some extent.

There are also distinctions between markets for RECs derived from "new" or "existing" renewable energy generation sources. The vintage of the renewable energy generation can be a consideration both for RPS compliance-depending on the implementing rules - and for supplying voluntary markets. For example, the Massachusetts RPS calls for electricity providers to meet $4 \%$ of their retail sales with electricity from new renewable energy sources by 2009. In this case, the RPS defines "new" as systems installed after December 31, 1997. However, not all RPS policies make a distinction between new and preexisting sources. In voluntary markets, the vintage of the source can be important, because many consumers feel that their dollars should be spent to support the development of new resources (i.e., they want to ensure that their purchase increases the amount of renewables in the resource mix). (Harmon and Starrs, 2004). For green power and REC products sold to retail consumers in voluntary markets, definitions of "new" have been established by the Green-e certification program. In fact, Green-e only certifies REC products derived from new renewable sources, as noted earlier.

Both compliance and voluntary markets for RECs are discussed in more detail below. Emissions markets (i.e., NOx or carbon) could provide additional market opportunities for non-emitting renewable energy sources; however, emission market rules must support renewable energy participation, and then the currency of RECs (MWh) must be converted to the currency of emissions (tons) for compliance purposes. Because these markets are still emerging - and there are still unresolved issues regarding whether RECs can be used for compliance - emissions markets are discussed in the section on Issues and Challenges.

\section{Compliance Markets}

Compliance markets are dominated by the use of RECs for satisfying RPS policies or renewable energy mandates, although utilities or electricity service providers may also purchase RECs to meet other government-imposed requirements, such as fuel mix 
disclosure. This section focuses on markets created by RPS policies, because these are expected to provide the most significant opportunities for RECs. In contrast to voluntary markets where RECs are also sold at retail, compliance markets typically involve only wholesale REC transactions; thus, data presented below on REC prices are for wholesale transactions.

Of the 18 states that have adopted RPS policies or mandates at the time of writing (Figure 1), most either explicitly or implicitly allow RECs to be used for compliance. To date, RECs have been traded in a number of states, but have been most actively traded for compliance with RPS policies in Texas, Massachusetts, Connecticut, and Maine; and, with some limitations, in New Jersey (Table 1). A brief description of each of these compliance markets follows.

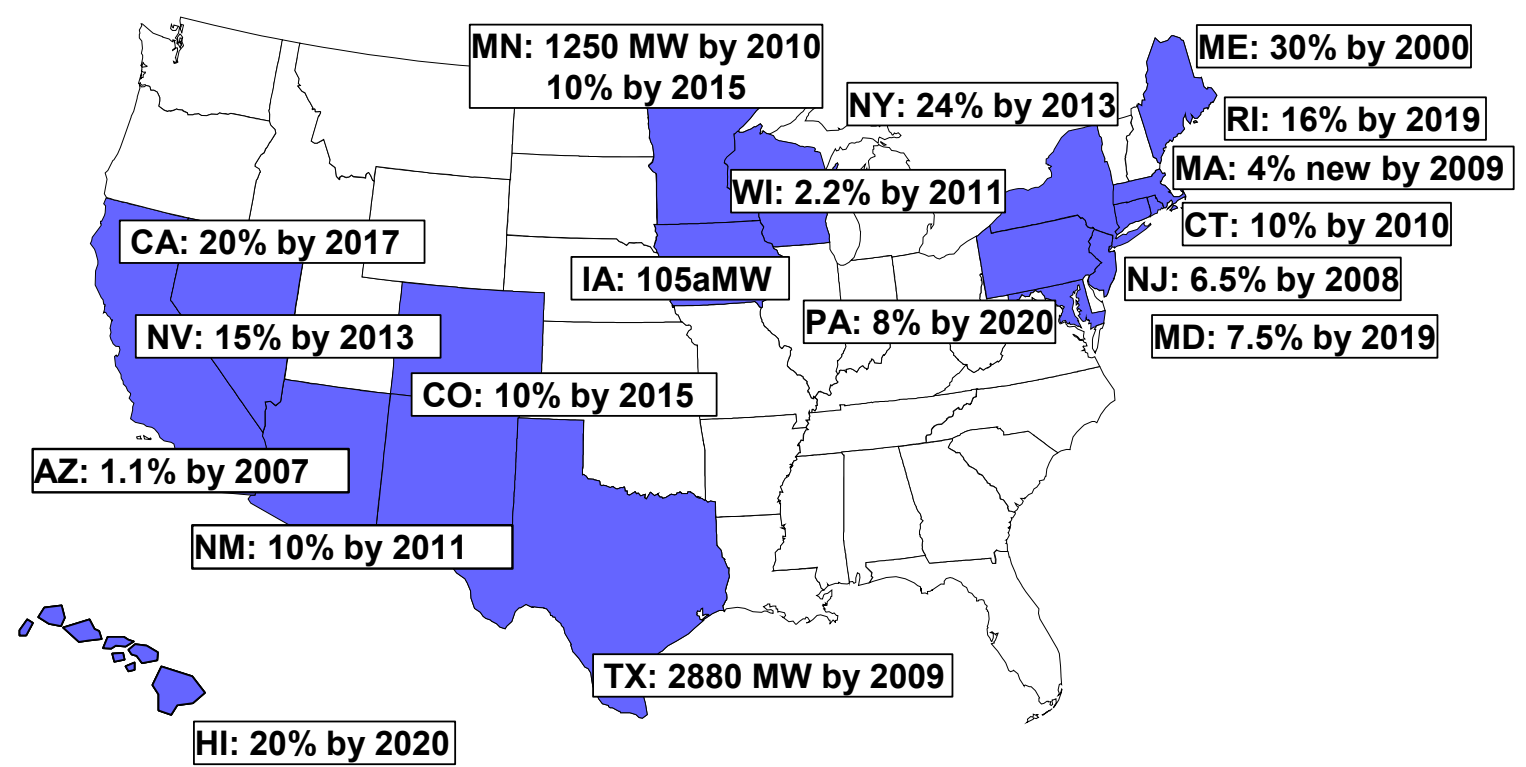

Figure 1. States with Renewable Portfolio Standards

Table 1. Sample Range of REC Trading Prices in Compliance Markets

\begin{tabular}{|l|c|c|c|}
\hline & $\begin{array}{c}2003 \\
\text { REC Trading Prices } \\
(\$ / \mathrm{MWh})\end{array}$ & $\begin{array}{c}\text { Jan-Oct 2004 } \\
\text { REC Trading Prices } \\
(\$ / \mathrm{MWh})\end{array}$ & $\begin{array}{c}\text { Noncompliance } \\
\text { Penalty } \\
(\$ / \mathrm{MWh})\end{array}$ \\
\hline Connecticut (Class I) & $37-48$ & $35-48$ & $\$ 55$ \\
\hline Maine/CT Class II & $\mathrm{N} / \mathrm{A}$ & $0.65-0.70$ & $\$ 55(\mathrm{CT})$ \\
\hline NJ (PJM) Class I & $4-6.50$ & $6.50-7.50$ & $\$ 50$ \\
\hline NJ (PJM) Class II & $2-4.50$ & $4.25-5$ & $\$ 50$ \\
\hline Massachusetts (New) & $21-40$ & $40-49$ & $\$ 51$ \\
\hline Texas & $10-14$ & $11-15$ & $\$ 50$ \\
\hline
\end{tabular}

Sources: Evolution Markets and Cantor Fitzgerald 
Texas - To date, the Texas RPS has created the largest and most active REC market in the United States. According to ERCOT, the Texas REC Program tracked 2.95 million MWh of renewable energy generation or RECs in 2003, of which $82 \%$ was from new renewable energy sources (ERCOT, 2004). The Texas RPS required utilities and competitive retailers to retire 1.226 million MWh of RECs from new sources annually in both 2002 and 2003 (Table 2); however, in these first two years of the program, the PUC allowed up to a $10 \%$ variance with any shortfall to be made up in the following year. ${ }^{13}$ In response, utilities and competitive retailers retired about 1.1 million MWh of RECs in 2002 and 1.27 million MWh in 2003. While RECs are used for tracking compliance, many electricity suppliers are meeting the RPS by entering into contracts for both the electricity and RECs (bundled) from wind or other renewable energy facilities.

Table 2. Texas REC Generation and RPS Compliance

\begin{tabular}{|l|c|c|}
\hline & $\begin{array}{c}2002 \\
\text { millions of MWh }\end{array}$ & $\begin{array}{c}2003 \\
\text { millions of MWh }\end{array}$ \\
\hline Total RECs Tracked & 2.793 & 2.949 \\
\hline Total New RECs Tracked & 2.186 & 2.383 \\
\hline RPS Requirement (new RECs) & 1.226 & 1.226 \\
\hline RECs Retired for RPS Compliance & 1.096 & 1.269 \\
\hline
\end{tabular}

Source: ERCOT (2004)

Initially, RECs were expected to trade for about $\$ 5 / \mathrm{MWh}$ (or perhaps less), because of the state's high-quality wind resources and the large amount of wind energy capacity installed in 2001, well in advance of the compliance deadlines (Wiser and Langniss 2001). However, since then, RECs have traded at considerably higher levels, but still well below the noncompliance penalty of $\$ 50 / \mathrm{MWh}$. Although there are little data available on bilateral contracts, REC brokers have provided some data on REC transactions in Texas and other states. According to brokers, RECs traded in the range of $\$ 10-12 / \mathrm{MWh}$ during most of 2003, peaking at $\$ 15 / \mathrm{MWh}$ during the first three-quarters of 2004 (Table 1).

REC prices have been higher than originally expected for a number of reasons. First, transmission constraints in Texas have required many of the existing wind energy generators to curtail their output. In addition, lack of access to transmission and the expiration of the federal production tax credit (PTC) have limited development of new wind energy projects. Since 2001 , only about $200 \mathrm{MW}$ of new wind energy capacity has come on-line; and, of that, only about $40 \mathrm{MW}$ are expected to be available for RPS compliance - although a number of projects are planned for $2005 .{ }^{14}$ Further, the state's active voluntary market has created additional demand for Texas RECs. And finally, some companies are "banking" RECs for future use or to see whether prices rise- under

\footnotetext{
${ }^{13}$ The Texas RPS, which was adopted as part of the state's 1999 restructuring law, requires the addition of 2000 MW of renewable energy capacity by 2009 , with interim targets of 400 MW by January 1, 2002; 850 MW by January 1, 2004; and 1,400 MW by January 1, 2006. The PUC has established capacity factors to determine the requirement in $\mathrm{MWh}$.

${ }^{14}$ A retail green power marketer has contracted for the output of a 160-MW wind project installed in 2003, which it plans to use to serve its green power consumers.
} 
the RPS rules, RECs can be banked for three years (the year generated, plus two additional years) before being used for compliance. Most of the RECs have been purchased under long-term power purchase agreements (bundled with electricity) by a few large electricity suppliers, which has raised some concern over market power. While there has been a surplus of RECs to meet RPS targets in past years, it is not clear whether there is sufficient annual generation to meet the January 2004 target of 2.61 million $\mathrm{MWh}$ ) and future targets. It will depend in part on how quickly new transmission capacity can be added.

New England - In several New England states, RECs have been actively traded to meet current and future RPS targets. Four New England states have adopted RPS policiesConnecticut, Maine, Massachusetts, and (most recently) Rhode Island. Each of these states allows RECs tracked in the NEPOOL GIS to be used for RPS compliance (and in some cases RECs from outside of the system). To date, REC trading has been most active in Massachusetts and Connecticut. In Maine, there has been some trading of RECs for RPS compliance, but prices are low because there is already sufficient renewable energy generation to meet the requirement. The recently adopted Rhode Island RPS is set at current generation levels until 2008, when it begins increasing by $0.5 \%$ annually; thus, it is not expected to stimulate much REC market activity until then.

In Massachusetts, there has been some trading of RECs to meet the RPS, which requires electricity providers to meet $1 \%$ of their retail sales with electricity from new renewable energy sources starting in 2003 , increasing by $0.5 \%$ per year to $4 \%$ in 2009 . There are no publicly available data on the quantity of RECs that have been required to meet the RPS to date. Based on 2002 utility retail sales data, approximately 460,000 MWh of RECs were required to meet the standard in 2003, and about 700,000 MWh are required in 2004. According to the NEPOOL GIS, there were about 315,000 MWh of RECs generated during 2003 that were eligible to meet the Massachusetts new renewables standard, although fewer may actually be available because some may be used for compliance with other RPS policies (Table 3). Massachusetts, similar to several other states, requires RECs sourced from outside of New England to be accompanied by delivered electricity.

Table 3. RECs Eligible for RPS Compliance in New England

\begin{tabular}{|l|c|r|}
\hline & 2002 & \multicolumn{1}{|c|}{2003} \\
& MWh & \multicolumn{1}{|c|}{ MWh } \\
\hline RECs Eligible for CT Class I & 222,897 & 299,869 \\
\hline RECs Eligible for CT Class II & $7,375,060$ & $5,896,549$ \\
\hline RECs Eligible as MA New Renewables & 250,219 & 315,346 \\
\hline RECs Eligible for ME RPS & $11,246,725$ & $11,924,279$ \\
\hline
\end{tabular}

Source: NEPOOL GIS

* These numbers are not additive for total RECs in New England, because of multiple eligibility.

These data suggest a shortfall in RECs, but there is some uncertainty in the amount of generation eligible to meet the Massachusetts RPS each year, because generation from an eligible existing facility that is above the facility's historical average is also eligible. The 
tight supply situation - as well as the modest quality of the renewable resources in the region and difficulties in siting new renewable energy projects - have resulted in REC prices that are among the highest in the country. Broker data indicates that trades have been in the range of approximately $\$ 40-49 / \mathrm{MWh}$ (see Table 1), which is near, but still below, the noncompliance penalty of $\$ 51 / \mathrm{MWh}$ in 2004 (\$50/MWh in 2003). ${ }^{15}$

The Connecticut RPS, which took effect in early 2004, has also stimulated some REC trading, including a number of forward trades, according to brokers. To date, most REC trades have been for "Class I" resources, which are defined under the RPS as wind, solar, fuel cells, new sustainable biomass, and landfill gas. Under the RPS, suppliers must use Class I renewables to meet $1 \%$ of retail sales in 2004 , increasing to $7 \%$ in 2010 . In addition, Connecticut suppliers must use Class I or Class II resources (which include MSW, hydro, and other biomass) to meet 3\% of retail sales from 2004 through 2010. RECs sourced in New England are eligible for Connecticut's RPS, as are RECs from New York and Mid-Atlantic states if the Board of Public Utilities Control determines that a comparable tracking system is in place.

According to data from brokers, REC prices for Connecticut Class I resources (essentially new renewable energy sources) have ranged from about $\$ 35 / \mathrm{MWh}$ to $\$ 48 / \mathrm{MWh}$, which again is near but still below (as one would expect) the noncompliance penalty of $\$ 55 / \mathrm{MWh}$. There are little historical data available on trades of Connecticut Class II RECs; however, during the third quarter of 2004, brokers reported a few trades of RECs eligible for the Connecticut Class II standard and the Maine RPS at prices in the range of $\$ 0.65$ to $\$ 0.70 / \mathrm{MWh}$. These prices are the lowest in the country for compliance RECs, because there are ample supplies in the region to meet both the Connecticut Class II standard and the Maine requirement, and the eligible sources are primarily existing generators that command relatively small premiums.

Because 2004 is the first year of the Connecticut RPS, there is no available information on the number of RECs that have been retired for compliance with the requirement. According to the NEPOOL GIS, there were about 300,000 MWh of RECs generated during 2003 that were eligible to meet Connecticut's Class I standard and 5.9 million MWh eligible for the Class II standard. Again, however, these data do not necessarily indicate the number of RECs that will actually be available or used for compliance, because these same RECs may be eligible for compliance with other state RPS policies as well.

New Jersey - Data provided by brokers (again, a limited dataset) indicates that RECs have been actively traded for compliance with New Jersey's RPS, which call for $6.5 \%$ of retail sales to be supplied from renewable resources by May 31, 2008 (according to revised standards issued by the Board of Public Utilities (BPU) in mid-2004). Similar to the Connecticut RPS, New Jersey's RPS specifies separate targets by resource class. Specifically, it requires $4 \%$ of retail generation from Class I resources (defined as wind, solar, fuel cells, geothermal, ocean, landfill gas and biogas, and sustainable biomass) and

\footnotetext{
${ }^{15}$ The penalty, called the alternative compliance payment, is adjusted annually by the Massachusetts
} Division of Energy Resources http://www.mass.gov/doer/rps/acp.htm. 
an additional $2.5 \%$ from Class I or Class II resources (small hydro and MSW) by May 31, 2008. Percentages beyond 2008 will be adopted in a future rulemaking.

Although data from brokers indicate that RECs have been traded for compliance with the New Jersey RPS, the rules do not allow the use of RECs until a tracking system is established. Therefore, electricity suppliers have been typically entering into contracts for both electricity and RECs to meet the requirement, but then swap the electricity, leaving them with just the REC. Thus, broker data are based on the net cost of these transactions. Once the PJM GATS system is functioning, electricity suppliers will officially be able to use RECs to demonstrate compliance with the RPS. Recognizing the importance of allowing RECs for compliance, the New Jersey BPU recently indicated its willingness to provide funding to finance the PJM GATS to accelerate its implementation.

Prices of RECs used for compliance with the New Jersey RPS have been among the lowest in the country. Table 1 shows that New Jersey Class I RECs have traded in the range of $\$ 4-7 / \mathrm{MWh}$, while Class II RECs have traded for $\$ 2-5 / \mathrm{MWh}$ - well below the noncompliance penalty of $\$ 50 / \mathrm{MWh}$. Prices have been low because of the availability of relatively low-cost generation sources, such as landfill gas facilities, to meet the standard thus far. In addition, New Jersey has a broad definition of geographic eligibility, which includes some areas with relatively high-quality renewable resources. The New Jersey RPS allows generation from eligible renewable energy sources located within PJM or those that can deliver electricity into PJM to meet the standard if those facilities commenced construction on or after January 1, 2003.

New Jersey also has a stringent solar requirement in its RPS. It calls for at least $0.16 \%$ of retail sales to be met with solar electric generation (approximately $90 \mathrm{MW}$ ) by 2008 as part of the 4\% Class I renewables requirement. Suppliers can meet the requirement through the use of solar RECs or by paying the noncompliance penalty (the Solar Alternative Compliance Payment), which has been set at \$300/MWh for 2004. New Jersey has established an on-line system to track RECs generated by solar-electric systems and to facilitate the issuance, transfer, and retirement of solar RECs. All electric suppliers are required to use this program to show compliance with the solar set-aside portion of the New Jersey RPS. According to the BPU, solar RECs are expected to trade in the range of \$150-200/MWh. ${ }^{16}$ Because the first compliance period does not end until mid-2005, no data are publicly available on the price and number of RECs that have traded to meet the standard.

Experience in Compliance Markets-Experience from these markets suggests that a number of factors impact the liquidity of REC markets and REC prices, such as:

1. Supplies and Geographic Eligibility. Of course, the availability of renewable energy supplies in the region, the type and quality of the renewable energy resources, the ability to site new renewable energy facilities, the RPS rules regarding the geographic region of eligible renewable energy generators, and the balance of supply and demand are all important factors that are reflected in REC

\footnotetext{
${ }^{16}$ Communication with Benjamin Scott Hunter, NJ BPU, October 28, 2004.
} 
trading prices. For example, prices for RECs in NEPOOL have been among the highest in the country, because of the limited renewable resources in the region and the difficulties to date in siting new projects. In contrast, REC prices in New Jersey have been among the lowest in the country, because of the broad geographic eligiblity for sources defined in the RPS and the availability of lowcost generation sources in the region to meet targets to date. Demand for RECs to supply voluntary markets also impacts compliance REC prices when there is competition for regional supplies. REC prices reflect the availability of supplies to meet current and future demand from both compliance and voluntary markets, and short-term price spikes may occur if supplies do not come on-line fast enough to meet demand, as is currently the case in New England.

2. Banking and Trading Rules. The rules for "banking" and trading RECs for future use can also have an impact on REC prices and available supplies. For example, initially under the NEPOOL GIS, RECs were only valid for compliance with an RPS during the quarter in which they were generated, which severely restricted the liquidity of the market and made it difficult for suppliers to comply with state RPS policies. This requirement has since been relaxed to one year and, as a result, market liquidity has improved. In contrast, RECs in Texas are valid for the year in which they were generated and two subsequent years, which encourages suppliers to hold onto RECs for future compliance, limiting market liquidity. Thus, "hoarding" may be playing a role in the higher-than-expected prices for RECs in the Texas market. Some market participants suggest that annual settlement of RECs may be optimal for market liquidity. The ability to conduct forward trades (trades involving RECs that will be generated at a future date) may also improve liquidity - as recent experience in New England suggests.

3. Penalties. The existence of noncompliance penalties (or alternative compliance mechanisms, ACMs) also impacts the price of RECs. Essentially, penalties and ACMs set a ceiling for RECs prices, because electricity providers would simply opt to pay the penalty if REC prices exceed the penalty price. Trading can occur well below the penalty price, as seen in Texas where RECs have traded for \$10$15 / \mathrm{MWh}$, while the penalty is set at $\$ 50 / \mathrm{MWh}$. However, in markets where renewable energy supplies are tight—-such as in New England-RECs have traded for prices near the level of the noncompliance penalty.

4. Tracking Systems. The availability of a REC tracking system can have an impact on the liquidity of a REC market, although it may have little impact on REC prices. In the markets discussed above, only New Jersey lacks a REC tracking system. This has made compliance with the RPS more difficult, essentially by requiring market participants to enter into electricity-swap contracts to ensure compliance. Thus, the presence of a tracking system can simplify the compliance process for electricity suppliers as well as simplify the verification process for regulators. As discussed earlier, tracking systems generally function only to track and retire RECs once they have been used for compliance with the RPS, while 
financial REC transactions are generally conducted through bilateral contracts or brokers.

\section{Estimating the Size of Compliance REC Markets}

In addition to the five states discussed above, another nine states currently allow the use of RECs for RPS compliance. Collectively, these 14 states have the potential to create significant demand for RECs, particularly in future years as renewable energy targets increase and as all of the policies take effect. ${ }^{17} \mathrm{We}$ estimate that these states collectively require nearly 13 million MWh of RECs or renewable energy generation currently (Table 4). Although REC trading has not yet taken off in some of these states, we estimate that nearly 8 million MWh of RECs were used for RPS compliance in New England and Texas in 2004, where REC tracking systems are in place. It is important to note that even in these states where REC tracking systems are being used to verify RPS compliance, the RECs are not always unbundled from the electricity. In Texas, for example, RECs have been purchased under long-term power purchase agreements with electricity to meet the RPS. By 2010, we estimate that RPS policies will require more than 45 million MWh of RECs or renewable energy generation.

To provide an indication of the value of this market, we apply current REC prices based on state and regional data provided by brokers and using professional judgment about the type and cost-effectiveness of available renewable resources where there are data gaps. In these calculations, we apply REC prices applicable to each resource class for states that set specific targets for solar or other classes of resources. For example, in Arizona, which calls for solar energy to meet $60 \%$ of its RPS, we assume the price of solar RECs will be $\$ 150 / \mathrm{MWh}$ and the price of RECs from other resources will be $\$ 15 / \mathrm{MWh}$. Applying this methodology to the states that currently allow the use of RECs for RPS compliance, we estimate that the current compliance REC market could be valued at nearly $\$ 140$ million, if entirely sourced from RECs (Table 4).

To provide a rough estimate of the potential future market value, we assume that REC prices will stay at current levels, except in the case of New England and PJM. In New England, we assume prices will drop as the region overcomes current supply constraints and more new renewable energy projects come on-line. In PJM, we assume that prices will increase modestly as state RPS policies are implemented, creating additional demand for RECs. In other regions, price trends are less clear; while technology improvements and economies of scale could send REC prices lower, these factors could be offset by the need to develop less cost-effective resources to meet higher targets in future years. Given these assumptions, we estimate that the compliance REC market could be worth more than $\$ 600$ million by 2010 (see Table 4). It is important to note that the market could be

\footnotetext{
${ }^{17}$ However, not all of this demand will be for RECs from new renewable energy sources, because existing renewables are also eligible for RPS compliance in many states. For example, in Maine there are sufficient renewable energy supplies currently available to meet the state's 30\% RPS target. Therefore, the RPS will stimulate some trading of RECs from existing facilities but will not stimulate much (if any) new renewable resource development.
} 
much larger if states such as California approve the use of RECs for RPS compliance. In addition, a number of states are considering increasing their RPS targets substantially.

Table 4. Estimated Value of Compliance REC Markets Through 2010

\begin{tabular}{|c|c|c|c|c|c|c|}
\hline & $\begin{array}{c}2004 \\
\text { Potential } \\
\text { REC Market } \\
\text { Size } \\
(M W h)^{1}\end{array}$ & $\begin{array}{c}2004 \\
\text { REC Value } \\
(\$ / M W h)^{2}\end{array}$ & $\begin{array}{c}2004 \\
\text { Potential } \\
\text { REC Market } \\
\text { Value } \\
\text { (\$ millions) } \\
\end{array}$ & $\begin{array}{c}2010 \\
\text { Potential } \\
\text { REC Market } \\
\text { Size } \\
(M W h)^{1} \\
\end{array}$ & $\begin{array}{c}2010 \\
\text { REC Value } \\
(\$ / M W h)^{3}\end{array}$ & $\begin{array}{c}2010 \text { REC } \\
\text { Market } \\
\text { Value } \\
\text { (\$ millions) }\end{array}$ \\
\hline Arizona & 284,000 & $\$ 150 / \$ 15$ & $\$ 27.3$ & 435,000 & $\$ 150 / \$ 15$ & $\$ 41.8$ \\
\hline Colorado & -- & -- & -- & $1,280,000$ & $\$ 10 / \$ \$ 150$ & $\$ 27.9$ \\
\hline Connecticut & $1,204,000$ & $\$ 40 / \$ 0.5$ & $\$ 12.5$ & $3,350,000$ & $\$ 20 / \$ 0.5$ & $\$ 47.4$ \\
\hline Maine & $2,996,000$ & $\$ 0.5$ & $\$ 1.5$ & $3,334,000$ & $\$ 0.5$ & $\$ 1.7$ \\
\hline Maryland & -- & -- & -- & $3,279,000$ & $\$ 10 / \$ 5$ & $\$ 23.8$ \\
\hline Massachusetts & 700,000 & $\$ 40$ & $\$ 28.0$ & $2,595,000$ & $\$ 25$ & $\$ 64.9$ \\
\hline Nevada & $1,786,000$ & $\$ 10 / \$ 100$ & $\$ 20.7$ & $4,897,000$ & $\$ 10 / \$ 100$ & $\$ 56.7$ \\
\hline New Jersey ${ }^{4}$ & $2,470,000$ & $\$ 6 / \$ 4 / \$ 150$ & $\$ 12.1$ & $5,498,000$ & $\$ 10 / \$ 5 / \$ 150$ & $\$ 63.4$ \\
\hline New Mexico & -- & -- & -- & $1,049,000$ & $\$ 10$ & $\$ 10.5$ \\
\hline New York & -- & -- & -- & $7,302,000$ & $\$ 15 / \$ 150$ & $\$ 129.2$ \\
\hline Pennsylvania & & -- & -- & $4,744,000$ & $\$ 10 / \$ 150$ & $\$ 47.7$ \\
\hline Rhode Island & -- & -- & -- & 389,000 & $\$ 25$ & $\$ 9.7$ \\
\hline Texas & $2,606,000$ & $\$ 10$ & $\$ 26.1$ & $6,132,000$ & $\$ 10$ & $\$ 61.3$ \\
\hline Wisconsin & 590,000 & $\$ 15$ & $\$ 8.9$ & $1,468,000$ & $\$ 15$ & $\$ 22.0$ \\
\hline Total & $12,635,000$ & & $\$ 137.0$ & $45,752,000$ & & $\$ 608.0$ \\
\hline
\end{tabular}

${ }^{1}$ The calculations are based on each state RPS requirement applied to the most recent (2002) retail electricity sales reported by the Energy Information Administration (EIA)

http://www.eia.doe.gov/cneaf/electricity/esr/esr tabs.html for obligated suppliers, assuming annual growth in retail sales of 1.8\%, consistent with the EIA Annual Energy Outlook 2004 with Projections to 2025. The Texas estimates are based on capacity targets, applying the current PUC-approved capacity factor of $35 \%$ for wind. The Maryland, Nevada, and New Mexico estimates are based on data from the Union of Concerned Scientists (Deyette, 2004).

${ }^{2}$ For states in which no data are publicly available on REC trading prices (Arizona, Colorado, Nevada, New Mexico, and Wisconsin), we apply values based on professional judgment. For states that set separate targets for solar or other classes of resources, we apply separate prices for each resource class. For example, in New Jersey, we apply $\$ 6 / \mathrm{MWh}$ for the Tier I resource requirement, $\$ 4 / \mathrm{MWh}$ for the Tier II requirement, and $\$ 150 / \mathrm{MWh}$ for the solar requirement.

${ }^{3}$ In Connecticut, a REC price of $\$ 20$ in 2010 is assumed, compared to \$25 for other New England states (Massachusetts and Rhode Island), because Connecticut allows RECs from surrounding states without a deliverability requirement once REC tracking systems are established. The analysis assumes that prices for RECs in PJM will increase slightly to $\$ 10$ for Tier I resources and $\$ 5$ for Tier II resources in 2010, because of increased demand in the region as RPS targets rise. In Nevada, a REC price of $\$ 100 / \mathrm{MWh}$ is assumed for the solar requirement to reflect the likely use of both PV and concentrating solar.

${ }^{4}$ The New Jersey targets beyond 2008 will be established at a later date. For this analysis, the target is assumed to remain at the 2008 level going forward, adjusted for growth in retail sales. 


\section{Voluntary Markets}

In voluntary markets, RECs are used to supply differentiated green energy products sold to end-use consumers. Consumers generally are willing to pay a premium for these products, because they want to support the development of renewable energy sources and their associated environmental benefits. To supply these products and to substantiate green power marketing claims, marketers and utilities purchase and retire RECs.

As discussed earlier in Section 3, marketers use RECs to supply both delivered renewable energy products (RECs bundled with electricity) as well as stand-alone REC products, which are sold separately from electricity. When RECs are bundled with electricity and sold as "green power" or renewable electricity, the use of RECs is often invisible to the end-use customer. This involves only a wholesale transaction. When RECs are sold as a stand-alone product, generally wholesale and retail transactions are involved. The following sections discuss sales and prices of RECs used to serve voluntary markets below, focusing both on retail and wholesale markets.

\section{REC Sales in Voluntary Markets}

\section{$\underline{\text { Retail Sales }}$}

More than 20 companies market unbundled REC products to retail customers. NREL has estimated that more than $650,000 \mathrm{MWh}$ of stand-alone or unbundled RECs were sold to about 5,000 retail customers in 2003 (Bird and Swezey, 2004). While stand-alone REC sales represented about $17 \%$ of all voluntary green power sales (bundled and unbundled), REC purchasers represented only about $1.2 \%$ of all retail green power consumers. The small fraction of customers purchasing stand-alone RECs at retail can be explained by the fact that they are generally targeted to and most popular among nonresidential consumers, such as businesses, universities, and government agencies. For example, the EPA Green Power Partnership reported in October 2004 that its member companies and institutions were collectively purchasing about 540,000 MWh of RECs, which indicates that nonresidential customers may be responsible for more than three-quarters of all stand-alone REC sales (Clouse 2004).

Available data suggest that stand-alone retail REC sales have grown significantly in recent years. For example, the Green-e certification program reported sales of Green-e certified REC products in 2002 and 2003. During this time, retail sales of Green-e certified RECs (sold separate from electricity) experienced more than a fourfold increase (Table 5), as a result of increased sales to nonresidential customers. Although Green-e certified retail sales represented only $52 \%$ of total retail REC sales in 2003, these growth trends are likely indicative of the broader retail RECs market, based on discussions with marketers. 
Table 5. Green-e Certified REC Customers and Sales

\begin{tabular}{|c|r|r|r|r|}
\hline & \multicolumn{2}{|c|}{ Customers } & \multicolumn{2}{c|}{ Sales(MWh) } \\
\cline { 2 - 5 } & $\mathbf{2 0 0 2}$ & $\mathbf{2 0 0 3}^{*}$ & $\mathbf{2 0 0 2}$ & $\mathbf{2 0 0 3}^{*}$ \\
\hline Residential & 2,000 & 2,727 & 8,600 & 8,020 \\
\hline Nonresidential & 187 & 394 & 68,000 & 332,033 \\
\hline Retail Total & 2,187 & 3,121 & 76,600 & 340,053 \\
\hline Wholesale & -- & 49 & 73,000 & $1,494,470$ \\
\hline Total & 2,187 & 3,170 & 149,600 & $1,834,523$ \\
\hline
\end{tabular}

Source: Center for Resource Solutions (2003) and Kvale (2004).

*2003 data represent preliminary (unaudited) figures.

\section{$\underline{\text { Wholesale Sales }}$}

In addition to the $650,000 \mathrm{MWh}$ of RECs that are sold to retail customers separate from electricity, marketers and utilities also purchase RECs at the wholesale level to supply bundled electricity products. In 2003, utilities reported that they collectively purchased about 420,000 MWh of RECs to supply green pricing programs (Table 6) (Bird and Cardinal 2004). Data suggest that utilities are becoming more comfortable with this method of procuring renewables. From 2002 to 2003, there was a fourfold increase in purchases of unbundled RECs by utilities for their green pricing customers. In addition, RECs represented about one-third of green pricing sales in 2003 , compared to $11 \%$ in 2002.

Table 6. Utility Use of RECs to Supply Green Pricing Programs

\begin{tabular}{|c|c|c|c|}
\hline & $\begin{array}{c}\text { Total Retail Sales } \\
\text { through Utility Green } \\
\text { Pricing Programs } \\
\text { (MWh) }\end{array}$ & $\begin{array}{c}\text { Utility Purchases of } \\
\text { RECs for Green } \\
\text { Pricing Programs } \\
\text { (MWh) }\end{array}$ & $\begin{array}{c}\text { \% of Total } \\
\text { Sales }\end{array}$ \\
\hline 2002 & 895,000 & 103,000 & $11 \%$ \\
\hline 2003 & $1,284,000$ & 419,000 & $33 \%$ \\
\hline
\end{tabular}

Source: Bird and Cardinal (2004)

Marketers also commonly purchase RECs at wholesale to supply bundled renewable electricity products in competitive electricity markets. Typically, this involves purchasing RECs from within the region and bundling them with electricity from the power pool. NREL has estimated that 1.9 million MWh of renewable energy from existing and new sources were sold to retail customers in competitive markets in 2003 . There are no data available on the fraction of this market supplied with RECs. Therefore, for purposes of estimating the size of the current market for RECs, we assume, based on discussions with marketers, that all 1.9 million MWh of retail green power sales involved bundling wholesale RECs with generic electricity.

Combining these submarkets, we estimate that the size of the voluntary REC market was roughly 3 million MWh in 2003, including stand-alone retail REC sales as well as RECs used to supply green pricing programs and bundled electricity products in competitive markets (Table 7). Because NREL has estimated the size of the entire voluntary green 
power market at 3.9 million $\mathrm{MWh}^{18}$, this represents about three-quarters of total retail green power sales (Bird and Swezey 2004).

Table 7. Estimated Wholesale RECs Supplying Voluntary Markets (2003)

\begin{tabular}{|l|c|c|}
\hline & $\begin{array}{c}\text { Retail Sales } \\
\text { Millions of MWh }\end{array}$ & $\begin{array}{c}\text { Estimated RECs Sales } \\
\text { Millions of MWh }\end{array}$ \\
\hline Utility Green Pricing & 1.3 & 0.4 \\
\hline Competitive Markets & 1.9 & 1.9 \\
\hline Unbundled RECs & 0.7 & 0.7 \\
\hline Total Green Power Market & 3.9 & 3.0 \\
\hline
\end{tabular}

As with retail sales, data suggest that wholesale REC sales have grown dramatically in recent years. In addition to the growth in the use of RECs to supply green pricing programs discussed above, the Green-e program has reported more than a 20 -fold increase in wholesale sales of Green-e certified RECs from 2002 to 2003 (CRS 2003; Kvale 2004). This growth may have resulted, in part, because 2002 was the first year that Green-e certified RECs. In addition, the Texas REC tracking system reported that utilities and marketers voluntarily retired about 800,000 MWh of RECs for use in green pricing programs or competitively marketed green power products in 2003, compared to 240,000 MWh in 2002 — nearly a threefold increase (Table 8) (ERCOT 2004). ${ }^{19}$

In contrast, data provided by the NEPOOL GIS show a decline in REC retirements from 2002 to 2003 , although the data are incomplete. ${ }^{20}$ In 2003, approximately $57,000 \mathrm{MWh}$ of RECs were retired and removed from the NEPOOL GIS (primarily for sale in unbundled REC products), compared to $113,000 \mathrm{MWh}$ in 2002 (Table 8). ${ }^{21}$ This represents a $50 \%$ decline, which may be explained partly by the high REC prices in the region following the initial implementation of the Massachusetts RPS. However, no data are available on the quantity of RECs used in bundled electricity products in NEPOOL during this time; thus, it is difficult to discern a full market trend based on these data.

Table 8. Voluntary Market REC Retirements in Texas and NEPOOL

\begin{tabular}{|c|c|c|}
\hline Year & $\begin{array}{c}\text { Texas Voluntary REC } \\
\text { Retirements } \\
(\mathrm{MWh})\end{array}$ & $\begin{array}{c}\text { NEPOOL Voluntary REC } \\
\text { Retirements } \\
(\mathrm{MWh})^{*}\end{array}$ \\
\hline 2001 & N/A & 0 \\
\hline 2002 & 241,000 & 112,973 \\
\hline 2003 & 797,000 & 56,905 \\
\hline
\end{tabular}

Sources: ERCOT 2004; NEPOOL GIS

\footnotetext{
${ }^{18}$ This includes generation from both existing and new renewable energy sources.

${ }^{19}$ In 2002, Austin Energy, City Public Service of San Antonio, and El Paso Electric voluntarily retired about 214,000 MWh of RECs to supply their voluntary green pricing programs. Green Mountain Energy company retired 27,000 MWh of RECs to serve its green power customers.

${ }^{20}$ See https://www.nepoolgis.com/mymodule/mypage.asp

${ }^{21}$ The NEPOOL GIS refers to RECs that are retired and removed from the system as reserved certificate transfers.
} 
In summary, we estimate that 3 million MWh of RECs (from new and existing sources) were used to serve voluntary green power markets in 2003 . However, this is likely an underestimate, because it may not include wholesale REC purchases by utilities under least-cost planning or purchases to meet voluntary renewable energy goals. For example, Fort Collins Utilities in Colorado buys RECs from a Wyoming wind farm to meet a goal set by the Fort Collins City Council, which requires that $2 \%$ of the city's electricity come from renewable sources by 2004 , increasing to $15 \%$ by $2017 .^{22}$ In addition, utilities such as PacifiCorp may be purchasing renewable energy bundled with RECs to meet their least-cost resource plans. The omission of these wholesale transactions could be significant because of their potential magnitude. However, it is not entirely clear that these REC purchases should be included under voluntary markets, particularly in the case of a utility that purchases wholesale RECs in response to a city council resolution or policy. One could argue such purchases should be included under compliance markets. Regardless, these purchases represent an omission in the market estimates presented in this report because they are not covered under either voluntary or compliance markets.

\section{REC Prices in Voluntary Markets}

\section{$\underline{\text { Retail Prices }}$}

As with most products, retail prices for RECs tend to be higher than wholesale prices to allow marketers to recoup their costs and retain a profit. Retail prices charged for RECbased green power products generally range from about $1 \phi / \mathrm{kWh}$ to $2.5 \phi / \mathrm{kWh}$; however, a few products are offered for $4 \phi / \mathrm{kWh}$ to $5 \phi / \mathrm{kWh}$, and one solar-only product is priced at $20 \notin / \mathrm{kWh}$ (Bird and Swezey, 2004) (Table 9). Typically, these prices are only for residential or small commercial customers. Larger customers are usually able to purchase RECs at lower prices, in some cases less than $1 \phi / \mathrm{kWh}$. Of course, product pricing is heavily influenced by the type and quality of the renewable resources used to supply the product. Most retail REC products are sourced from new renewable energy generation facilities, which is a requirement of the Green-e certification program. Wind energy is the most commonly used renewable energy source, although a number of REC products blend other renewable energy sources, such as landfill gas and solar.

While retail prices for RECs marketed to residential and small commercial customers have remained nearly the same during the past few years, prices for RECs sold to some large nonresidential customers have declined. Because many purchasers do not publicly report the price paid for green power, there are limited data available to determine price trends. However, discussions with marketers and other industry participants, as well as data on wholesale prices of RECs in some regions (see discussion below), suggest that prices for large-volume purchases have declined in recent years, depending on the type and location of the generating sources. One potential concern about such downward price trends is that voluntary markets may not be able to provide meaningful support for the development of new renewable energy projects, which is already problematic due to the uncertainty of demand and the unwillingness of investors or lenders to rely on voluntary

${ }^{22}$ http://www.fcgov.com/news/index.php?ID=062004060413001 
Table 9. Renewable Energy Certificate Product Offerings (July 2004)

\begin{tabular}{|c|c|c|c|}
\hline Company & Product Name & Resource Mix & $\begin{array}{l}\text { Residential Price } \\
\text { Premium }\end{array}$ \\
\hline 3 Phases Energy Services & Green Certificates & $100 \%$ wind & $2.0 \phi / \mathrm{kWh}$ \\
\hline Aquila Inc. & Aquila Green Credits & $100 \%$ wind & Nonresidential only \\
\hline $\begin{array}{l}\text { Bonneville Environmental } \\
\text { Foundation }\end{array}$ & Green Tags & $\begin{array}{c}\geq 98 \% \text { wind }, \leq 1 \% \\
\text { solar, } \leq 1 \% \\
\text { biomass }\end{array}$ & $2.0 \phi / \mathrm{kWh}$ \\
\hline Community Energy & New Wind Energy & $100 \%$ wind & $2.5 \phi / \mathrm{kWh}$ \\
\hline \multirow{2}{*}{ EAD Environmental } & $\begin{array}{l}100 \% \text { Wind Renewable } \\
\text { Energy Certificates }\end{array}$ & $100 \%$ wind & $1.5 \phi / \mathrm{kWh}$ \\
\hline & $\begin{array}{l}\text { Home Grown Hydro } \\
\text { Certificates }\end{array}$ & $\begin{array}{c}100 \% \text { small hydro } \\
(<5 \mathrm{MW})\end{array}$ & $1.2 \phi / \mathrm{kWh}$ \\
\hline Green Mountain Energy & TRCs & $100 \%$ renewable & Nonresidential only \\
\hline $\begin{array}{l}\text { Maine Interfaith Power \& } \\
\text { Light/BEF }\end{array}$ & $\begin{array}{l}\text { Green Tags (supplied by } \\
\text { BEF) }\end{array}$ & $\begin{array}{c}\geq 98 \% \text { wind }, \leq 1 \% \\
\text { solar, } \leq 1 \% \\
\text { biomass }\end{array}$ & $2.0 \phi / \mathrm{kWh}$ \\
\hline Maine Interfaith Power \& Light & First Wind of Maine & $100 \%$ wind & $4.0 \phi / \mathrm{kwh}$ \\
\hline Maine Power Options & $\begin{array}{l}\text { MPO MaineMade } \\
\text { Certificates }\end{array}$ & $\begin{array}{c}50 \% \text { hydro, } 50 \% \\
\text { biomass }\end{array}$ & Nonresidential only \\
\hline $\begin{array}{l}\text { Mass Energy/ People's Power } \\
\text { and Light }\end{array}$ & New England Wind & $100 \%$ wind & $5.0 \phi / \mathrm{kWh}$ \\
\hline \multirow{3}{*}{ Mainstay Energy } & $\begin{array}{l}\text { Fossil Free } 100 \% \\
\text { Renewable }\end{array}$ & $100 \%$ renewable & $2.0 \phi / \mathrm{kWh}$ \\
\hline & Fossil Free $100 \%$ Wind & $100 \%$ wind & $2.5 \phi / \mathrm{kWh}$ \\
\hline & Fossil Free $100 \%$ Solar & $100 \%$ solar & $20 \phi / \mathrm{kWh}$ \\
\hline \multirow{3}{*}{ NativeEnergy } & WindBuilders & $100 \%$ wind & $\begin{array}{c}1.0 \phi / \mathrm{kWh} \\
\$ 10 / \text { ton of } \mathrm{CO} 2 \\
\end{array}$ \\
\hline & CoolHome & Biogas and wind & $\begin{array}{c}1.0 \phi / \mathrm{kWh} \\
\$ 10 / \text { ton of } \mathrm{CO} 2 \\
\end{array}$ \\
\hline & $\begin{array}{l}\text { WindBuilders Business } \\
\text { Partners }\end{array}$ & $100 \%$ wind & Nonresidential only \\
\hline NUON Renewables Ventures & $\begin{array}{l}\text { PVUSA Solar TRCs } \\
\text { (nonresidential) }\end{array}$ & $100 \%$ solar & NA \\
\hline Pacific Renewables, Inc & Green Tags & $100 \%$ biomass & $\sim 3 \phi / \mathrm{kWh}$ \\
\hline PG\&E National Energy Group & PureWind Certificates & $100 \%$ wind & $4.0 \phi / \mathrm{kWh}$ \\
\hline Pepco Energy Services & PES Green TRC & $100 \%$ renewables & Nonresidential only \\
\hline PPM Energy & $\begin{array}{l}\text { Green Tags from Wind } \\
\text { Energy }\end{array}$ & $100 \%$ wind & Nonresidential only \\
\hline Renewable Choice Energy & American Wind & $100 \%$ wind & $2.0-4.0 \phi / \mathrm{kWh}$ \\
\hline Sterling Planet & Green America & $\begin{array}{c}45 \% \text { wind, } 50 \% \\
\text { biomass, } 5 \% \text { solar }\end{array}$ & $1.6 \phi / \mathrm{kWh}$ \\
\hline Sun Power Electric & ReGen & $\begin{array}{c}99 \% \text { landfill gas, } \\
1 \% \text { solar }\end{array}$ & $3.6 \phi / \mathrm{kWh}$ \\
\hline Waverly Light \& Power & lowa Energy Tags & $100 \%$ wind & $2.0 \phi / \mathrm{kWh}$ \\
\hline WindCurrent & Chesapeake Windcurrent & $100 \%$ wind & $2.5 \phi / \mathrm{kWh}-3.0 \phi / \mathrm{kWh}$ \\
\hline Viking Wind & Green Energy Tags & $100 \%$ wind & Nonresidential only \\
\hline Vision Quest & Green Energy & $100 \%$ wind & Nonresidential only \\
\hline
\end{tabular}


demand as security for financing (see full discussion of project financing issues in Section 5).

\section{Wholesale Prices}

Prices of RECs sold at wholesale to supply voluntary markets typically vary by the type and location of the renewable energy source, as well as other factors such as whether the RECs are generated from new or existing sources (vintage), the year or years in which they will be generated, the volume purchased, the level of competition created by compliance markets, and the level of overall renewable energy market development (Hanson and Van Son 2003). Similar to compliance markets, there are limited data available on REC trading prices; however, broker data gives an indication of current market prices.

Table 10 shows that there are considerable differences in the price of RECs sold at wholesale in voluntary markets, depending on the type of renewable resource and the location of the generator. RECs from new solar energy systems have commanded the highest prices, ranging from $\$ 30 / \mathrm{MWh}$ to $\$ 150 / \mathrm{MWh}$ for systems in the Western Electricity Coordinating Council (WECC) and \$80/MWh to \$200/MWh for systems selling into PJM. The high prices for solar RECs reflect the higher generating costs of photovoltaic systems (compared to other renewable energy sources) and the fact that consumers have expressed strong preferences for solar in market research (Farhar 1999; Winneg et al. 1998; EPRI 1997). Prices for solar RECs in PJM are likely to remain high, at least in the near term, because of the substantial amount of solar required to meet the New Jersey and Pennsylvania RPS policies. However, prices should stay below $\$ 300 / \mathrm{MWh}$, which is the current level of the solar noncompliance penalty for the New Jersey RPS. The noncompliance penalty for Pennsylvania is $200 \%$ of the average solar REC market price.

Table 10. Sample Range of Voluntary Market REC Prices for New Sources (by Type and Region/Powerpool in \$/MWh)

\begin{tabular}{|l|c|c|c|c|}
\hline & Wind & Solar & Biomass & Small Hydro \\
\hline California & $1.75-2.00$ & & 1.50 & \\
\hline WECC & $1.25-7.50$ & $30.00-150.00$ & $1.50-3.50$ & \\
\hline Central & $2.00-5.50$ & & 1.50 & \\
\hline PJM & $15.00-17.00$ & $80.00-200.00$ & $4.00-5.00$ & \\
\hline New York & $15.00-16.00$ & & 6.00 & \\
\hline NEPOOL & 35.00 & & 45.00 & 5.00 \\
\hline SPP & $2.50-5.00$ & & & \\
\hline Southeast & & & 3.50 & \\
\hline
\end{tabular}

Sources: Evolution Markets and GT Energy (data for July 2003 through October 2004).

RECs from wind, biomass, and hydro sources have traded for much lower prices, typically in the range of $\$ 2 / \mathrm{MWh}$ to $\$ 6 / \mathrm{MWh}$. Specifically, RECs from new biomass energy sources, mostly landfill gas generators, have traded for approximately $\$ 3 / \mathrm{MWh}$ in 
the WECC and the Southeast; about \$5/MWh to \$6/MWh in New York and the MidAtlantic; and as high as $\$ 45 / \mathrm{MWh}$ in supply-constrained New England. Although the number of trades has been very limited, RECs from new small or low-impact hydro sources have sold for $\$ 5 / \mathrm{MWh}$.

The price of wind energy RECs has varied considerably by region, with significant differences in trading prices of RECs from wind facilities in the western interconnect (WECC) and the central United States compared to those in the Northeast (Figure 2). These higher prices in the MidAtlantic and New York have resulted from: 1) lowerquality wind regimes, compared to those in the west and central regions, and 2) relatively tight supplies because of strong consumer demand for locally generated renewables and the need for resources to meet the growing number of state RPS policies in the region.

The data in Figure 2 also show that REC prices are influenced by demand and supply considerations over time. For example, REC prices for wind generation in the WECC declined during 2004, following significant additions of wind energy capacity in the region at the end of 2003. In contrast, prices of new wind RECs from New York and MidAtlantic generators increased slightly from about \$15/MWh in the fall of 2003 to $\$ 16-17 / \mathrm{MWh}$ in 2004 . This modest upward trend was likely a result of relatively strong consumer demand for RECs and continued progress on regional RPS policies, including the New York RPS (which has since been formally adopted). New projects underway in the region are expected to alleviate shortages in the coming years.

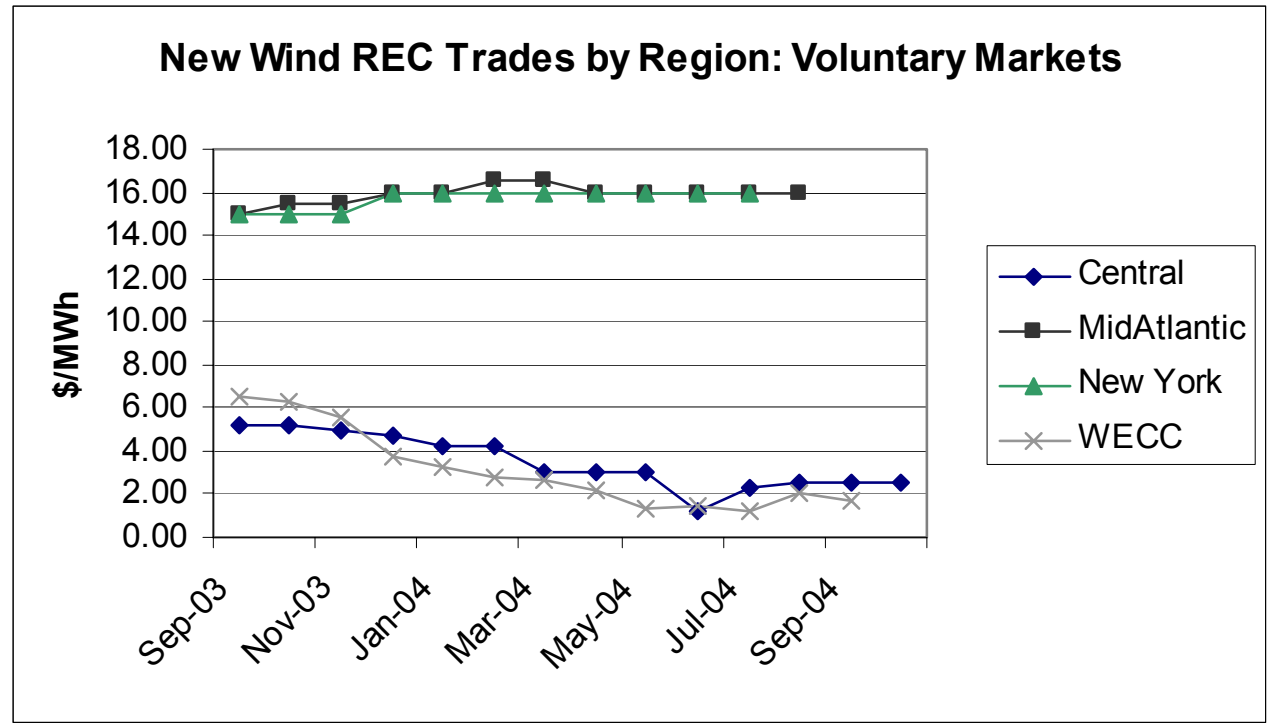

Source: Evolution Markets

Figure 2. New Wind REC Prices in Voluntary Markets by Region (July 2003-May 2004)

RECs from preexisting renewable energy sources have typically traded for lower prices in voluntary markets, which may or may not be the case in compliance markets, depending on RPS eligibility rules. According to data from Evolution Markets, RECs from existing sources have generally traded in the range of $\$ 2 / \mathrm{MWh}$ to $\$ 3 / \mathrm{MWh}$, with 
trades occurring as low as \$0.25/MWh and as high as \$6/MWh in 2003 and 2004 (Table 11).

One reason for the price differential between new and existing sources is that many existing renewable energy sources do not require large premiums to continue operation. Another reason is that there is a greater supply of existing RECs and a more limited market for them in voluntary markets. For example, the Green-e program requires certified electricity products to contain a minimum percentage of new renewable energy sources; and Green-e will only certify unbundled REC products if they are from new renewable generation. In addition, some marketers prefer to offer products comprised largely of new renewable energy sources, because they offer clearer benefits to consumers by affecting the generation mix (Harmon and Starrs, 2004). Finally, some consumers have expressed preferences for products containing new renewables (Holt et al., 2001; Blank et al., 2002; Hanson and Van Son 2003).

The inclusion of existing renewables in retail products can help lower prices for end-use consumers, but at the same time may undercut the ability of new renewables to compete. For example, utilities with existing hydropower or biomass plants that have historically been rate-based can remove such plants from the rate base and sell their RECs to marketers at a low cost, because the plants have already been largely paid for. On one hand, the low cost may encourage more customers to buy RECs or bundled energy; but, on the other hand, it does not provide any additional impetus to renewable resource development or any additional environmental benefits.

\section{Table 11. Sample Range of Voluntary Market REC Prices for Existing Sources (by Type and Region/Powerpool in \$/MWh)}

\begin{tabular}{|l|c|c|c|c|c|}
\hline & Biomass & Geothermal & Hydro & Small Hydro & LIHI Hydro \\
\hline WECC & $0.25-2.50$ & $1.00-3.50$ & & & \\
\hline Central & & & & & \\
\hline PJM & & & & & \\
\hline New York & $2.00-5.00$ & & $2.00-3.00$ & $1.00-3.50$ & \\
\hline NEPOOL & & & & $2.00-4.00$ & 6.00 \\
\hline Southeast & & & & & \\
\hline
\end{tabular}

Source: Evolution Markets. Data for July 2003 through October 2004.

\section{Estimating the Size of Voluntary Markets}

One forecast by Lawrence Berkeley National Laboratory (LBNL) and NREL estimates that the entire voluntary green power market could reach about 8 million MWh annually under a low-growth scenario, and 61 million MWh annually under a high-growth scenario by 2010 (Wiser et al. 2001). The forecast did not differentiate between demand for bundled RECs and energy, and unbundled RECs. If we assume that three-quarters of the future green power market would be supplied with RECs as it is today, then the REC market would be between about 6 million MWh and 46 million MWh annually by 2010, 
with the middle of the range (20 million MWh) more likely, given that the size of the REC market today is estimated at nearly 3 million MWh and growing rapidly (Table 12). ${ }^{23}$

Table 12. Estimated Voluntary REC Market Size and Value in 2003 and 2010

\begin{tabular}{|l|c|c|c|}
\hline & 2003 & $\begin{array}{c}2010 \\
\text { Low Growth } \\
\text { Scenario }\end{array}$ & $\begin{array}{c}2010 \\
\text { High Growth } \\
\text { Scenario }\end{array}$ \\
\hline Size (millions of MWh) & 3.0 & 5.9 & 45.8 \\
\hline Value @ \$5/MWh (\$ millions) & $\$ 15$ & $\$ 29.5$ & $\$ 229$ \\
\hline Value @ \$15/MWh (\$ millions) & $\$ 45$ & $\$ 88.5$ & $\$ 687$ \\
\hline
\end{tabular}

Estimating the value of this market is more complicated than for compliance markets, given the variety of products offered in the marketplace, differences in the price of products sold to residential and nonresidential consumers, and the variety of resources used to supply the market. To give a rough indication of the value of this market, we apply a range of $\$ 5 / \mathrm{MWh}$ to $\$ 15 / \mathrm{MWh}$, based on current retail prices and recognizing that sales to large nonresidential customers dominate retail sales. Thus, we estimate the voluntary REC market is currently valued at between \$15 million and \$45 million annually and could grow to as much as $\$ 90$ million to $\$ 690$ million annually by 2010 , with a range of $\$ 100$ million to $\$ 300$ million more likely given current market size (Table 12).

\section{ISSUES AND CHALLENGES IN EXPANDING RECS MARKETS}

This section discusses several issues significant to expanding RECs markets. These issues relate to project finance, the challenges faced in marketing and communicating RECs, the need for substantiation and verification of compliance and marketing claims, REC ownership ambiguity, uncertainty about environmental claims, and emissions markets opportunities. It then circles back to the question of the definition of a REC and the issue of disaggregating REC attributes for sale into emissions markets.

\section{Project Financing with RECs}

It is easy to forget that RECs are not an end, but a means, to facilitating trade in renewable energy attributes and ultimately to supporting the development of new renewable energy projects. Stepping back to this bigger picture, it is useful to remember that financing new renewable projects is one of the biggest challenges facing independent renewable developers.

\footnotetext{
${ }^{23}$ While these estimates indicate that voluntary markets hold the potential to create significant demand for RECs, developers may continue to face challenges in financing new renewable energy projects to supply voluntary markets, because of the short-term nature of most voluntary purchases, the uncertainty of future demand, and the unwillingness of lenders or investors to rely on voluntary demand as security for financing (see full discussion of project financing in Section 5).
} 
Typically, to obtain financing, new renewable projects need long-term agreements for the bundled electricity and RECs (i.e., a power purchase agreement or PPA) because the above-market cost of most renewable projects makes them too risky to finance otherwise. Long-term contracts provide the security a financier needs to manage risk.

Utilities have generally filled the role of long-term contractor for the renewable plant output. In most cases, the decision to do so has been heavily influenced by Public Utility Regulatory Policies Act (PURPA) requirements, by regulatory direction, or as part of a package to obtain approval for other desired projects (e.g., a coal-fired plant). In a few cases, utility willingness to make long-term commitments reflects an interest in environmental risk management, or the project is cost-effective in the utility's integrated resource plan. In addition, some utilities have supported projects to supply their green pricing programs.

Otherwise, utilities are reluctant to make long-term purchase commitments because of the risk that prices may fall and they will be locked into paying an uncompetitive price. They are also concerned about regulatory approval for cost recovery from projects with abovemarket costs.

Although voluntary demand for renewable energy or RECs can provide important revenue for renewable energy projects, generally it is inadequate to serve as the primary basis for project finance. Even demand backed by a long-term RPS by itself is insufficient by itself for project financing, because financial institutions generally require a more direct and legally enforceable commitment. Part of the problem is that projects are financed over 10 to 20 years, while most purchase commitments for voluntary and compliance demand are for only one or two years. Furthermore, in competitive markets, REC marketers are generally too small and have insufficient credit to provide the necessary security.

Several possible avenues exist to partially address the issue of project financing involving RECs:

- It may be possible to finance projects in the absence of a utility PPA, if large creditworthy end-users, such as universities or government agencies, make long-term commitments (i.e., 10 years or more) to purchase stand-alone RECs or RECs bundled with energy. For example, a REC contract for differences would provide price stability to the buyer and revenue security to the seller. ${ }^{24}$ (Aulisi and Hanson 2004) While it provides budgeting certainty for the end-user, most are uneasy about making long-term budget commitments for energy.

\footnotetext{
${ }^{24}$ A REC-based contract for differences (CFD) is the purchase of RECs based on an agreed fixed price, also referred to as the "strike price." Each party agrees to pay the other the difference between the agreed upon price and the actual market price of power. If the market price is less than the strike price at the time of production, the buyer pays the generator the difference between the two. On the other hand, if the market price is greater than the strike price, the generator pays the difference to the buyer. This provides a benefit to both parties - the generator gets revenue certainty, while the buyer gets a hedge against volatile or rising electricity prices, as well as the RECs.
} 
- State renewable energy funds could offer a price floor for RECs to ensure minimum REC revenue, as one component of a risk management strategy. The Massachusetts Renewable Energy Trust provides one such example, offering to purchase - or purchase options to buy - RECs for a period of up to 10 years. These funds are limited, however, in the number of projects they can support.

- States could require long-term contracts for bundled energy or stand-alone RECs as a means of satisfying an RPS. In Colorado, contracts to acquire renewable energy to satisfy the RPS must have a minimum term of 20 years; while, in Nevada, contracts must exceed 10 years. New York, with its central procurement of RECs on behalf of obligated energy providers, is seeking contracts from new projects with a term of not greater than 10 years.

- Regulators could require green pricing utilities to offer to buy RECs or bundled energy from projects that are not yet built. While most green pricing programs offer electricity from new renewable energy projects, they may not cause new facilities to be built, because they rely on excess generation from projects brought online for other reasons, such as to satisfy RPS policies.

- RECs that will be generated over the lifetime of a renewable energy project could be sold in advance to consumers before the project is constructed. In this way, the revenue stream can be used to finance the project directly. As noted earlier, one green power marketer has used this approach to help develop one or more small renewable energy projects. However, this is a slow method to generate financing, and is unlikely to support substantial expansions in renewable capacity.

\section{Marketing and Communications Challenges}

One of the big challenges for REC marketers is how to communicate about RECs to consumers. Larger consumers that are interested in green power are more likely to take the time to understand the concept of RECs if they are not already aware, and marketers can afford to educate one-on-one if the potential sale is a large one. The real communications difficulty is in mass marketing. Developing language to market green power can be difficult; and when marketing RECs, it is harder still to be concise, catchy, and accurate.

\section{Disclosing and Explaining Certificates}

Trying to market stand-alone RECs calls for explanation about certificates or attributes, and care must be taken to avoid the impression that consumers will receive electricity. So how do marketers overcome this marketing challenge without confusing potential customers? Most rely on Web sites to provide explanation and education. While this is a 
good way to provide more information, the marketing challenge remains to get consumers to visit the Web site. One marketer, Renewable Energy Choice, uses door-todoor canvassing; and, for interested customers, in-home meetings. This can be hard to replicate on a large scale.

Several marketers, such as Bonneville Environmental Foundation and Community Energy, concentrate on regional sales, where media coverage of local resource development and high-profile local sales can help increase awareness and understanding. ${ }^{25}$

Until RECs enter the consciousness of more consumers, communicating the concept will be a challenge. The National Association of Attorneys General (NAAG) recommends that "certificate-based claims be accompanied by a clear and prominent disclosure of the use of a tagging system to substantiate the claim," and goes on to comment, "unless state law allows otherwise, marketers are cautioned to avoid making claims based on a tagging system that state or imply that the supplier has actually purchased the power itself - as opposed to its environmental attributes - from the preferred generators." (NAAG 1999)

The Green-e certification standard also provides guidance for marketing RECs, to a large extent adopted from the NAAG Guidelines. Green-e advises REC marketers to avoid misrepresenting REC products as electricity products, and requires them to describe where the environmental benefit will occur by identifying the regional grid in which the electricity is being generated. Green-e suggests language that the RECs represent the environmental benefits of electricity from renewable energy sources, or that they offset or reduce the environmental impacts of electricity use by purchasing renewable energy attributes.

Examples from REC marketer Web sites illustrate how these guidelines are being applied. Readers can judge for themselves how well these examples comply with the guidelines.

- 3 Phases Energy Services: "A Green Certificate...represents the delivery of one megawatt-hour of renewable power to the total energy infrastructure. Certificates represent the environmental benefits created when electricity is generated from renewable resources instead of fossil fuels, like coal and natural gas, that release air pollution...By purchasing Certificates, you are supporting clean energy development and offsetting the emissions from the production of your company's electricity."

- Sterling Planet: "You can offset power plant emissions that contribute to global warming, acid rain, urban smog and health concerns. Plus, stimulate new renewable energy development."

- Mass Energy Consumers Alliance: "New England Wind ${ }^{S M}$ certificates represent the environmental attributes of the energy produced from a new wind generating

\footnotetext{
${ }^{25}$ Some REC marketers team with utilities or competitive electricity providers to sell to consumers through programs such as National Grid GreenUp, but this results in a rebundled green power product. In that case some of the communications challenges are eliminated.
} 
facility. Your purchase of New England WindSM offsets the production of polluting energy sources like coal, oil and nuclear, while creating a market demand for new wind resources."

- Pacific Renewables: "Tradable Renewable Credits represent the environmental and health benefits associated with using renewable energy and alternative transportation fuels that reduce greenhouse gases caused by waste and fossil fuel consumption."

- NativeEnergy: [Green Tags are a] "traded commodity that consists of the rights to claim the emissions reductions and other environmental benefits of green electricity. Green Tags became a commodity because people who want to buy green electricity often don't have it available to them. The industry developed Green Tags so everybody can achieve the same environmental benefits by buying Green Tags to offset the pollution caused by their consumption of electricity generated by fossil fuels."

- Sun Power Electric: "Each unique certificate represents all of the environmental attributes or benefits of the renewable generation, namely the benefits that everyone receives when conventional fuels, such as coal, nuclear, oil, or gas, are displaced. You usually buy certificates from someone other than your electricity provider and you will continue to receive a separate bill from your utility."

\section{Geographic Limitations}

In addition to the challenge of communicating an unfamiliar concept about an intangible product, RECs marketers face the difficulty of marketing a product nationally.

Marketers and advocates often tout the fact that RECs can be generated and sold anywhere. Even customers that don't have access to a green electricity product can still choose to support a preferred energy resource by buying RECs. Clearly, RECs have access to a broader market than specific electricity products, but that does not automatically make a national market. Selling RECs nationally is a very expensive proposition, and Web sites (though good to provide information) are not an effective means of promotion. First, customers must be attracted to the site.

A few marketers offer REC products nationally via their Web sites, but appear not to be promoting them heavily. Most marketers have focused on regional markets, either as competitive RECs marketers or through regional partnerships with utilities. We believe that the reason for this is that RECs created within a region are perceived as more tangible.

The easier it is for the consumer to see a tangible benefit to the product, the easier it is to attract buyers. In this case, "seeing" might be literal, as in being able to see a specific generating facility that is located within driving distance. In addition, consumers interested in supporting renewable energy may be motivated by local or regional air quality benefits, or local or regional economic development and jobs. These factors may tend to limit retail markets, at least, to regional geography or power grids. 
Most marketers emphasize regional resource development in their product descriptions, but some also offer opportunities via Web sites to accommodate a national market. The following Web site text illustrates how marketers communicate the benefits of REC products to a national audience.

- Bonneville Environmental Foundation: "We tell you exactly which wind, solar and other facilities are producing your Green Tags, how much they've generated, and when. We don't just buy anonymous credits from a national power exchange." Also, "Your purchase of BEF Green Tags...is supporting the production of renewable energy in the Western region, which includes 15 Western states."

- Community Energy: State or region-specific products emphasize the location of the generation. For other regions, the Product Content Label states, "The purchase of renewable energy certificates supports renewable energy generation, which helps offset conventional electricity generation in the region where the renewable energy generator is located," and discloses a Mid-Atlantic location for wind generation.

- Sterling Planet: "These TRCs support renewable electricity production nationwide...Y Your purchase of renewable certificates can help offset conventional electricity generation in the region where the renewable generator is located. Your purchase also helps build a market for renewable electricity and may have other local and global environmental benefits, such as reducing global climate change and regional air pollution."

- Renewable Energy Choice: "American Wind is a blend of Renewable Energy Certificates from wind farms across the US...The Renewable Energy Certificate represents electricity added to the national power grid from a clean energy source."

- A few REC marketers have nothing that could be found addressing the location of the generation or the distribution of environmental benefits.

\section{Substantiation and Verification}

REC tracking systems are important because they provide essential consumer protection; and because by issuing, tracking, and retiring RECs in a transparent structure, tracking systems add credibility to RECs themselves. They also offer a more cost-effective mechanism for marketers to prove environmental marketing claims and to verify compliance with various state policy requirements. For consumer protection, tracking systems make it easier to prevent double sales of RECs, or double use (using the same REC to satisfy a mandate, for example, and selling the same REC to consumers in a voluntary market) because each certificate has a unique serial number that can be tracked. Tracking systems also reduce disputes about ownership, because only one party at a time can hold the certificate in its account.

The challenge for RECs markets is that tracking systems have yet to be developed in a number of regions, and there are obstacles to their implementation. Furthermore, even 
where tracking systems are in operation, there may be rules in place that limit REC market growth.

Figure 3 shows the regions of the United States that rely on, are developing, or are considering certificate-tracking systems.

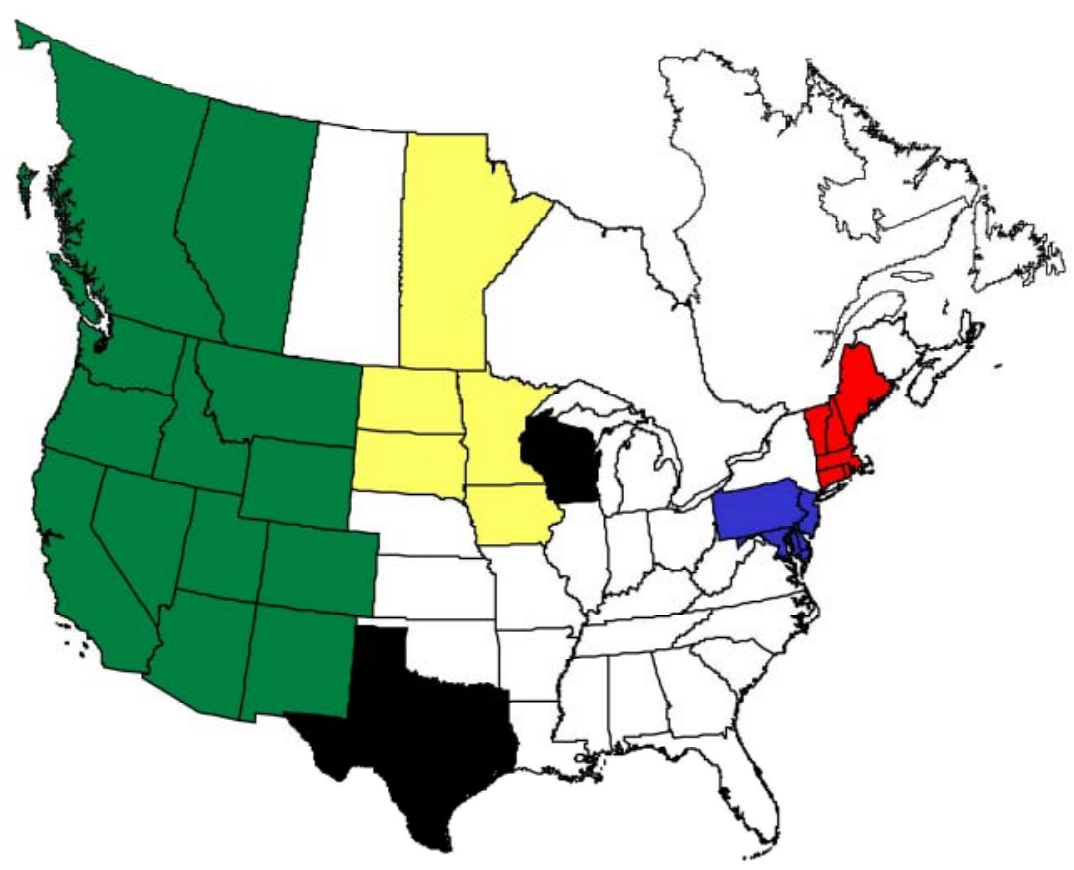

Figure 3. Regions with REC Tracking Systems in Operation or Development

Generators may find it more difficult to sell their RECs in regions without tracking systems. Buyers may be more cautious about purchasing unverified RECs, because of the greater risk of market abuses. To initiate tracking-system development in these regions, market stakeholders will have to generate political interest. Regional tracking systems are likely to be more generally accepted if they receive the clear support of state agencies and policy-makers. In most cases, the presence of state RPS or environmental disclosure policies has been the driver to developing tracking systems, although supporting voluntary markets and finding wider markets for regional certificates may also interest policy-makers.

For regions considering a tracking system, cost recovery can be a contentious issue. Who should pay for the tracking system? Some argue that all customers benefit from facilitating renewable energy markets, so the costs should be spread across all MWh sold. Others argue that states that pursue mandatory renewable energy policies, and want the tracking system to verify compliance, should have to pay; while states without such policies should not have to pay. Still others believe that users - meaning renewable energy generators, marketers, or REC traders - should pay; but some oppose this approach, because it will have the effect of making renewables more expensive relative to 
other sources, and potentially discourage larger REC markets. Cost recovery is a difficult issue that may affect the growth of REC markets.

In developing or operating tracking systems, stakeholders face a variety of issues and choices that may restrict REC markets. ${ }^{26}$ The challenge for RECs proponents is to ensure that tracking systems are flexible enough to support broader markets. One such issue is the lifespan of a REC (the period of time in which it may be traded), which affects the size and liquidity of the market.

Generally, state policy determines whether there is a limit on REC lifespan, and tracking system rules reflect these policies. For example, the NEPOOL GIS began operation with a requirement for settling all certificates quarterly, based on state policies requiring disclosure of electricity labels on a quarterly basis. Some participants argued that this provided insufficient time for sellers and buyers to find each other and conclude transactions. As a result, modifications to the operating rules were made in 2003 that allowed certificates to be traded until the end of the fourth-quarter trading period, which has improved market liquidity.

On the other hand, a three-year REC lifespan in Texas has resulted in poor market liquidity because the longer lifespan "takes away much motivation to get into the market and the RECs sit on the shelf." (Mason 2004) Apparently both too short and too long a lifespan can affect markets negatively.

Another issue for tracking systems is the treatment of REC imports and exports. As with REC lifespan, whether or not tracking systems support interregional trade generally reflects state policies. These policies often favor local resources over imports to encourage local renewable energy development with its concomitant economic development and environmental benefits, or to protect local or regional resources from competition from cheaper RECs from outside the region. State policies, or tracking systems, that do not support imports and exports may be viewed as an unconstitutional restraint of interstate trade under the U.S. Commerce Clause. ${ }^{27}$ But even if state policies or tracking-system operating rules are not judged to be a restraint of trade, they can limit REC market liquidity or impede the creation of larger markets. In general, tracking systems should be policy-neutral, and hard-wiring policy decisions into tracking system design should be avoided.

Some of these potential barriers may be overcome if tracking systems all agree to a common set of principles. The North American Association of Issuing Bodies has been

\footnotetext{
${ }^{26}$ For more detail, see National Wind Coordinating Committee, Design Guide for Renewable Energy Certificate Tracking Systems, 2004. Available at http://www.nationalwind.org.

${ }^{27}$ Whether or not a policy is considered a restraint of trade may depend on how it is implemented. (Rader and Hempling 2001) Rather than an outright ban on imports, some states give preference to local renewables by offering credit multipliers for in-state renewable generation (e.g., $\mathrm{CO}, \mathrm{NM}$ ), or by requiring that imported RECs be accompanied by electricity delivered to the state (e.g., CA) or to the regional power pool (e.g., MA, NY), or by requiring that electricity be delivered into the state with a dedicated transmission line (e.g., TX, NV).
} 
proposed to help establish just such a set of common principles and facilitate interregional trade between tracking systems. ${ }^{28}$

\section{National Markets and REC Liquidity}

One goal for REC markets is greater liquidity, meaning there are enough sellers and buyers (supply and demand) to create a fluid market with easy-to-find counterparties and sufficient transparency to keep competitive pressure on prices.

Market liquidity may be enhanced with the ability to transact forward trades. In a "forward" trade, renewable generators and suppliers reach agreement on the sale and purchase of future RECs that have not yet been created. The development of a forward market has helped improve liquidity in New England. (Mason 2004)

Another way to increase liquidity is to broaden the geographic scope of the market to bring in more participants. For RECs, this should be possible because they can be bought and sold anywhere.

Unlike electricity, REC sales are not constrained to the local distribution or regional transmission systems, so even customers that don't have access to a green electricity product can still choose to support a preferred energy resource by buying RECs. Clearly, RECs have access to a broader market than specific electricity products, and there is evidence that nationally sourced RECs offer a stronger value proposition to large corporate customers because of the lower cost and greater variety of options. (Hanson 2004)

With this kind of flexibility, one might think that a national market for RECs will soon develop. Regions with the most abundant and lowest-cost renewable resources could theoretically develop an export business and compete with RECs from local generators.

Instead of a single national market, however, the evidence reported earlier in Section 4 is that multiple state or regional markets exist, each with differing prices. There are several possible explanations for this.

- One explanation is that REC markets are, in part, driven by the need for compliance with state policy mandates, some of which require that energy or RECs be sourced from regional or in-state renewable resources, or that imported RECs be accompanied by power delivery into the regional grid. States also adopt different eligibility criteria for renewable resources to qualify for an RPS.

As discussed earlier, REC tracking systems, which are heavily influenced by state requirements, may have a similar limiting effect if they recognize imported RECs only when they are accompanied by imported electricity. The NEPOOL GIS, for

\footnotetext{
${ }^{28}$ For more information about the North American Association of Issuing Bodies, see http://www.resourcesolutions.org/naaib/index.htm
} 
example, will issue certificates for imported energy but will not accept RECs unaccompanied by energy. The Interim Operating Rules for WREGIS, however, will allow RECs to be issued to generators outside the tracking region, whether or not all or a portion of the energy generated with the certificates is delivered into the Western Electricity Coordinating Council.

- It is not only compliance markets that tend to constrain national RECs markets. There is some evidence that consumers in voluntary markets prefer to support local or regional resource development, perhaps because they are motivated by local environmental or economic benefits, or because the product is more tangible if the specific generating facility can be seen within driving distance. Purchasing data suggests that smaller nonresidential consumers support local resources by relying more on utility-offered bundled green power than on stand-alone RECs. (Clouse 2004). Universities, state agencies, and some federal agencies such as EPA have also exhibited preferences for local or regional resources. (Blank et al. 2002) ${ }^{29}$

Consumer preference for local or regional development may be why most retail marketers emphasize regional markets, either in their own promotional efforts or through alliances with local utilities or energy service providers. Another reason may be that it is prohibitively expensive to market a REC product nationally.

- A third factor that tends to limit the development of national markets is that renewable energy development in regions rich with cost-effective resources-but where electricity demand is low and not growing significantly — may be constrained by the availability of transmission to carry the electricity to load centers. Although the RECs may travel freely, the electricity must still find a market. This is a huge issue in the Upper Midwest and portions of the West. The transmission planning process is cumbersome, requiring multistate and federal cooperation and agreement.

Transmission access policies, siting, cost allocation, and risk associated with cost recovery are also contentious issues that can delay implementation of transmission solutions.

Although national markets, in the quest for greater liquidity, are desirable for some market participants, it is not a one-sided story. National RECs may undercut the ability of some local RECs to compete.

National markets would lead to uneven geographic development of renewable resources, as some regions are better endowed with cost-effective resources than others. Based on modeling of proposed federal RPS legislation, analysts at the U.S. Energy Information Administration (EIA) predict that a national RPS would lead to significant wind development in the Northwest and Midwest, where strong wind resources make wind power most cost competitive; and significant biomass development in the Southeast and Central states. (EIA 2002). Less well-endowed regions would end up paying for renewable energy development elsewhere in order to achieve compliance at the least cost.

\footnotetext{
${ }^{29}$ See descriptions of purchases by state and federal agencies on the Green Power Network Web site at http://www.eere.energy.gov/greenpower/buying/customers.shtml.
} 
Such an outcome would mean the loss of local benefits for which state policy-makers strive. They recognize that renewable resources developed in their state or region can provide jobs, income and tax revenue. They also recognize that local or regional renewable energy generation provides local and regional environmental and health benefits.

The tension between larger and more liquid RECs markets, on the one hand, and public policy goals that aim to encourage local benefits, on the other, is not easily resolvable. However, these factors limit the growth of national REC markets.

\section{Ownership Issues}

Questions about the ownership of RECs arise when money changes hands for renewable electricity or for renewable energy systems. Does payment for renewable electricity or system installations convey a right to the RECs that are produced?

The answer obviously matters to utility-scale generators, but may seem inconsequential to small generators. However, RECs can be quite valuable for small systems, particularly solar photovoltaic (PV) systems. For example, a 2-kW PV system can generate about one MWh of RECs per year, which could be worth up to \$200 annually.

Further, some market intermediaries are interested in aggregating RECs from small customer-sited generators. While small system owners may not be willing to incur the transaction costs of selling their few RECs each year, aggregators may be willing to buy the RECs and sell them into the RECs market. The Northwest Solar Cooperative, for example, will pay $\$ 100 / \mathrm{MWh}$ for RECs from small systems. To be eligible, however, system owners must be sure that they haven't signed away their rights to the RECs when they sign a net-metering agreement or accept a subsidy for system installation.

\section{Ownership Under PURPA Contracts}

This issue has arisen most notably in the context of utility contracts for qualifying facilities under the Public Utility Regulatory Policies Act (PURPA) of 1978. This federal law - and the state regulatory rules implementing it at the state level-require utilities to purchase the output from certain qualifying facilities (QFs) that include renewable energy generators, at the interconnecting utility's avoided cost. Because power purchase agreements did not contemplate RECs until recently, older PURPA contracts are silent about which party owns them.

In 2003, several QFs petitioned the Federal Energy Regulatory Commission (FERC) for a declaratory order that the sale of QF energy and capacity under a PURPA contract, based solely on avoided cost pricing, does not automatically transfer RECs from the QF to the 
purchasing utility. In its response, FERC essentially agreed, and left it to the states to decide ownership of RECs under PURPA contracts that are silent on the issue. ${ }^{30}$

Both prior and subsequent to this FERC ruling, others have sought clarification from state public utility commissions. In 2002, the Maine Public Utilities Commission initiated an investigation on this issue and tentatively concluded that the purchasing utilities have the rights to RECs associated with pre-existing QF contracts. Although the commission received comments, no further action has been taken as of this writing. ${ }^{31}$

In Connecticut, the Department of Public Utility Control ordered that a landfill gas owner transfer existing and future RECs to the power buyer (Connecticut Light and Power), because the utility was required to buy the facility's full output, expressly because of the renewable nature of the capacity. The DPUC also required that the generator transfer to the utility proceeds from any prior sale of the RECs. ${ }^{32}$

Idaho Power requested clarification from the Idaho Public Utilities Commission on who owns the RECs (the QF owner or the utility that contracts to buy the power). But the PUC declined to rule, saying the matter is "not ripe for declaratory judgment," because the state has not enacted renewable portfolio standards, has not created a green tag program, and has not established a trading market for green tags. ${ }^{33}$

The issue will continue to arise as demand for (and the value of) RECs increases in other states.

\section{Ownership Under Net Metering}

Another area where ownership of RECs may be in dispute is net metering. Thirty-eight states have net-metering rules in effect today. The rules vary, but the question for this discussion is whether the utility earns the right to claim the RECs from a system installed behind the customer meter.

The basic legal premise is that RECs belong to system owners, unless and until they are sold or otherwise legally transferred to another party. The question, in this case, is

\footnotetext{
${ }^{30}$ Specifically, FERC wrote that "the avoided cost rates for capacity and energy sold under contracts entered into pursuant to PURPA do not convey the RECs, in the absence of an express contractual provision." RECs are creations of the States, and therefore "they exist outside the confines of PURPA. PURPA thus does not address the ownership of RECs. And the contracts for sales of QF capacity and energy, entered into pursuant to PURPA, likewise do not control the ownership of RECs (absent an express provision in the contract). States, in creating RECs, have the power to determine who owns the REC in the initial instance, and how they may be sold or traded...Contracts for the sale of QF capacity and energy entered into pursuant to PURPA do not convey RECs to the purchasing utility (absent an express provision in the contract to the contrary). While a state may decide that a sale of power at wholesale automatically transfers ownership of the state-created RECs, that requirement must find its authority in state law, not PURPA." Federal Energy Regulatory Commission, Docket No. EL03-133-000, Order Granting Petition for Declaratory Order, October 1, 2003.

${ }^{31}$ Maine Public Utilities Commissions, Docket No. 2002-506, September 6, 2002.

${ }^{32}$ Connecticut Department of Public Utility Control, Docket No. 96-07-21RE01, March 19, 2004.

${ }^{33}$ Idaho PUC, Case No. IPC-E-04-2.
} 
whether utilities are legally entitled to RECs in return for offering net metering to their customers.

If the utility is required to offer net metering as a matter of state law, and the regulations do not expressly provide for the transfer of RECs as a condition of accepting net metering, utilities have no legal basis for taking the RECs. On the other hand, if the utility is offering net metering on its own volition - without any legal mandate - then it is entitled to condition the grant of that benefit (the advantages of net metering to the system owner) on receiving the RECs.

Most net-metering and interconnection rules are silent on who owns the RECs that result from customer-owned systems.

One exception is New Jersey, where rules state that net-metered customers own the RECs and may participate in New Jersey's Solar RECs program, which provides a means for solar certificates to be created and verified - and further allows the certificates to be sold to electric suppliers to meet their solar RPS requirement.

In contrast, NorthWestern Energy in Montana claims the RECs as part of its interconnection and net-metering agreement with customers. "NWE is solely responsible to apply and qualify for, and shall have the right to receive, the benefits of any and all RECs...created or granted as a result of the net metering arrangement with Customer."34

In a situation like this, a utility might argue that regulatory approval of its interconnection and net-metering agreement gives the utility the right to force the transfer of RECs; but others might argue that legislation or regulations must state explicitly that net metering is conditioned on the legal transfer of the REC to the utility.

The State of Missouri passed a law in 2002 that provides for interconnection and net billing at the avoided cost rate. Because it does not credit on-site generation at the retail rate, it is not technically considered net metering; but the law, nevertheless, introduces some ambiguity about RECs ownership. It implies that the distribution utility (retail electric supplier) owns the RECs when it says, "The wholesale generator, at the option of the retail electric supplier, shall receive credit for emissions avoided by the wholesale generator because of electric energy purchased by the wholesale generator or the retail electric supplier from a qualified net metering unit." 35 There is no other mention of certificates, credits, or emissions attributes in the law.

As with RECs associated with PURPA contracts, disagreements over REC ownership under existing net-metering agreements will probably be settled by the state regulatory commissions, but the uncertainty is still a potential problem for new agreements and should be clarified by state regulators.

\footnotetext{
${ }^{34}$ NorthWestern Energy Interconnection Agreement for Customer-Owned, Grid-Connected Electric Generating Facilities of 50 Kilowatts or Less Generating Capacity. March 2003.

${ }^{35}$ Missouri Revised Statutes, Title XXV, Chapter 386.887. See www.moga.state.mo.us/statutes/C300399/3860000887.HTM.
} 


\section{Ownership for Systems Receiving Subsidies}

Finally, some states or utilities may claim the RECs (or restrict their sale) from customersited and owned systems for which they have provided grants or rebates (Fitzgerald et al. 2003). The Energy Trust of Oregon, a nonprofit administrator of the revenues created by a system benefits charge, funds renewable energy projects through a variety of programs. In general, the trust aims to subsidize a portion of the above-market costs of renewable energy systems; and, in exchange, will own that same proportion of the RECs that the systems produce, usually over the life of the system. ${ }^{36}$ The trust may retain, transfer, or sell the RECs it owns, as long as the action furthers the goals of the trust and benefits the customers of the utilities that collect the system benefits charge (West 2004).

NorthWestern Energy, which administers Universal System Benefits Charge monies it collects in Montana, claims the right to all RECs from systems that it supports financially, regardless of what portion it funds. ${ }^{37}$

The Connecticut Clean Energy Fund (CCEF) offers \$5/Watt for PV systems installed on commercial, industrial, and institutional customer buildings. Early in the PV program, CCEF felt that small system owners would not trouble to sell the RECs. So, in its first solicitation, CCEF required the transfer to CCEF of all RECs generated by a customerowned system receiving a rebate. More recently, CCEF recognized that interest in solar RECs is increasing; and, in a modification to the solicitation, CCEF reversed itself, leaving the RECs with the system owner. ${ }^{38}$ The RECs that CCEF owns from previous projects are sold, and the revenue is used to support other CCEF programs.

Under Austin Energy's Solar Rebate Program, customers are required to transfer, to the utility, all RECs and other environmental attributes from power generated by PV systems receiving rebates from Austin Energy. As in Connecticut, the standard rebate level is $\$ 5 /$ Watt. $^{39}$

These examples of funding entities receiving the RECs (or a portion of them) from systems they subsidize may be perceived as a matter of policy; but, as with REC ownership under net metering, there is also a legal question. Are the funding entities or

\footnotetext{
${ }^{36}$ This may vary by program. For example, for residential PV systems, the Trust may give owners the choice of either (1) the current incentive (\$3 per Watt) and the owner can have the RECs for the first four years, and the Trust will keep them for the remainder of the system life; or (2) a lower incentive and the owner will keep more of the RECs.

${ }^{37}$ See http://www.northwesternenergy.com/energy/publications/bright ideas.pdf.

${ }^{38}$ RFP No. CCEF-PV-03-002 issued December 29, 2003, stated, "CCEF shall be entitled to all renewable energy (and all other green power) credits, market premiums and/or similar rights arising out of, or related to, the project. The owner will ensure that proper metering equipment is installed as required to record the generation of any credits within the GIS System of the ISO New England. CCEF and the owner shall develop a protocol for the timely transfer of the credits to or for the benefit of CCEF. The owner shall take such action as CCEF shall reasonably require in connection with such transfer." In a modification to the RFP issued September 15, 2004, CCEF emphasized that it will no longer retain ownership of RECs, stating, "The system owner shall be entitled to all RECs and/or market premiums arising out of the installed system."

${ }^{39}$ Austin Energy, Solar Rebate Program, "Renewable Energy Credit Assignment Agreement," April 2004.
} 
utilities legally entitled to RECs in return for providing a subsidy to renewable generators? The answer appears to be "yes," but only where the transfer of RECs is specifically provided by law, and the system owner is clearly informed that giving up the RECs is a condition of receiving the funding or other support. (Starrs 2004)

In addition, policy-makers should consider their goals and the economic signals they are sending if they contemplate offering incentives with one hand and taking value away with the other. The Regulator's Handbook on Tradable Renewable Certificates suggests that if the customer has title to the equipment, it should also have title to the RECs. ${ }^{40}$

\section{Environmental Claims}

Another key issue for RECs involves the types of claims that can be made regarding environmental benefits. Because renewable energy sources tend to have less environmental impact than traditional electricity generation sources, renewable energy generators and marketers want to make claims of environmental benefits. Such claims can be tricky, however, for a number of reasons.

First is the issue of regional environmental benefits. RECs generally create environmental benefits in the region where the renewable facilities are located, by displacing fossil generation within that region. If unbundled RECs are sold within the region in which they were generated, their environmental benefits are identical to the benefits accrued if the RECs had been bundled with electricity and sold in the region as green power. But if unbundled RECs are sold to retail customers outside the region in which they are generated, RECs purchasers may not receive regional environmental benefits, although they will receive any global environmental benefits that may occur from reductions in greenhouse gases, for example.

When RECs are sold outside of the region in which they are generated, what environmental benefits can marketers claim? They may be able only to make statements that the power plant is pollution-free, or has low emissions relative to some average - but the environmental benefits (cleaner air, for example) may not reach the REC buyer. For this reason, the National Association of Attorneys General (NAAG) recommends the following:

"Consumers should be informed, by clear and prominent disclosure, if a claim states or implies an environmental ...benefit which actually occurs or exists outside the geographic area in which the environmental marketing claim is being made."(NAAG 1999)

Green-e goes further and requires certified RECs to inform prospective customers of the geographic location, by state or region, of the generation resources used in the product.

\footnotetext{
${ }^{40}$ For more information on ownership issues, see Hamrin, J. and M. Wingate, Regulator's Handbook on Tradable Renewable Certificates. Center for Resource Solutions, May 2003; and E. Holt, "Renewable Energy Certificates and Generation Attributes," Regulatory Assistance Project Issuesletter, May 2003.
} 
Armed with this information, consumers concerned about regional air pollution could judge whether they are downwind of the originating region and would benefit from cleaner air.

Some states will support imported RECs for compliance purposes, only if they are accompanied by imports of electricity into the regional power pool. This has the effect of displacing dirtier generation in the region of purchase, such that a claim of regional environmental benefit may be made.

Next there is the issue of environmental claims by generators that have sold their RECs. Renewable energy generators that have sold their RECs to a third party have only generic electricity to sell. For example, they cannot claim to be wind electricity, or emission-free, without creating a situation of double claims (two parties claiming to own the same attributes).

For states that require electricity labels, it can be a challenge to determine how to describe electricity when the attributes have been sold into another market. The NEPOOL GIS assigns the system average attributes to such "null" power, in order to facilitate compliance with electricity labeling requirements.

Finally, there is the question of whether RECs include environmental benefits if they are generated in a state or region where emissions are capped and renewables are not allowed to participate in a cap-and-trade program. ${ }^{41}$ For example, this is the situation with sulfur dioxide $\left(\mathrm{SO}_{2}\right)$, which is capped by federal law. $\mathrm{SO}_{2}$ emission allowances are currently allocated only to polluting plants; so if a renewable generator causes a fossil plant to reduce output and emissions, the fossil plant can sell the allowances no longer needed to a generator that has insufficient allowances. The overall cap is not affected, and thus the total amount of pollution is unlikely to be reduced. This market and other emissions markets are described more fully in the next section.

In situations where renewable energy cannot obtain emissions allowances, because it is excluded from a cap-and-trade program, the Center for Resource Solutions recommends that "suppliers refrain from making claims about $\mathrm{SO}_{2}$ benefits unless the supplier is retiring $\mathrm{SO}_{2}$ offsets or otherwise can substantiate their claims. This recommendation also applies for any pollutant that is capped based on an allowance cap-and-trade program for which full aggregation is not possible." (CRS 2002)

Ironically, because $\mathrm{CO}_{2}$ is not capped, it is easier to claim that renewable generation offsets $\mathrm{CO}_{2}$ emissions. Backing off fossil plants does, in fact, lower $\mathrm{CO}_{2}$ emissions. For capped pollutants, however, environmental claims remain problematic. It can be argued that renewables have at least a partial impact on capped emissions, because federal air regulators take existing RPS policies into account when setting the level of the cap. Whether this is sufficient to justify making a marketing claim of environmental benefit needs clarification. Until then, marketers must be careful not to imply a benefit that may not exist.

${ }^{41}$ This issue is not unique to RECs. It applies equally to bundled green power. 


\section{Emissions Markets}

Because renewable generation has low or zero on-site emissions (depending on the energy resource and conversion technology), renewable energy developers are increasingly looking to emissions markets for new revenue opportunities. One analysis estimated that the value of emission reductions could range from about $\$ 6$ to $\$ 39$ per $\mathrm{MWh}$, depending on the assumption about the future value of $\mathrm{CO}_{2}$ allowances. The total value to biomass, geothermal, photovoltaics, and wind generators could reach more than $\$ 1.2$ billion per year, based on a low assumption about the value of $\mathrm{CO}_{2}$ allowances (Wooley 2000).

Before renewable generators can start counting this income, however, the issue of whether renewables can even participate in these markets must be resolved. To understand eligibility, one must understand the different markets. Some emissions are regulated with a cap on emissions and trading of emission allowances. In that case, air regulators must decide whether to permit renewables to earn emission allowances. Generally, eligibility is not a question for voluntary transactions that are not regulated by cap-and-trade. ${ }^{42}$ Any two parties can agree to trade emission reductions, but such unregulated markets are weak or nonexistent. Regulated markets with cap-and-trade rules, on the other hand, are stronger because they are mandated.

Whether regulated as cap-and-trade markets (or unregulated), emissions markets in which renewables are eligible are in a very early stage of development. Similar to other RECs markets, there is no single emissions market, and each has its own set of rules, which can also vary from state to state.

The U.S. Environmental Protection Agency (EPA) operates a national $\mathrm{SO}_{2}$ cap-and-trade program under its Acid Rain Program. $\mathrm{SO}_{2}$ emissions allowances have been granted primarily to fossil plants; only a tiny amount of renewable generation has been credited for the avoided emissions. ${ }^{43}$ This market is effectively closed to renewables currently.

Another emissions market is the federal NOx Budget Trading Program, a cap-and-trade program that currently applies to 19 Eastern states. Although it is a federal program, implementation is left to the states, which decide whether to allow renewable energy to participate in these markets. Currently, just seven states-Indiana, Maryland, Massachusetts, New Hampshire, New Jersey, New York, and Ohio - provide a set-aside of allowances for renewable generation. ${ }^{44}$ Under a set-aside, renewable generators must

\footnotetext{
${ }^{42}$ Renewable eligibility can be an issue in organized voluntary markets, however, as illustrated by the Chicago Climate Exchange (CCX) for greenhouse gas emission reductions. CCX, rather than government, sets the rules, and participants agree to a voluntary cap on emissions. Renewables are eligible under certain circumstances.

${ }^{43}$ Wooley and Morss (2001) describe an element of the $\mathrm{SO}_{2}$ trading program called the Conservation and Renewable Energy Reserve (CRER). CRER is a set-aside of allowances for energy efficiency and renewables but has been largely ineffective in encouraging applications for reasons the authors explain.

${ }^{44}$ New Hampshire's set-aside is not part of the federal NOx Budget Trading Program, and hence it is usually not included in this list. Its NOx emission trading program was established under the earlier Ozone Transport Commission.
} 
apply for allowances; allowances are not automatically granted. Only one example - in Maryland - is known where renewable generation has applied for allowances (U.S. EPA 2004a, Elsen 2004).

Under the proposed Clean Air Interstate Rule (CAIR), the NOx program would be extended to 29 states (plus the District of Columbia) in the Eastern half of the United States, as shown in Figure 4. These states would have to meet overall emission caps but they can decide how to do it, including whether or not to participate in the cap-and-trade program. In its CAIR Supplemental Notice of Proposed Rulemaking, EPA leaves the question of allowance allocations up to the states, but does mention that states could decide to include renewables and energy efficiency (US EPA 2004b).

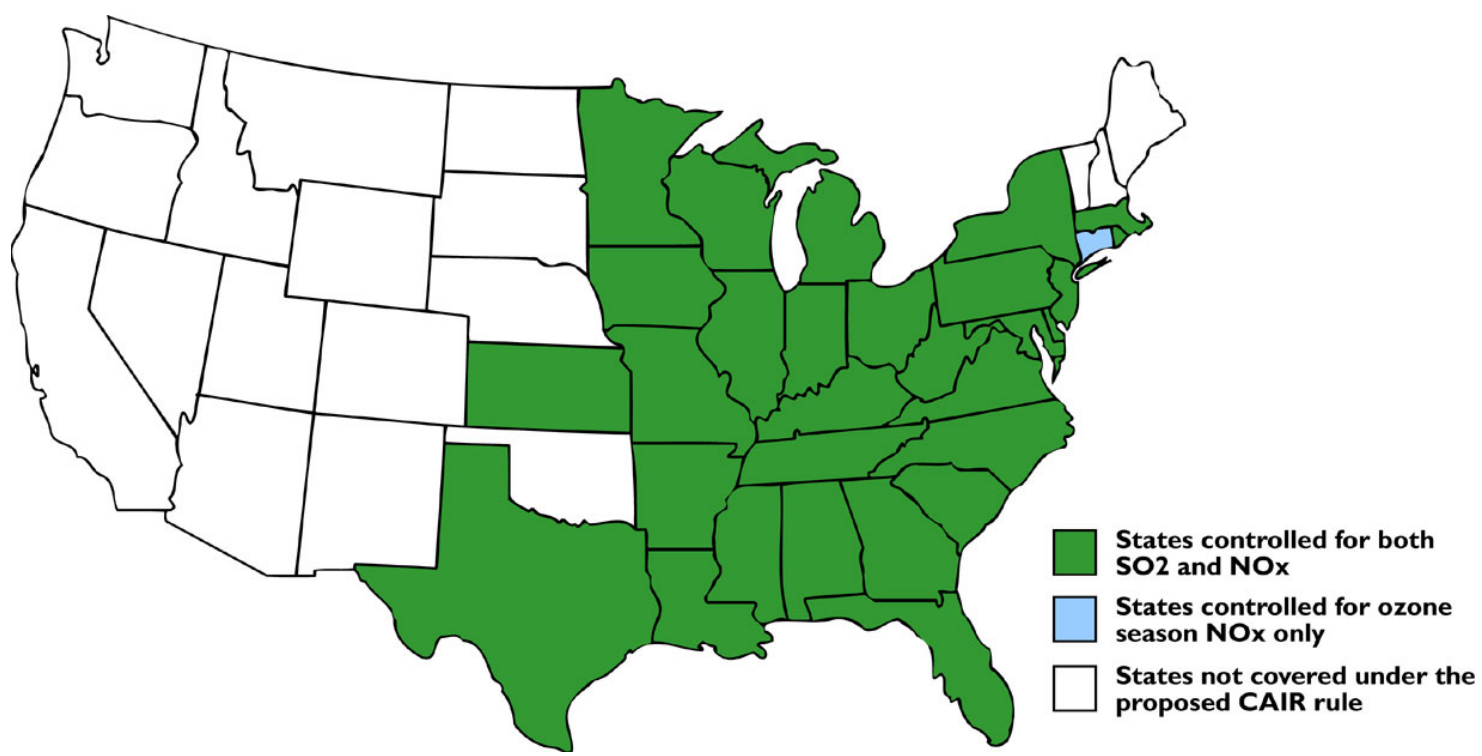

Figure 4. States Included in EPA CAIR Proposal

The market for $\mathrm{CO}_{2}$ emission reductions is currently unregulated in the United States, and trading is generally weak given uncertainty about future regulation and potential rules. ${ }^{45}$ In the absence of federal action on greenhouse gases, Northeastern states have agreed to develop a cap-and-trade program under the Regional Greenhouse Gas Initiative (RGGI). This is a work in progress, and it is not clear whether, or how, renewable energy will be included. It is also not certain that the states will actually adopt the cap-and-trade program once it is developed.

Other environmental markets may emerge as regulation or cap-and-trade is extended to mercury or other emissions, and renewable generation will face the same questions about program rules and eligibility in these markets. The current status is summarized in Table 13.

\footnotetext{
${ }^{45}$ In the European Union Emission Trading Scheme for $\mathrm{CO}_{2}$, emissions from power plants are capped, but nonemitting renewables are not awarded emission allowances. The argument is that the compliance costs borne by fossil plants will make renewables relatively more cost-effective, and that renewables already enjoy strong direct policy support.
} 
Table 13. Status of Renewable Energy Eligibility in Emission Markets

\begin{tabular}{|l|l|l|l|}
\hline & \multicolumn{1}{|c|}{$\mathbf{S O}_{2}$} & \multicolumn{1}{c|}{ NOx } & \multicolumn{1}{c|}{$\mathbf{C O}_{2}$} \\
\hline $\begin{array}{l}\text { Regulated by } \\
\text { cap-and-trade } \\
\text { program? }\end{array}$ & Yes, nationally & $\begin{array}{l}\text { Yes, currently in 19 } \\
\text { states, EPA proposal } \\
\text { for 29 }\end{array}$ & $\begin{array}{l}\text { No, but RGGI is } \\
\text { developing proposed } \\
\text { cap-and-trade for } \\
\text { Northeast }\end{array}$ \\
\hline $\begin{array}{l}\text { Renewables } \\
\text { eligible to earn } \\
\text { allowances? }\end{array}$ & $\begin{array}{l}\text { No (with minor } \\
\text { exceptions) }\end{array}$ & $\begin{array}{l}\text { In only seven states } \\
\text { with set-asides for } \\
\text { RE. Allowances not } \\
\text { awarded automatically }\end{array}$ & $\begin{array}{l}\text { CO2 is unregulated, } \\
\text { hence allowances do } \\
\text { not exist. RGGI rules } \\
\text { still under development }\end{array}$ \\
\hline $\begin{array}{l}\text { Ability to claim } \\
\text { emission } \\
\text { reductions? }\end{array}$ & $\begin{array}{l}\text { No, because } \\
\text { RE cannot } \\
\text { earn } \\
\text { allowances }\end{array}$ & $\begin{array}{l}\text { Yes, in seven states if } \\
\text { emission allowances } \\
\text { are applied for and } \\
\text { granted }\end{array}$ & $\begin{array}{l}\text { Yes, but not via } \\
\text { allowances }\end{array}$ \\
\hline
\end{tabular}

What would these allowances be worth? Wooley (2000) estimated that NOx allowances would be worth about $\$ 1.50 / \mathrm{MWh}$, and $\mathrm{SO}_{2}$ allowances about $\$ 1.20 / \mathrm{MWh} . \mathrm{CO}_{2}$, assuming allowances at $\$ 5 /$ ton, would be worth $\$ 3 / \mathrm{MWh}$. More recent prices for emission allowances from broker Evolution Markets (Table 14) suggest that NOx might be worth $\$ 2.25 / \mathrm{MWh}, \mathrm{SO}_{2}$ about $\$ 4.20 / \mathrm{MWh}$, and $\mathrm{CO}_{2}$ (based on recent trades on the Chicago Climate Exchange) less than $\$ 1 / \mathrm{MWh} . \mathrm{CO}_{2}$ would increase in value if it were capped and allowances allocated. Thus, if renewable generators could earn income from all three emissions markets, it might be worth $\$ 5$ to $\$ 10 / \mathrm{MWh}$, a significant revenue stream roughly equivalent to what they could make at the lower end of values in REC compliance or voluntary markets.

Table 14. Comparison of Emission Market Values and Energy Market Values

\begin{tabular}{|l|r|c|l|}
\hline \multicolumn{1}{|c|}{ Application } & $\begin{array}{c}\text { Emissions } \\
\text { Value }\end{array}$ & Energy Value & \multicolumn{1}{|c|}{ Comments } \\
\hline CO2 & $\begin{array}{l}\$ 1.45 / \text { ton } \\
\text { NOx }\end{array}$ & $\$ 0.87 / \mathrm{MWh}$ & $\begin{array}{l}\text { Value would increase with cap-and- } \\
\text { trade }\end{array}$ \\
\hline SOx & $\$ 700 /$ ton & $\$ 2.25 / \mathrm{MWh}$ & In six states with set-asides \\
\hline $\begin{array}{l}\text { Compliance } \\
\text { RECs }\end{array}$ & $\begin{array}{r}\text { Not } \\
\text { applicable }\end{array}$ & $\$ 5-\$ 45 / \mathrm{MWh}$ & $\begin{array}{l}\text { Allowances not available, with } \\
\text { exceptions }\end{array}$ \\
\hline Voluntary RECs & $\begin{array}{r}\text { Not } \\
\text { applicable }\end{array}$ & $\$ 5-\$ 15 / \mathrm{MWh}$ & See Chapter 4 for more detail \\
\hline
\end{tabular}

Source: Evolution Markets

Of course, the value that might be available to renewable generation depends in part on the calculation of avoided emissions, and that brings us to a second and related issue: how to quantify the emissions reduction resulting from the generation of renewable energy onto the grid. A primary attribute of most renewable generation is low or no onsite emissions, but the emission reductions are a derived attribute. The emission reduction by a generator that pollutes may be measured directly, but the emission reduction that is caused by backing other generation off the system must be estimated by comparison to a system emissions baseline. 
Average emission reductions may be the simplest baseline to obtain, but they are unlikely to reflect accurately the emissions of the plants that are actually backed down. Marginal emission reductions, based on plants operating on the margin, will vary depending on the renewable generator's operating profile. Determining the marginal plants, though not impossible, can be a difficult and expensive analysis. Analysts are still working to obtain greater accuracy while retaining the simplicity and transparency of standardized figures. ${ }^{46}$ Finally, it should be noted that quantifying emission reductions are important primarily if nonemitting renewables are eligible to earn allowances, or if there is a voluntary market for emission-reduction credits, though quantification of renewable impacts is still important in setting emissions caps.

It is unclear whether emission markets will provide the key to long-term financing for renewable energy. For example, emissions markets may be no larger or no more stable (long-term) than RPS markets. Creating larger and stronger opportunities for renewables in emissions markets seems much like the challenge of expanding RPS and voluntary markets long term. Achieving either goal will require either federal action or state-bystate advocacy with close attention paid to the implementation details.

\section{Definition of RECs}

Earlier, we defined a REC as representing the attributes of energy created when renewable electricity is generated. The idea that a REC incorporates environmental attributes - as well as resource type, location, vintage, etc.-is generally agreed upon and is supported by a variety of policies and practices (see text box). For example, Texas, California, and New Jersey have all issued RPS rules that define RECs as including the environmental attributes of the renewable generator. The PJM Generation Attributes Tracking System and the Western Renewable Energy Generation Information System also use this as their current working definition.

But not everyone accepts that definition. Some market participants and stakeholders think that a REC is simply proof of renewable generation, and that the environmental attributes exist separately from the REC. Advocates of this view offer several arguments: ${ }^{47}$

- Simplifying a REC to its resource attribute only (wind, solar, biomass) creates a more fungible commodity that differs only in its resource type, rather than by other environmental characteristics or benefits.

- RECs cannot claim to contain all environmental attributes in cap-and-trade markets where renewable energy is not eligible for emission allowances. Therefore, we should define RECs to exclude those attributes whose presence is questionable.

\footnotetext{
${ }^{46}$ The U.S. Environmental Protection Agency, Lawrence Berkeley National Laboratory and the World Resources Institute, among others, are working on this task.

${ }^{47}$ Leahy, Patrick and Alden Hathaway, "Renewable Energy Certificates and Air Emissions Benefits: Developing an Appropriate Definition for a REC." Washington, D.C.: Environmental Resources Trust, April 2004.
} 


\section{Examples of REC Definitions}

For the Texas RPS, a REC is defined as "a tradable instrument that represents all of the renewable attributes associated with one (1) MWh of production from a certified renewable generator." (ERCOT Protocols, Section 14, Renewable Energy Credit Trading Program). California has adopted a preliminary definition that a REC includes all environmental attributes directly attributable to a generating unit. In a continuing rulemaking, the Administrative Law Judge has issued an opinion that includes a detailed definition of environmental attributes, as well as what is not included. (California PUC, Order Instituting Rulemaking to Implement the California Renewables Portfolio Standard Program. Rulemaking 04-04-026. Opinion Adopting Standard Contract Terms and Conditions, mailed May 17, 2004, at www.cpuc.ca.gov/PUBLISHED/COMMENT_DECISION/36751.htm) New York, in its solicitation of renewable energy attributes for compliance with its RPS, uses a definition of attributes that is similar to California's. See http://www.nyserda.org/rps/default.asp. The New Jersey RPS rules define a REC as "a certificate representing the environmental benefits or attributes of one megawatt-hour of generation..." (New Jersey Administrative Code 14:48.2)

The PJM Generation Attributes Tracking System (GATS) concept paper states that a Certificate "represents all attributes associated with each MWh generated whether bundled or unbundled, traded or not traded." (Draft dated 3/17/2004 at http://www.pjm.com/committees/working-groups/gats/gats.html) WREGIS Interim Operating Rules defines a REC as "all of the attributes from one MWh of electricity generation" and further defines a "whole certificate" as "one where none of the renewable attributes have been separately sold, given, or otherwise transferred to another party by a deliberate act of the certificate owner. Renewable attributes shall include the environmental attributes that are defined as any and all credits, benefits, emissions reductions, offsets, and allowances, howsoever entitled, directly attributable to the generation from the generation unit(s)." But WREGIS also notes that individual states and provinces may create different definitions of renewable certificates. (WREGIS Interim Operating Rules: Functional Requirements, at http://www.westgov.org/wieb/wregis/documents.htm)

Nongovernmental organizations have also weighed in on this issue. Green-e, through a national stakeholder process in 2001, adopted criteria for certifying RECs. "A [REC] must contain all the environmental attributes associated with a unit of renewable generation, to the extent possible based on current law. Where emissions credits are not assigned to a renewable generator, for example in a $\mathrm{SO} 2$ cap-and-trade regime, the purchase of additional emissions credits is not required to qualify as a fully aggregated [REC]." (CRS 2002)

The Renewable Energy Working Group, in comments submitted to the Regional Greenhouse Gas Initiative by the Center for Resource Solutions in 2004, recommends that greenhouse gas allowances issued to renewable energy production be required to accompany the renewables and be retired if used for compliance with an RPS unless the RPS administrator determines otherwise. (Memo and attached comments from Jan Hamrin to RGGI State Representatives, Staff Working Group, and RGGI Participants dated September 9, 2004, at http://www.rggi.org/stakeholder_comments.htm)

- In uncapped markets, renewables provide only an indirect reduction that threatens the integrity of environmental claims, as it is not clear who can claim the reduction- the renewable generator that displaced an emitting plant, or the emitting plant that generated less electricity and pollution. Double counting of the emission reductions will likely result.

- Excluding attributes from the REC definition renders moot the issue of disaggregation of attributes (i.e., selling the attributes separately from the REC), because they are not included in the first place. 
Proponents of a definition that specifies the inclusion of all attributes offer their own arguments:

- Consumers expect that cleaner energy sources - and, in particular, their voluntary payments for renewable energy - create environmental benefits. Consumer support for renewable energy policy also stems from their perception that it provides environmental benefits relative to nonrenewable sources (Farhar 1993, EPRI 1997).

- Claiming that RECs offer no environmental attributes or benefits strains credibility and is contradictory to common sense. It would be difficult to explain to consumers what they are getting from RECs with no environmental attributes.

- Large consumers typically also want all the attributes, as evidenced by RFPs for renewable energy and RECs. Some corporate customers, such as those participating in the Green Power Market Development Group, are motivated to purchase RECs in large part due to the environmental attributes (Hanson and Van Son 2003).

- Defining a REC without emissions attributes would make it problematic to satisfy environmental disclosure (electricity labeling) required in many states. What would suppliers disclose if RECs have no attributes? If they disclose zero emissions at the same time someone else is claiming the emission reductions, would this constitute double counting? Or would RECs be assigned system average emission attributes?

- Certificate-tracking systems are not designed to track individual attributes. If individual attributes are disaggregated from the REC, it would be difficult to verify attribute claims unless tracking systems are modified significantly.

The definition of a REC could become a legal issue. If consumers believe that renewable energy and RECs inherently include the environmental attributes of generation, then it could be deceptive to sell RECs defined to exclude such attributes, assuming such exclusion is not disclosed. According to the National Association of Attorneys General, "A claim is deceptive, and therefore unlawful, if it contains an express or implied representation or omission of fact that is likely, or has a tendency, to mislead consumers... The omission of information may also be deceptive in certain circumstances. Deception can occur through the omission of information that is necessary to prevent an affirmative representation from being misleading. Similarly, it can be deceptive simply to remain silent under circumstances that constitute an implied but false representation. The test for whether an omission is deceptive is whether the overall impression created by the advertisement is deceptive." (NAAG 1999)

Many stakeholders are concerned that a lack of agreement about the definition of a REC will reinforce, if not exacerbate, the fragmented markets that exist today. On the other hand, there are those who think that the idea of a consensus definition is inimical to markets and innovation. Since there is no overall markets czar, it will be left to consumer preferences (and their advocates) to determine the outcome in voluntary markets. In compliance markets, regulators should be more explicit about their intent. Practically speaking, the momentum of policy and education favors the inclusion of environmental attributes, because it would be difficult and confusing to reverse five or more years of policy development and understanding. 


\section{Disaggregation of REC Attributes}

The term "disaggregation" is distinct from unbundling of RECs from electricity. Disaggregation means stripping off individual attributes (especially the emissions attributes, to the extent that they have not been expropriated by emission market regulations) from the REC and selling them separately.

If stakeholders were to adopt the definition of a REC as proof of generation, then whether or not to disaggregate attributes is a moot question. By definition, attributes are not part of the REC. Under a definition in which a REC includes all attributes, however, then there is a further question of whether or not disaggregation of the REC should be allowed, or under what circumstances.

If renewables are eligible to participate in emission markets, then most observers agree that a REC owner should be able to choose between selling its attributes aggregated as a REC, on the one hand, or selling disaggregated attributes in emissions markets, on the other. In other words, the owner could use the REC in one or the other market, but could not use the same REC in both markets. For any generator or REC owner, the choice could vary, depending on which markets (compliance or voluntary RECs vs. emission allowances or credits) offered the best revenue potential. Tracking systems could easily support this option, as the REC owner that wanted to sell the attributes in emissions markets would be required to take the REC out of circulation from further trading or application as a REC.

The issue here, however, is not whether REC owners should have this choice, but whether RECs used in energy-related voluntary or compliance markets should be disaggregated; and, if so, under what circumstances.

Opponents of disaggregation, who tend to be retail REC marketers, argue that consumers expect certain environmental benefits when they buy renewable energy or RECs, and that to sell one or more of those benefits to another party would be misleading at best and fraudulent at worst, and would hurt the credibility of RECs markets. The National Association of Attorneys General states that a seller should possess competent and reliable evidence that the same generated electricity — and, by implication, the same REC derivative - was not sold to more than one consumer.

Proponents see disaggregation as an opportunity to earn multiple revenue streams from the same REC. This could be important to the cost-effectiveness of a renewable energy project and perhaps critical to its ability to obtain financing. These proponents tend to be

renewable developers and owners, and brokers who seek more markets. They would also argue that disaggregating and selling different attributes to different parties is not a double sale because the attributes sold in each transaction are different.

Some believe that the solution to disaggregation is to disclose the omission of any individual attributes to potential buyers. The National Association of Attorneys General (NAAG) does not address disaggregation explicitly, because it was not a concept under 
discussion when NAAG wrote its environmental marketing guidelines for electricitybut it does lend its support to disclosure. Following NAAG guidelines, a marketer would make no claim of environmental benefit. Also, to counter consumer expectation of inherent environmental benefit, the marketer would state clearly and prominently what specific environmental benefits are not achieved by the purchase of the REC.

Others think that disclosure is not the answer, contending it is hard enough to explain a REC to most consumers, much less explain disaggregation and what that means for a specific product. There might be an exception for large, sophisticated consumers (corporations or institutions) that have the legal staff and the time to negotiate customized REC contracts (NWCC 2001). Most large buyers, however, want all the attributes so they can count them toward organizational environmental goals. ${ }^{48}$ Nevertheless, they might be interested in disaggregated RECs, if the RECs can be purchased at a lower cost than a "whole" REC.

Disaggregation could be acceptable in compliance markets under certain circumstances. States with an RPS might explicitly allow the disaggregation and separate sale of emissions attributes. Policy-makers might decide that they want to make it less expensive to comply with an RPS by allowing the same MWh of renewable energy to earn revenue from RPS compliance and from selling an allowance into an emissions market. These policy-makers would allow a less-than-whole REC for RPS compliance. Other policymakers might decide that they want their energy and emissions policies to be additional to each other, meaning that each would have its own incremental effect and the two programs together would create a bigger benefit in more renewables and cleaner air. These policy-makers would allow only whole RECs for RPS compliance.

To our knowledge, the only state that has explicitly supported a disaggregated REC for RPS compliance, in law or rule, is Maryland. ${ }^{49}$ However, several states, including California and New York, have explicitly defined a REC for compliance purposes to include all the environmental attributes directly resulting from renewable generation. Most states, however, are silent on the issue.

\footnotetext{
${ }^{48}$ See, for example, a recent U.S. General Services Administration RFP that defines RECs as representing "all of the environmental attributes or benefits." GSA requires providers to file an annual report verified and certified by an independent third party auditor, including an attestation that "all environmental attributes, including any attendant emission credits convey to the purchaser...; the offeror has not sold any emission allowances/credits, or other environmental attributes associated with renewable power/RECs." (US GSA 2004)

${ }^{49}$ For its RPS, Maryland defines a REC as the "generation attributes" of one MWh derived from an eligible resource. This seems ambiguous, except that another section of the law states that "A customer who surrenders credits under this subsection retains all rights and title to any environmental or other attributes associated with the credits, including emission reductions or related allowances." http//mlis.state.md.us/2004rs/chapters/Ch_487_SB0869E.rtf. This applies to certain industrial customers that obtain their own RECs for compliance, and renewable on-site generators, but it is not clear if this disaggregation for compliance purposes also applies to obligated electricity suppliers or other generators.
} 
The issue of using individual attributes from the same REC in different markets may be addressed by either energy or environmental regulators as they develop rules for an RPS or for cap-and-trade programs. ${ }^{50}$

In general, however, they seem to not be very aware of the issue or are not coordinating their policy-making. The result is ambiguity. If regulators are to address the issue clearly, they will need more awareness and education.

While there is a lot of industry discussion about disaggregation, it should be kept in perspective that disaggregation is, to a large extent, hypothetical at this time. As previously discussed, most emissions markets are not open to renewables. If renewables are accorded set-asides in more NOx-capped states, and if $\mathrm{CO}_{2}$ is capped and regulators award renewable energy with emission allowances, these markets could become significant - it is this hope that spurs the debate.

\section{SUMMARY AND CONCLUSIONS}

RECs markets have been growing rapidly during the past several years, and they hold the potential for significant expansion. RECs are increasingly being used in a variety of applications, including compliance with RPS policies and other government-imposed requirements, as well as to supply retail green power products; and, to a lesser extent, to assist with renewable energy project financing. Going forward, we will likely continue to see innovative applications of RECs, because of the flexibility that they provide. The implementation of REC tracking systems, particularly those underway in PJM and the WECC region, will also facilitate expansion of REC markets.

In voluntary markets, RECs are most commonly purchased wholesale and used to supply bundled renewable energy products. However, they are increasingly being sold as standalone products separate from electricity. Large purchasers, such as universities, government agencies, and large businesses - often with facilities in multiple locationsare driving the market for stand-alone RECs, because of their added flexibility and the potential cost-savings compared to other retail products.

Marketers have reported limited success in selling unbundled RECs to residential consumers, in part because of the difficulties in explaining the concept of a REC. Thus, bundled electricity products (RECs plus electricity) may continue to dominate residential markets at least in the near term. One approach, in particular, that shows promise for growth in the residential sector is the trend toward utility-marketer partnerships through which default suppliers or utilities team with competitive marketers to offer green power

\footnotetext{
${ }^{50}$ Environmental regulators are more likely to be aware of using renewables in emission trading markets than energy regulators, for several reasons. The early acid rain allowance trading program included a setaside program from renewables, but it was ineffective. The EPA, in its model rules for the NOx budget program, provided for a set-aside option for renewables in its model for State Implementation Plans, and the same would be allowed under EPA's proposed Clean Air Interstate Rule and mercury rule. And the issue is on the table in the Northeast's Regional Greenhouse Gas Initiative. Energy regulators, on the other hand, have much less awareness and understanding of clean air programs.
} 
products sourced from RECs to their retail customers. This approach avoids the problem of convincing the consumer to switch suppliers and of explaining the concept of a REC.

Compliance markets may pose the largest opportunities for REC trading, particularly in coming years, when RPS targets increase and most state policies take effect. Currently, states that allow the use of RECs for RPS compliance provide an annual potential market of nearly 13 million MWh. Although REC trading has not taken off in some of these states, we estimate that nearly 8 million MWh of RECs were used for RPS compliance in New England and Texas in 2004, where REC tracking systems are in place. In comparison, we estimate that about 3 million MWh of RECs were used to supply voluntary green power purchases in 2003 . Thus, compliance markets are currently about three to four times the size of voluntary markets. By 2010, we estimate that compliance REC markets could reach about 45 million MWh, while voluntary markets could reach 20 million MWh, based on one available forecast. ${ }^{51}$

Market prices for RECs differ between voluntary and compliance markets, as well as by region, resource type, vintage, and volume. Limited data are available, but brokers provide some indication of REC trading prices. To date, REC prices have generally been higher in compliance markets than voluntary markets, particularly in supply-constrained New England. Prices of RECs used for RPS compliance are affected by available supplies, the quality of the renewable energy resources in the region, the ability to site new projects, rules regarding geographic eligibility and banking, and the level of the noncompliance penalty (which essentially sets a cap on REC prices). Because RPS policies set specific targets that must be met at a particular time - and because these targets increase in subsequent years - there is potential for price volatility if short-term supply shortages are created. Prices of compliance RECs have varied considerably by region and resource standard, ranging from as low as $\$ 0.7 / \mathrm{MWh}$ for existing renewables in Maine and Connecticut, to $\$ 4-\$ 8 / \mathrm{MWh}$ in New Jersey, $\$ 10-\$ 15 / \mathrm{MWh}$ in Texas, and as high as $\$ 35-\$ 49 / \mathrm{MWh}$ for new renewable energy sources in New England.

Voluntary market prices may be somewhat less subject to variability, but are influenced by prices in compliance markets. Generally, RECs used to supply voluntary purchasers have traded in the wholesale range of $\$ 2-\$ 6 / \mathrm{MWh}$. However, voluntary markets have supported higher prices for preferred resources, such as solar and wind, or local resources. For example, solar RECs have traded for as much as $\$ 200 / \mathrm{MWh}$ in voluntary markets, while wind has traded for relatively high prices $(\$ 15-\$ 17 / \mathrm{MWh})$ in the Northeast. RECs from preexisting sources have generally traded at wholesale for lower prices, in the range of $\$ 1-\$ 3 / \mathrm{MWh}$ typically.

\footnotetext{
${ }^{51}$ This comparison of compliance and voluntary markets may be unfair if one considers the potential for these markets to support the development of new renewable energy resources. A number of states have adopted provisions, such as requiring long-term purchase contracts, to ensure that new renewables are developed for RPS compliance, while developers are likely to continue to face challenges in financing new renewable energy projects to supply voluntary markets because of the short-term nature of most voluntary purchases, the uncertainty of future demand, and the unwillingness of lenders or investors to rely on voluntary demand as security for financing.
} 
Given current REC trading prices and market estimates, compliance REC markets are currently worth more than $\$ 100$ million annually and could reach a value of nearly $\$ 600$ million annually by 2010 . In addition, the voluntary market is estimated to be currently worth from $\$ 15$ million to $\$ 45$ million annually and could grow to perhaps $\$ 100$ million to $\$ 300$ million annually by 2010 , based on a market forecast. This represents significant revenue to support the development of renewable energy generation. However, to enable continued growth of REC markets, a number of issues need to be resolved.

- Project finance and RECs. Renewable energy developers generally need an upfront guarantee of a revenue stream to obtain project financing. This can come from the long-term sale of either the bundled energy and RECs or the RECs alone. Currently, voluntary markets provide insufficient security for project finance, and even compliance markets are not certain enough to completely ameliorate concerns about risk on the part of lenders or equity investors. Some possible solutions that can help facilitate new project development include large institutions or corporate buyers that are willing to "go long" to hedge price risk, simultaneously providing a guaranteed revenue stream to project developers; state renewable energy funds offering price floors as insurance against uncertain future markets; states requiring long-term contracts for RECs as part of RPS regulations; state regulators requiring utilities to buy RECs or bundled energy from new projects to supply green pricing programs; and consumer purchases of future RECs from unbuilt renewable energy projects. Perhaps none of these offers a complete solution, but long-term commitments will continue to be necessary for finance for the foreseeable future.

- Communicating RECs. RECs are intangible and difficult to explain, yet the National Association of Attorneys General suggests that marketers disclose to consumers when they are providing certificates, not power. To make consumers aware of the distinction between RECs and renewable electricity will require consistent public education, perhaps over many years. While consumers who shop for green power or RECs can be educated at Web sites and through product advertising, many consumers may never understand the difference. Government, regulatory commissions, consumer advocates, REC marketers, and market intermediaries (such as brokers and independent product certifiers) bear a significant responsibility for this education.

The difficulties in communicating the concept of a REC may limit the effectiveness of efforts to market stand-alone RECs to residential consumers. However, arrangements in which marketers team with electricity providers offer some promise.

- REC substantiation and verification. Electronic databases that track the movement of RECs at the wholesale level can improve the integrity of REC markets. While tracking systems have either been developed or are under development in a number of regions, there are some areas of the country that will not be served by these systems. For regions lacking a tracking system, a simple default tracking system could be created as a temporary measure until such regions are ready to develop more permanent, sophisticated systems. Through this stop-gap system, their certificates could gain more legitimacy and credibility than if no tracking system is present. The 
tracking system could be turned over to local stakeholders once there is sufficient regional support to design and pay for a more tailored system.

There is also a need for greater coordination among regional tracking systems. Existing tracking systems should collaborate, perhaps through an organization such as the North American Association of Issuing Bodies, to develop common rules or standards especially pertaining to REC imports and exports. In addition, a national registry for renewable generators could help ensure that a generator is not registered in, and issued RECs from, more than one tracking system.

- National REC markets. The potential for national markets is primarily at the wholesale level. Legitimate regional preferences and policies may hinder the development of a national REC market, but it is important for regional rules and tracking systems to enable buyers and sellers to trade across regions. Tracking systems that facilitate national trade (regional REC imports and exports) would help, without prejudice to state preferences. Other factors that could encourage larger markets include a federal RPS that supports national REC trading, a stronger federal greenhouse gas policy that recognizes the contribution of renewables, stronger federal direction to states on including renewables in emission cap-and-trade programs, and more large companies buying RECs nationally (such as the Green Power Market Development Group).

- REC ownership uncertainty. REC markets have been hindered by questions about ownership in certain circumstances. REC ownership is not specified in many PURPA contracts between qualifying facilities and utilities, in most state net-metering laws, nor in situations where generators receive financial incentives from public or quasipublic funds. To reduce market uncertainty, regulators - and in some cases legislators - need to clarify their intent; and, in the case of net metering, protect consumers who choose to install renewable energy generation on-site.

- Environmental claims. One challenge for marketers is communicating the environmental benefits associated with RECs. This is especially problematic for RECs sourced from areas where emissions markets (such as $\mathrm{SO}_{2}$ and $\mathrm{NOx}$ ) are regulated by cap-and-trade programs that do not provide allowances for renewables. Although most renewables are emissions-free, they are unlikely, in these circumstances, to reduce emissions. The simplest way to resolve this issue is for capand-trade programs to grant allowances to renewable energy generators. However, given the large number of programs that are being implemented in various states, consistency is not likely.

Alternatively, emissions caps should be set taking into account not only existing RPS policies (which is done now) but also projected renewables requirements and voluntary demand for renewable energy. Because of their effect on the level of the cap, renewables should then be allowed to claim environmental benefits. On this basis, NAAG and CRS should be encouraged to change their guidelines to indicate that renewables can make environmental claims even if not under an emissions cap. 
- Emissions markets. Opportunities for renewables to participate in emission markets are still emerging. In many cases, renewables are not eligible to participate-or rules have not been finalized to allow participation.

The rules for the national $\mathrm{SO}_{2}$ market discourage renewable participation, while only six states currently allow renewables to participate in NOx cap-and-trade programs. Renewables may be able to play in $\mathrm{CO}_{2}$ markets, but these are currently unregulated and are consequently generally weak and illiquid. It is possible that a few additional states will make renewables eligible under the expanded NOx program proposed by the U.S. EPA; and perhaps the Northeast states will make renewables eligible under the Regional Greenhouse Gas Initiative, if it is adopted.

It is important for federal, and particularly state, governments to recognize the emission-reduction benefits of renewable energy and include renewables in their allowance allocations. Whether these markets will provide enough of a guarantee of future revenue to help meet the financing needs of project developers, however, will probably not be settled for several years. Since these decisions are being made at the state level, it will require enough states to include renewables under the cap to make a large and worthwhile market for renewable attributes.

- REC definition. The debate about the definition of a REC, driven largely by the interaction between RECs and emissions markets, could fragment and confuse REC markets further unless some agreement is reached. A REC definition that includes environmental attributes (insofar as federal and state laws and regulations have not taken specific attributes as a matter of law) is more credible and more practical given policy precedent, difficulties in tracking the separation of attributes, the potential for consumer confusion if an alternate definition were used, and the fact that the market has largely been operating for a number of years under a definition that assumes environmental attributes are included.

- Disaggregation of attributes. There is general agreement that a REC owner can choose to sell a whole REC (assuming a REC is defined to include all attributes) in voluntary or compliance markets, or sell the attributes in emissions markets without double counting. But the desire to maximize revenue from multiple markets leads to an interest in disaggregating whole RECs and selling component parts in separate markets.

REC disaggregation could be appropriate in certain circumstances, for example, where policy-makers explicitly state that RECs without environmental attributes may be used for compliance with an RPS, or where voluntary REC sales are negotiated in customized contracts with knowledgeable counterparties such as large institutional or corporate customers. However, there is potential to confuse residential or small commercial customers who may assume that these air quality benefits or other attributes are included and may not understand disclosure. 
Whether disaggregation of a REC will lead to greater revenue for renewable projects is uncertain, because it is unclear that revenue streams from multiple markets will return more income than revenue from a whole REC. It is also unclear that a REC from which one or more attributes have been sold will be worth the same as a REC with all its attributes. In time, only markets can make that determination.

Given the current size of REC markets at more than 10 million MWh annually with an estimated value of $\$ 150$ million or more, and the potential for growth to more than 60 million MWh annually by 2010 , valued at perhaps more than $\$ 700$ million, it is very important to resolve these issues. A lack of resolution creates uncertainty in the marketplace and could slow market development. Therefore, it is important for states, and perhaps the federal government, to address these questions. Market changes might be facilitated if interest groups would create uniform positions and communicate their views on these issues to state and federal policy-makers.

To make progress on the challenges still facing REC markets, state policy-makers and regulators (both energy and environmental) must be educated about these issues and the implications of their choices relating to REC ownership and communication issues, RPS rule-makings, net metering and financial incentives, the interaction of voluntary and compliance markets, and rule-making for environmental cap-and-trade programs. Clear policies are important because silence leads to ambiguity, which stymies markets.

Finally, given the current state-by-state approach to these questions, a lack of uniformity may be a barrier to expansion of REC markets, or at least of larger and more liquid markets. Although a federal RPS does not appear likely, some form of federal direction to states regarding a uniform method of allocating emission allowances, or a uniform standard for regional REC imports and exports, could foster greater harmonization of REC markets. 


\section{REFERENCES}

Aulisi, A., and C. Hanson, 2004. Developing "Next Generation" Green Power Products for Corporate Markets in North America. Washington, DC: World Resources Institute, December. http://www.thegreenpowergroup.org/publications.html

Automated Power Exchange (APX) News Release, “APX Pioneers Trading of Green Tickets.” April 22, 1999.

Bird, L., and K. Cardinal, 2004. Trends in Utility Green Pricing Programs (2003), NREL/TP-620-36833. Golden, CO: National Renewable Energy Laboratory, September. http://www.eere.energy.gov/greenpower/pdfs/36833.pdf

Bird, L. and B. Swezey, 2004. Green Power Marketing in the United States: A Status Report (Seventh Edition), NREL/TP-620-36823. Golden, CO: National Renewable Energy Laboratory, September. http://www.eere.energy.gov/greenpower/pdfs/36823.pdf

Blank, E. with L. Bird and B. Swezey. "A Certificate-Based Approach to Marketing Green Power and Constructing New Wind Energy Facilities." Conference paper prepared for Windpower 2002, June 2-5, 2002, Portland, Oregon.

http://www.eere.energy.gov/greenpower/resources/pdfs/0602 newwind cert.pdf

Center for Resource Solutions, 2003. Green-e Verification Report, 2002

http://www.green-e.org/what is/standard/verification.html

Center for Resource Solutions (CRS), 2002. Green-e TRC Standard http://www.greene.org/pdf/trc standard.pdf

Clouse, M. 2004. “Green Power Partnership Market Observations," U.S. Environmental Protection Agency (EPA) Green Power Partnership. Presentation to the Ninth National Green Power Marketing Conference, Albany, New York, October 4.

Community Energy Inc. News Release, "Community Energy, Inc. Wind Power Purchases Cross 2 Billion kWh Mark", April 22, 2004

http://www.communityenergy.biz/cei_pr_earthday_2004.html

Deyette, J. 2004. Phone and email communication, Union of Concerned Scientists, Washington, D.C., November 19.

Elsen, A. 2004. "Regional Wind Power Purchase," presented at $9^{\text {th }}$ Green Power Marketing Conference, Albany, NY, October 4.

EPRI, 1997. Green Power Guidelines, Volume 1: Assessing Residential Market Segments. TR-109192-V1. Palo Alto, CA: Electric Power Research Institute, December. 
Electric Reliability Council of Texas (ERCOT), 2004. ERCOT's 2003 Annual Report on the Texas Renewable Energy Credit Trading Program. Report submitted by ERCOT to the Public Utility Commission (PUC) of Texas http://www.texasrenewables.com/reports.htm

Enron presentation, 1997. "GreenTags: A Proposal for Environmental Labeling in New Hampshire," fax date of April 14.

EU Directive, 2001. "2001/77/EC of the European Parliament and of the Council of 27 September 2001 on the promotion of electricity produced from renewable energy sources in the internal electricity market." Official Journal L, 283, pp. 0033-0040, October 27. http://europa.eu.int/smartapi/cgi/sga doc?smartapi!celexapi!prod!CELEXnumdoc\&lg=en \&numdoc $=32001 \mathrm{~L} 0077 \&$ model $=$ guichett

Farhar, B, 1993. Trends in Public Perceptions and Preferences on Energy and Environmental Policy: Executive Summary. NREL/TP-461-4857a. Golden, Colo: National Renewable Energy Laboratory, March.

Farhar, B.C., 1999. Willingness to Pay for Electricity from Renewable Resources: A Review of Utility Market Research. NREL/TP-550-26148. Golden: CO: National Renewable Energy Laboratory, July. http://www.eere.energy.gov/greenpower/resources/pdfs/farhar 26148.pdf

Fitzgerald, G., R. Wiser and M. Bolinger, 2003. The Experience of State Clean Energy Funds with Tradable Renewable Certificates. Lawrence Berkeley National Laboratory and Clean Energy States Alliance, November.

Hamrin, J. and M. Wingate, 2003. Regulator's Handbook on Tradable Renewable Certificates. San Francisco: Center for Resource Solutions, May.

Hanson, C. and V. Van Son, 2003. Renewable Energy Certificates: An Attractive Means For Corporate Customers To Purchase Renewable Energy. Washington, DC: World Resources Institute, September. http://pdf.wri.org/gpmdg corporate guide 05.pdf

Hanson, C. 2004. "Next Generation Green Power Products for Corporate Customers," presented at $9^{\text {th }}$ Green Power Marketing Conference, Albany, NY, October 4.

Harmon, R., and T.J. Starrs, 2004. Changing the Mix: Meeting Customer Expectations in the Green Power Market. Paper prepared for the American Solar Energy Society presented at SOLAR 2004 Conference, Portland, Oregon, July 9-14.

Holt, E.A., R. Wiser, M. Fowlie, R. Mayer and S. Innis, 2000. Understanding NonResidential Demand for Green Power. Report prepared for the American Wind Energy Association and National Wind Coordinating Committee, December. http://www.nationalwind.org/pubs/gpm/non-residential.pdf 
Kvale, L. 2004. Phone and email communication, Center for Resource Solutions, San Francisco, California, November 15.

Lieberman, D. 2004. The Need for Green-e Certification and Verification in an Era of Renewable Energy Tracking Systems. Center for Resource Solutions Issue Brief, March. http://www.crs2.net/lib/CRS-IB Certification-Tracking 4-1-04.pdf

Mason, A. 2004. Email communication, Conservation Services Group, Westborough, Massachusetts, December 21.

National Association of Attorneys General (NAAG), 1999. Environmental Marketing Guidelines for Electricity, December.

National Wind Coordinating Committee (NWCC) 2001. Consensus NWCC Credit Trading Opportunities and Guidelines. May.

Niermeijer, P. 2005. General Secretary RECS. Personal communication, January 19.

Pepper, Janis C. 1998. Opportunities for Wind in the APX Green Power Market ${ }^{\mathrm{TM}}$. Windpower '98, April 30.

Rader, N. and S. Hempling, 2001. The Renewable Portfolio Standard: A Practical Guide. Washington: National Association of Regulatory Utility Commissioners, February. http://www.naruc.org/associations/1773/files/rps.pdf

Renewable Energy Certificates System (RECS) 2004. Background information at http://www.recs.org.

Renewables Working Group 1996. Report to California PUC, August.

Starrs, T. 2004. Email communication, Bonneville Environmental Foundation, Portland, Oregon, November 5, 2004 and January 3, 2005.

Sterling Planet News Release "Major U.S. Corporations, World Resources Institute and Sterling Planet Make History with Record-Setting Corporate Renewable Energy Purchase," November 13, 2003. http://www.sterlingplanet.com/newsRelease27.php

U. S. Energy Information Administration, 2002. Impacts of a 10-Percent Renewable Portfolio Standard. (SR/OIAF/2002-03), February.

US EPA, 2004a. Energy Efficiency and Renewable Energy Set-Aside in the NOx Budget Trading Program: A Review of State Programs. Draft Report, March 5.

US EPA, 2004b. Supplemental Proposal for the Rule to Reduce Interstate Transport of Fine Particulate Matter and Ozone (Clean Air Interstate Rule), in Federal Register Vol. 69 Nol.112, June 10, at http://www.epa.gov/air/interstateairquality/rule.html. 
US GSA, 2004. Renewable Energy Certificate (REC) RFP for Energy Center of Expertise. Washington, D.C. Posted Oct 19, 2004.

West, P. (Energy Trust of Oregon) 2004. Phone conversation and email exchange, September 25.

Wingate, M. and E. Holt, 2004. Design Guide for Renewable Energy Certificate Tracking Systems. Washington, DC: National Wind Coordinating Committee, July.

Winneg, K., M. Herrmann, A. Levy, B. Roe, 1998. Summary Report: Baseline Survey Consumer Knowledge, Practices, and Attitudes. National Council on Competition and the Electric Industry, January.

Wiser, R. and O. Langniss, 2001. The Renewables Portfolio Standard in Texas: An Early Assessment. Berkeley, CA: Lawrence Berkeley National Laboratory, November, LBNL49107 http://eetd.lbl.gov/EA/EMS/reports/49107.pdf

Wiser, R., M. Bolinger, E. Holt, and B. Swezey, 2001. Forecasting the Growth of Green Power Markets in the United States. NREL/TP-620-30101, Golden: CO: National Renewable Energy Laboratory, October. http://www.eere.energy.gov/greenpower/resources/pdfs/30101.pdf

Wiser, R. 2004. Email communication, Lawrence Berkeley National Laboratory, Berkeley, California, November 15.

Wooley, D. 2000. "A Guide to the Clean Air Act for the Renewable Energy Community," REPP Issue Brief No. 15. Washington, DC: Renewable Energy Policy Project, February.

Wooley, D. and E. Morss, 2001. The Clean Air Act Amendments for 1990: Opportunities for Promoting Renewable Energy. NREL/SR-620-29448. Golden, CO: National Renewable Energy Laboratory, January. 


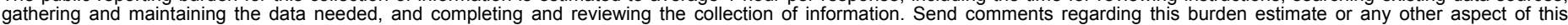

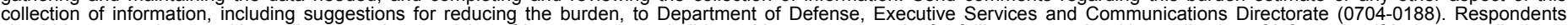

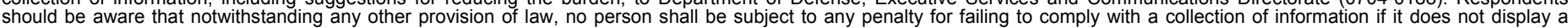

should be aware that notwithstanding

PLEASE DO NOT RETURN YOUR FORM TO THE ABOVE ORGANIZATION.

\begin{tabular}{ll|l}
\hline $\begin{array}{l}\text { 1. } \\
\text { REPORT DATE (DD-MM-YYYY) } \\
\text { January } 2005\end{array}$ & $\begin{array}{l}\text { REPORT TYPE } \\
\text { Technical Report }\end{array}$ \\
\hline 4. & TITLE AND SUBTITLE
\end{tabular}

Emerging Markets for Renewable Energy Certificates:

Opportunities and Challenges

3. DATES COVERED (From - To)

5a. CONTRACT NUMBER

DE-AC36-99-G010337

5b. GRANT NUMBER

5c. PROGRAM ELEMENT NUMBER

5d. PROJECT NUMBER

NREL/TP-620-37388

5e. TASK NUMBER

ASG4.1005

5f. WORK UNIT NUMBER

7. PERFORMING ORGANIZATION NAME(S) AND ADDRESS(ES)

National Renewable Energy Laboratory

1617 Cole Blvd.

8. PERFORMING ORGANIZATION REPORT NUMBER

NREL/TP-620-37388

Golden, CO 80401-3393

9. SPONSORING/MONITORING AGENCY NAME(S) AND ADDRESS(ES)

10. SPONSOR/MONITOR'S ACRONYM(S) NREL

11. SPONSORING/MONITORING AGENCY REPORT NUMBER

12. DISTRIBUTION AVAILABILITY STATEMENT

National Technical Information Service

U.S. Department of Commerce

5285 Port Royal Road

Springfield, VA 22161

13. SUPPLEMENTARY NOTES

\section{ABSTRACT (Maximum 200 Words)}

Renewable energy certificates (RECs) represent the attributes of electricity generated from renewable energy sources. These attributes are unbundled from the physical electricity, and the two products-the attributes embodied in the certificates and the commodity electricity-may be sold or traded separately. RECs are quickly becoming the currency of renewable energy markets because of their flexibility and the fact that they are not subject to the geographic and physical limitations of commodity electricity. RECs are currently used by utilities and marketers to supply renewable energy products to end-use customers as well as to demonstrate compliance with regulatory requirements, such as renewable energy mandates. The purpose of this report is to describe and analyze the emerging market for renewable energy certificates. It describes how RECs are marketed, examines RECs markets including scope and prices, and identifies and describes the key challenges facing the growth and success of RECs markets.

15. SUBJECT TERMS

Green power; renewable energy certificates; RECs; product certification; REC markets; renewable portfolio standards; RPS; REC tracking systems; net metering; emissions markets; Lori Bird; Ed Holt

\begin{tabular}{|c|c|c|c|c|}
\hline \multicolumn{3}{|c|}{ 16. SECURITY CLASSIFICATION OF: } & \multirow{2}{*}{$\begin{array}{l}\text { 17. LIMITATION } \\
\text { OF ABSTRACT } \\
\text { UL }\end{array}$} & \multirow{2}{*}{$\begin{array}{ll}\text { 18. } & \text { NUMBER } \\
\text { OF PAGES }\end{array}$} \\
\hline $\begin{array}{l}\text { a. REPORT } \\
\text { Unclassified }\end{array}$ & $\begin{array}{l}\text { b. ABSTRACT } \\
\text { Unclassified }\end{array}$ & $\begin{array}{l}\text { c. THIS PAGE } \\
\text { Unclassified }\end{array}$ & & \\
\hline
\end{tabular}

19a. NAME OF RESPONSIBLE PERSON

19b. TELEPHONE NUMBER (Include area code) 